\title{
Early Development of Four Cyprinids Native to the Yangtze River, China
}
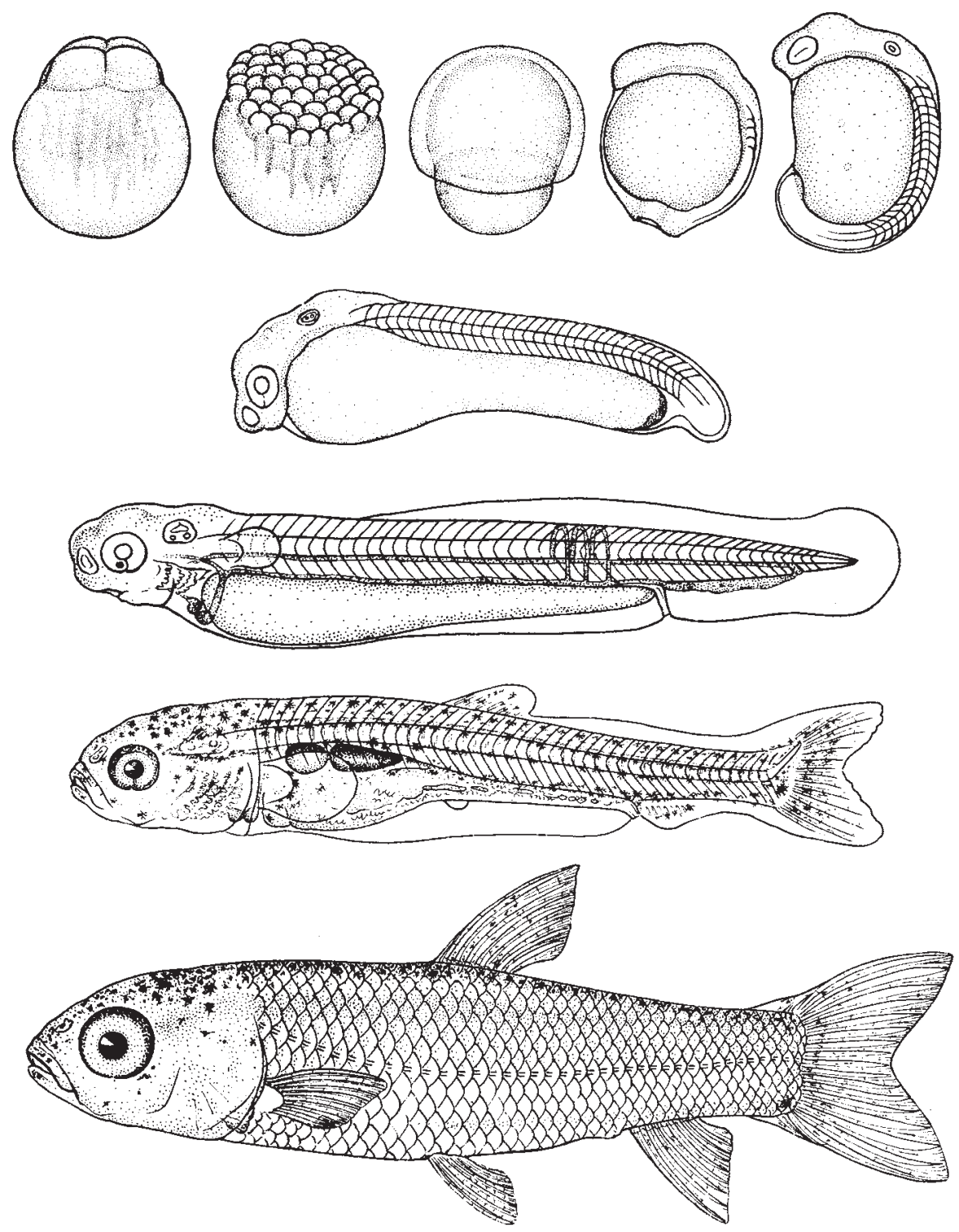

Data Series 239 
Cover: Selected early developmental stages of grass carp (Yi and others, 1988) 


\section{Early Development of Four Cyprinids Native to the Yangtze River, China}

Edited by Duane C. Chapman

Chapter 1

Notes on the Translation and Use of "A Study of the Early Development of Grass Carp, Black Carp, Silver Carp, and Bighead Carp in the Yangtze River, China"

By Duane C. Chapman and Ning Wang

Chapter 2

A Study of the Early Development of Grass Carp, Black Carp, Silver Carp, and Bighead Carp in the Yangtze River, China

By Bolu Yi, Zhishen Liang, Zhitang Yu, Renduan Lin, and Mingjue He

Data Series 239 


\section{U.S. Department of the Interior DIRK KEMPTHORNE, Secretary}

\section{U.S. Geological Survey \\ Mark D. Myers, Director}

\section{U.S. Geological Survey, Reston, Virginia: 2006}

For product and ordering information:

World Wide Web: http://www.usgs.gov/pubprod

Telephone: 1-888-ASK-USGS

For more information on the USGS--the Federal source for science about the Earth, its natural and living resources, natural hazards, and the environment:

World Wide Web: http://www.usgs.gov

Telephone: 1-888-ASK-USGS

Any use of trade, product, or firm names is for descriptive purposes only and does not imply endorsement by the U.S. Government.

Although this report is in the public domain, permission must be secured from the individual copyright owners to reproduce any copyrighted materials contained within this report.

Suggested citation:

Chapman, D.C., ed., 2006, Early development of four cyprinids native to the Yangtze River, China: U.S. Geological Survey Data Series 239, 51 p. 


\section{Volume Contents}

Chapter 1: Notes on the Translation and Use of "A Study of the Early Development of Grass Carp, Black Carp, Silver Carp, and Bighead Carp in the Yangtze River, China"...................1 by Duane C. Chapman and Ning Wang

Chapter 2: A Study of the Early Development of Grass Carp, Black Carp, Silver Carp, and

Bighead Carp in the Yangtze River, China 11

by Bolu Yi, Zhishen Liang, Zhitang Yu, Randuan Lin, and Mingjue He

\section{Conversion Factors}

SI to Inch/Pound

\begin{tabular}{lll}
\hline \multicolumn{1}{c}{ Multiply } & \multicolumn{1}{c}{ By } & \multicolumn{1}{c}{ To obtain } \\
\hline millimeter $(\mathrm{mm})$ & \multicolumn{1}{c}{ Length } & inch (in.) \\
meter $(\mathrm{m})$ & 0.03937 & foot $(\mathrm{ft})$ \\
kilometer $(\mathrm{km})$ & 3.281 & mile (mi) \\
meter $(\mathrm{m})$ & 0.6214 & yard ( $\mathrm{yd})$ \\
\hline \multicolumn{1}{c}{ Area } & \\
\hline square meter $\left(\mathrm{m}^{2}\right)$ & 1.094 & acre \\
square kilometer $\left(\mathrm{km}^{2}\right)$ & 0.0002471 & acre \\
square centimeter $\left(\mathrm{cm}^{2}\right)$ & 247.1 & square foot $\left(\mathrm{ft}^{2}\right)$ \\
square meter $\left(\mathrm{m}^{2}\right)$ & 0.001076 & square foot $\left(\mathrm{ft}^{2}\right)$ \\
square kilometer $\left(\mathrm{km}^{2}\right)$ & 10.76 & square mile $\left(\mathrm{mi}^{2}\right)$ \\
\hline
\end{tabular}


Page intentionally blank 


\section{Notes on the Translation and Use of "A Study of the Early Development of Grass Carp, Black Carp, Silver Carp, and Bighead Carp in the Yangtze River, China"}

By Duane C. Chapman and Ning Wang

Chapter 1 of

Early Development of Four Cyprinids Native to the Yangtze River, China

Edited by Duane C. Chapman

Data Series 239-1 


\section{Contents}

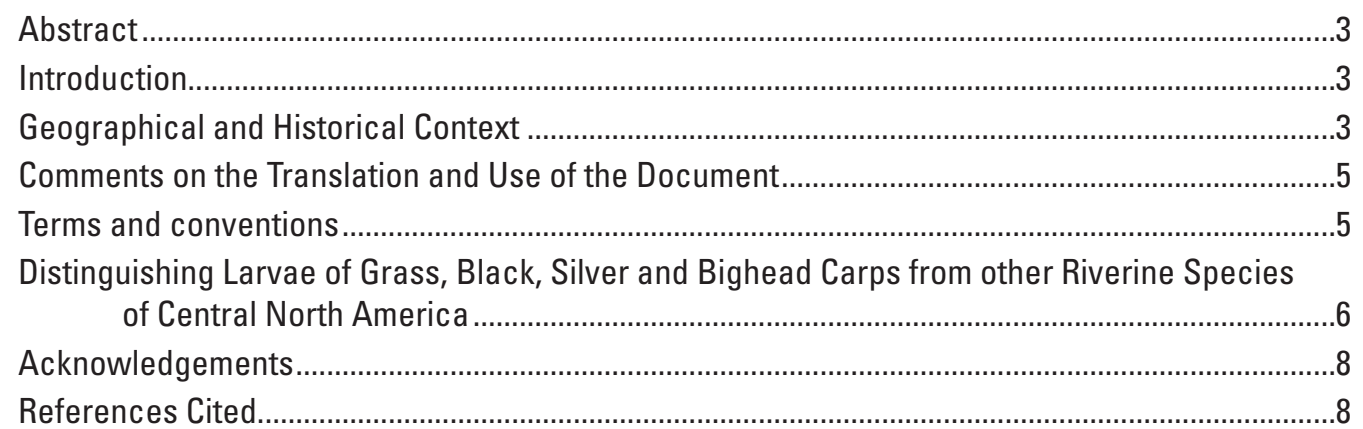

\section{Figures}

1. Map showing location of the Yangtze River in China .......................................................

2. Illustration showing grass carp larva, showing myomere number and difference in carp larvae myomere count methods between China and North America ......................6

3-4. Photographs showing-

3. Ventral view of grass carp at three different early developmental stages ........................7

4. Melanophores on the preanal and postanal fin folds of bighead carp and silver carp ...8 
Chapter 1

\section{Notes on the Translation and Use of "A Study of the Early Development of Grass Carp, Black Carp, Silver Carp, and Bighead Carp in the Yangtze River, China"}

\author{
By Duane C. Chapman and Ning Wang
}

\begin{abstract}
The document, "A Study of the Early Development of Grass Carp, Black Carp, Silver Carp, and Bighead Carp in the Yangtze River, China" (Chapter 2 of this volume), contains the most detailed description available of the early development of the subject fishes. This chapter is designed to place that translation into the appropriate context for the benefit of the North American scientist. We describe the historical context in which the data were collected. We also provide direction on the use of the translation, including a description of the Chinese morphometric conventions, which differ from those used by North American scientists. Lastly, we provide information on how the larvae of the subject fishes, which are now established in the Mississippi River Basin, may be differentiated from other fishes present in the basin.
\end{abstract}

\section{Introduction}

The document, "A Study of the Early Development of Grass Carp, Black Carp, Silver Carp, and Bighead Carp in the Yangtze River, China" (Yi and others, 1988a), provides the best existing comparative description of the early life stages of these fishes. Although the document was developed to address these fishes in their native range, we now require the ability to accurately identify these Asian fishes in North America. Non-native grass carp (Ctenopharyngodon idella), silver carp (Hypophthalmichthys molitrix), and bighead carp (H. nobilis) are established in the Mississippi River and its tributaries, including the Ohio, the Missouri, and the Illinois Rivers (Kolar and others, in press), and are considered invasive. The Mississippi Interstate Cooperative Resource Association (MICRA), a consortium of 28 state natural resource departments, considers bighead and silver carps the most important aquatic nuisance species in the basin. In addition, several black carp (Mylopharyngodon piceus) have been captured from the basin and this species may also be established in North America (Nico and others, 2005).

A national plan for the management and control of these invasive carps (Wilson, 2006) indicates a need for further investigations into their life history requirements and chronology of development. Many of the studies will require the identification of the larvae and juveniles; this translation is designed to aid in those studies.

In this chapter we provide (1) the geographical and historical context of Yi and others (1988a), (2) comments on the translation of the document and its use by North American scientists, including explanations of the myomere and fin-ray numbering conventions used, which differ from North American conventions currently in place, and (3) some short notes that may be useful to scientists endeavoring to distinguish the early developmental stages of grass, black, silver, and bighead carps from those of other fishes resident in the Mississippi River Basin of North America.

\section{Geographical and Historical Context}

The Yangtze River (fig. 1), also known as the Changjiang River in China, is over 6,000 km long; it is the longest river in Asia and the third longest in the world. It drains a watershed of over 1,700,000 $\mathrm{km}^{2}$. The headwaters are in eastern Tibet within the Dangla Mountains. The river flows through eastern Qinghai Province and turns southward towards Yunnan province, dropping in altitude from above $5,000 \mathrm{~m}$ to less than $1,000 \mathrm{~m}$. It reaches the basin of Sichuan at Yibin. The river then passes through the famous Three Gorges between the city of Chongqing and Hubei province. The Yangtze River continues through Jiangxi, Anhui, and Jiangsu provinces, terminating in the East China Sea at Shanghai. The "trunk stream" of the Yangtze River, as referred to in the translated document, consists of the 2,800-km portion of the Yangtze River below Yibin. The trunk stream consists of three main sections, the upper from Yibin to Yichang, the middle from Yichang to Hukou, and the lower from Hukou to Shanghai.

Grass, black, silver, and bighead carps are native to the Yangtze River and are thought to mainly exist in the middle 


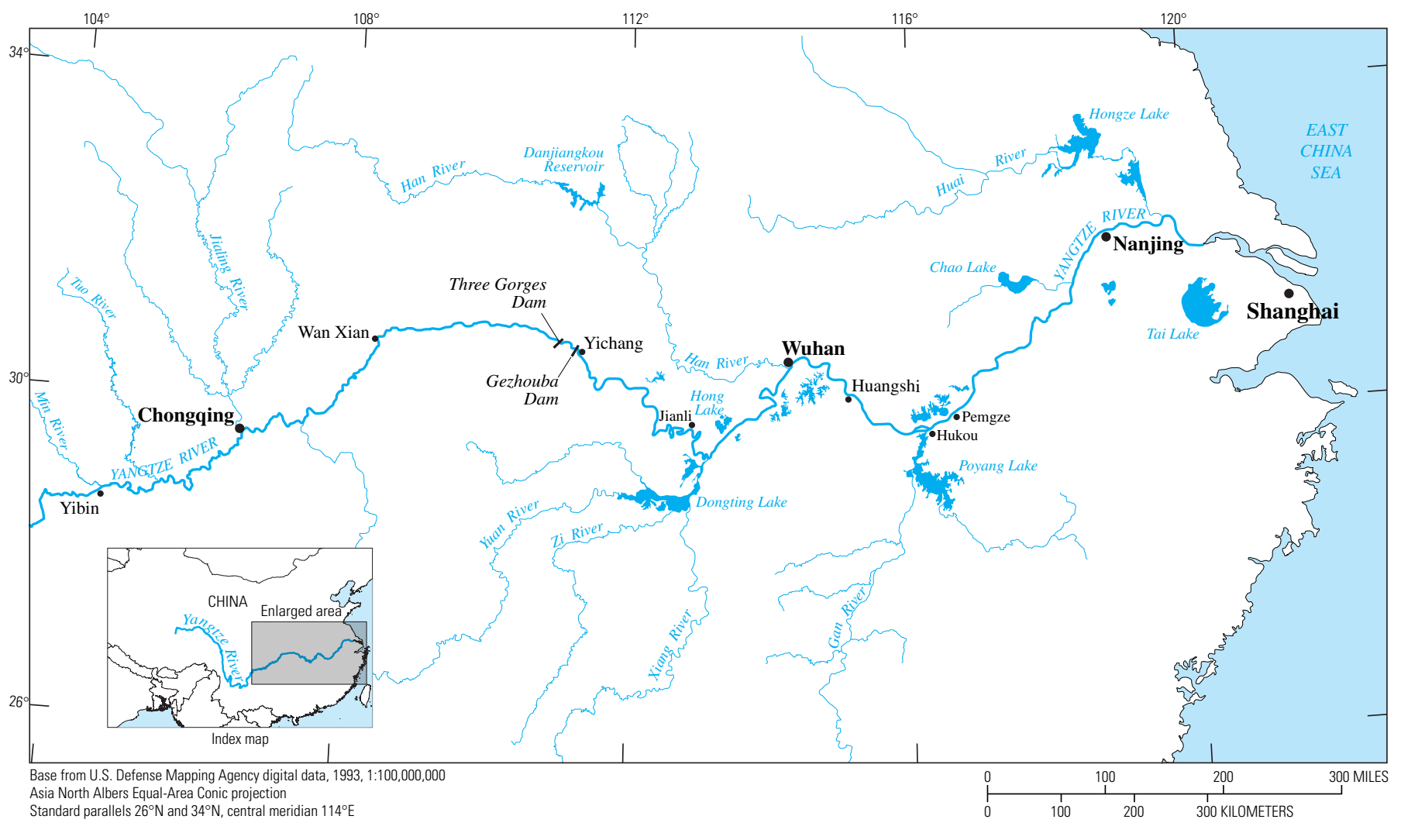

Horizontal coordinate information is referenced to the Geographic Coordinate Systems World Geodetic Survey Datum of 1984 (GCS WGS 1984)

Figure 1. Location of the Yangtze River in China. The Yangtze River in China is over 6,000 km long and drains a watershed of 1,7000,000 $\mathrm{km}^{2}$. The trunk stream of the Yangtze consists of $2,800 \mathrm{~km}$ between Yibin and Shanghai. It is within the trunk stream where the research of $\mathrm{Yi}$ and others (1988a) was conducted on the grass, black, silver, and bighead carp, mainly in the 1960s, in preparation for the building of dams near Yichang.

and lower sections of the trunk stream and the associated lakes in the Yangtze Plain (Institute of Hydrobiology, 1973, 1976; Li and others, 1990), although the fishes sometimes occur farther upstream. This floodplain area contains thousands of lakes. Many of these lakes connect permanently or intermittently with the Yangtze River and are thought to be important, both as nurseries and as adult feeding grounds for grass, black, silver and bighead carps (Yi and others, 1966, 1988b; Institute of Hydrobiology, 1973, 1976). Most of the larval fishes used in the development of the document (Yi and others, 1988a) were collected from the Yangtze, but some came from the Han River, the largest tributary of the Yangtze, which enters at Wuhan.

In the late 1950s, the planned construction of the Gezhouba Dam and the Three Gorges Dam on the Yangtze River (fig. 1) evoked concerns that the change would negatively affect the populations of grass, black, silver and bighead carps. The four species are important commercially-harvested fishes in China (Zhong and others, 1965; Institute of Hydrobiology, 1973, 1976; Zhang and others, 1989; Li and others, 1990), where they are known collectively as the "four famous domestic fishes." Companion studies by Yi and others (1988a,b) and Yu and others (1988) were undertaken to determine if the construction of the dams might be detrimental to reproduction and recruitment of these four fishes by interfering with their migrations or spawning area. To make these determinations, the studies investigated the distribution of spawning areas in the 1,700-km section of the Yangtze River between Chongqing and Pengze. The research took place over several years during the 1960s (Yi and others, 1966; Yi and others, 1988b; Yu and others, 1988). Comparative identification studies were conducted to understand the four fishes' early developmental stages and their spawning areas. The results were partially published in the 1960s (Yi and others, 1966) and 1970s (Institute of Hydrobiology, 1973, 1976). The publication of the whole article was delayed until the late 1980s, with the intent of continually adding more information (Yi and others, 1988a).

The artificial spawning of grass, black, silver and bighead carps is now commonplace. If a study on comparative development of these fishes was to be performed now, certainly a researcher would use that technology to begin with embryos of known species. In the early 1960s, when this study was begun, artificial spawning had not yet been devel- 
oped. The embryos and larvae in this study were collected from the Yangtze River drift with no knowledge of their species until they had developed into identifiable juveniles. Before artificial spawning methods were developed, larvae of these carps had been commonly captured for use in pond aquaculture for over a thousand years (Institute of Hydrobiology, 1973). This had been done, however, without much knowledge of the species being transplanted until the fish grew to an identifiable size. Being unable to identify the embryos and larvae posed substantial difficulties to the researchers in this study. Also, the economics of the time and place precluded use of photographic microscopy. These difficulties were overcome by painstaking effort; thousands of embryos and larvae were collected and maintained alive in individual small dishes aboard a research vessel. The vessel and its scientific crew remained on the river day and night over the three-month spawning season for the several years of the study. It was necessary to keep the individual eggs and larvae alive as they were drawn and redrawn multiple times in great detail (see figures, Chapter 2, this volume), returning each individual to its specific container between sketchings.

This unique dataset and publication provides the scientific basis of current knowledge regarding the ontogeny of these four fishes. Therefore, we provide this translation to facilitate the identification and classification of early life stages of these species within the Mississippi River Basin.

\section{Comments on the Translation and Use of the Document}

The translated document is as close to a verbatim translation as possible, although we have included a few footnotes. The original document, which is an outstanding product of its time and place, includes certain information that may seem odd to North American scientists and may appear to be shortcomings or superfluous information. For example, information on the differences in color of eggs or color of different larval structures (i.e. "loquat-yellow" and "butter-yellow") may be of little use to most scientists, especially if examining preserved specimens, which are not likely to retain most colors (Snyder, 1983). Even if fish are observed alive, as they were for the translated document, the reader is cautioned that the color of fishes from the Yangtze River in the 1960s might not match that of the same species collected from other places and times. Although the water-hardened eggs of grass, black, silver, and bighead carps are generally larger than most species with drifting eggs in the Mississippi River basin, care should be exercised in the use of these sizes to distinguish between the four species, at least until those data are verified for their use in North America. There are many variables that can influence egg size, including the age and size of parental stock (Balon 1984) and the ionic makeup of the water in which eggs are held (Kucera and others, 2002).
Another caution concerns the ages for the different stages recorded in the document. The temperature of the water in which the eggs and larvae were held could not be strictly controlled on the Chinese research vessel. Because development rates of larvae are highly dependent on temperature, the exact age of larvae collected in other studies might differ somewhat from ages listed for the different stages in the translated document. The ages in the translated document should be used as guidelines or as relative ages.

Most users will find the figures and tables, the information on myomere counts at the various stages, and the relative developmental stage of grass, black, silver and bighead carps to be the most useful portions of the translation. This information constitutes a great improvement over other documents currently available in English in terms of comparative morphology and identification of these fishes. Because individual stages are described in fine detail, the document also provides an excellent resource for those who wish to determine the relative ages of embryos and larvae of these fishes. Readers should note that the numbering of individual drawings within figures 1 through 8 of the translated document is dependent on the stage of the embryo or young fish and is consistent across species. For example, drawing 32 in figure 5 of the translated document (referred to as fig. 5-32 in the text) is a depiction of the rudimentary-pectoral-fin stage of grass carp, and drawing 32 in figure 6 of the translated document is the same developmental stage for black carp. Not all stages are depicted for all species, thus the numbering of the drawings within figures 1 through 8 of the translated document is not always sequential. In contrast, note that the numbering of drawings in figure 10 of the translated document do not refer to developmental stages and are numbered sequentially. We have maintained the structure of the original document in this matter.

\section{Terms and Conventions}

Melanophore types: The Chinese term "flower melanophore" is here interpreted to mean stellate melanophore. All other pigment spots are referred to as simply "melanophores."

Myomere numbering: Since the 1960s, the convention for numbering myomeres has differed between China and North America. In North America, all myomeres transected by a vertical line from the point of interest (such as the posterior margin of the anus) are typically included in the count of myomeres anterior to that point (Siefer, 1969; Snyder, 1983; fig. 2). The translated document uses the Chinese convention whereby myomeres for which the ventral margin aligns above the posterior margin of the anus, and all anterior myomeres, are termed "preanal" myomeres (fig. 2). This results in a preanal myomere number that is generally one or two smaller, and a corresponding increase in the number of postanal myomeres than would be commonly interpreted with the North American convention. 


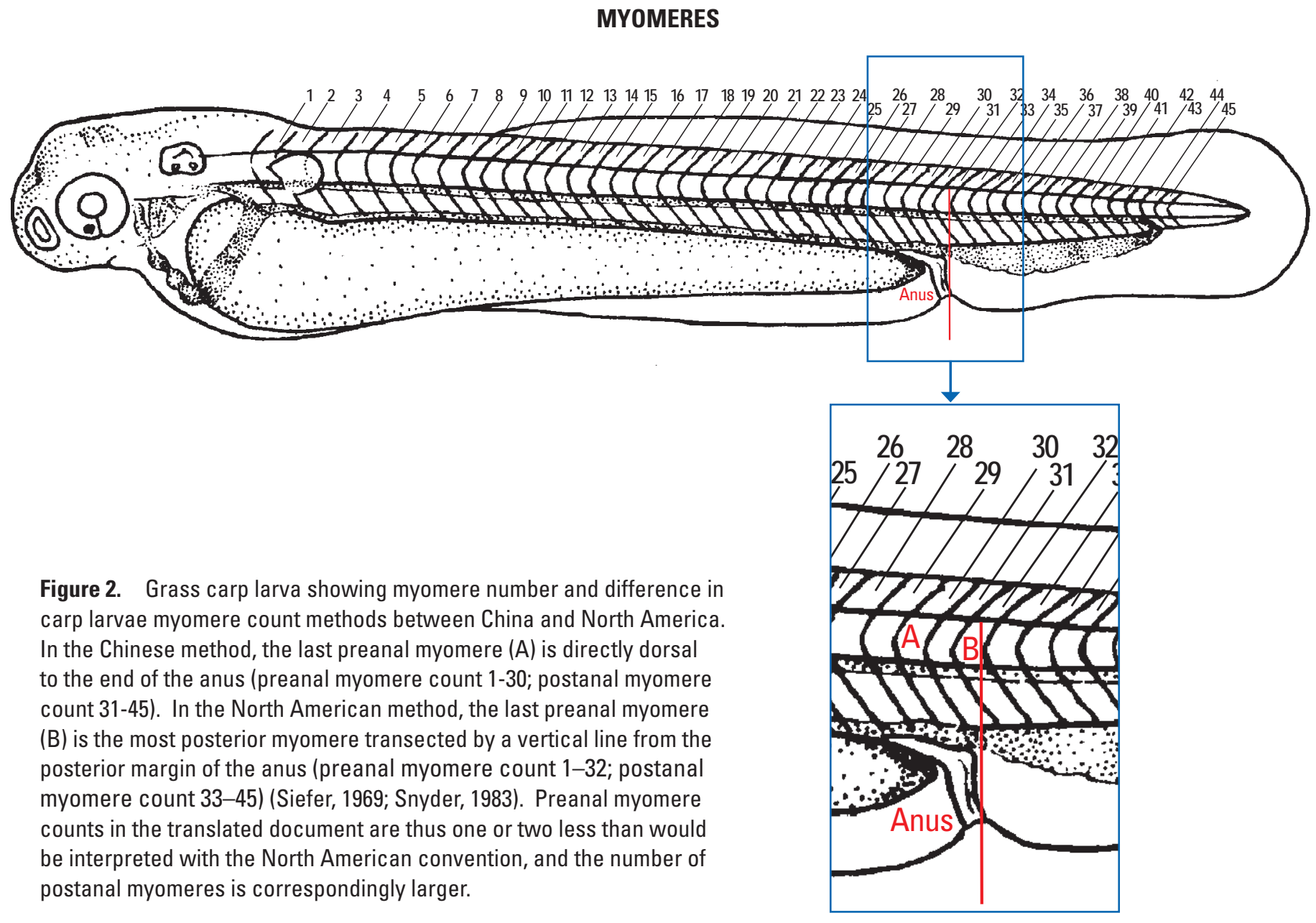

The translated document also uses another myomere numbering convention with which North American readers may not be familiar. The convention breaks preanal myomeres into "predorsal" myomeres (those for which the dorsal margins align under or anterior to the origin of the dorsal fin or dorsal finfold) and "middle" myomeres (those between the predorsal and postanal myomeres). The convention is expressed as " $8+22+13=43$ " for grass carp at the hatching stage (8 predorsal, 22 middle, and 13 postanal myomeres for a total of 43).

Lastly, there is generally some natural variation in myomere numbering of larval fishes of a given species; myomere counts are thus normally reported as a range. In the translated document a single modal value is given, but early in the text it is noted that myomere counts sometimes varied by one, more or less, than the given value. This equates closely to the ranges given elsewhere for myomere counts for these carps (Soin and Sukanhova, 1972).

Fin-ray numbering: The convention used in the translated document consists of a lower case Roman numeral and an Arabic numeral, separated by a comma. The Roman numeral indicates the number of un-branched rays in the fin, and the Arabic numeral indicates the number of branched rays. For example, "iii, 8 " would denote a fin with three un-branched rays and eight branched rays.

Scientific names: The translated document accurately reflects the original in terms of scientific names. The translated document uses Aristichthys as the generic name for bighead carp, which was the generally accepted name at that time. In western literature, bighead carp is now commonly grouped with silver carp under the genus Hypophthalmichthys (Kolar and others, in press) although the Aristichthys genus used in the translation is still sometimes used (Lovell and others, 2006). Kolar and others (in press) provides an account of the history and controversy regarding the generic name of bighead carp. We also note that bighead carp and silver carp hybridize freely in the wild, and that the resulting hybrids are fertile (Kolar and others, in press). We regard this as a further indication that bighead carp should remain under the genus Hypophthalmichthys. Similarly, we retained the original use of the older specific name for grass carp (idellus rather than idella). 


\section{Distinguishing Larvae of Grass, Black, Silver and Bighead Carps from other Riverine Species of Central North America}

Before North American scientists can use the information contained in the translation to distinguish the different species and life history stages of these four fishes, it is necessary to distinguish the four species from other resident cypriniform species. As a part of our research on the Missouri River in 2005, we have identified the larvae of thousands of grass, silver, and bighead carps, but not black carp. The four most useful characteristics we found include:

(1) Myomere counts: Preanal counts of the four Asian carp species are greater than postanal counts. Using the North American convention, grass carp have 31-33 preanal and 10-12 postanal myomeres and Hypophthalmichthys spp. have 25-28 preanal myomeres and 12-14 postanal myomeres.

Common carp (Cyprinus carpio) has a similar myomere count $[(24-25)+(12-14)=(36-39)]$, but it has distinctive pigmentation that allows easy identification (Auer and others, 1982). Postanal myomere counts for grass, black, silver and bighead carps are 11 or greater (using the commonly used North American convention; 13 or greater using the method of Yi and others, 1988a), which eliminates similar-appearing catastomid fishes of the basin. Myomere counts, both preanal and postanal, do overlap with several other cyprinids of the basin.

(2) Overall egg and larvae size: The water-hardened eggs of grass, black, silver and bighead carps have a large perivitelline space and are larger in diameter than those of most other Mississippi River basin species with drifting eggs. The waterhardened egg diameters listed in Yi and others (1988a) for the four carps were usually between 4.9 to $6.0 \mathrm{~mm}$ in diameter. For comparison, the eggs of emerald shiner (Notropis atherinoides), another cyprinid commonly found in the drift, range between 3.0 to $3.3 \mathrm{~mm}$ (Auer and others, 1982). While we caution using small differences in egg size to differentiate between species of Asian carps without evaluating the efficacy, these large differences in egg size are sufficient to distinguish between Asian carps and native species likely to be found in the drift in the Mississippi River basin. At hatching, the four carps are around $6 \mathrm{~mm}$ in total length, compared to about $4 \mathrm{~mm}$ at hatching for emerald shiner (Auer and others, 1982). The larvae of many native cyprinids are much smaller, relative to the state of development, than those of grass, black, silver, and bighead carps.

(3) Eye shape: The eyes of grass, black, silver and bighead carps are relatively large and more completely circular than many other native larvae shortly after hatching (Fuiman and others, 1983). The early larvae of many native cyprinids and catostomids have distinctly dorso-ventrally flattened eyes. Asian-carp eyes also tend to be positioned more anteriorly in the head relative to many cyprinid larvae. There are other cyprinids with large round eyes, notably in the Notropis and

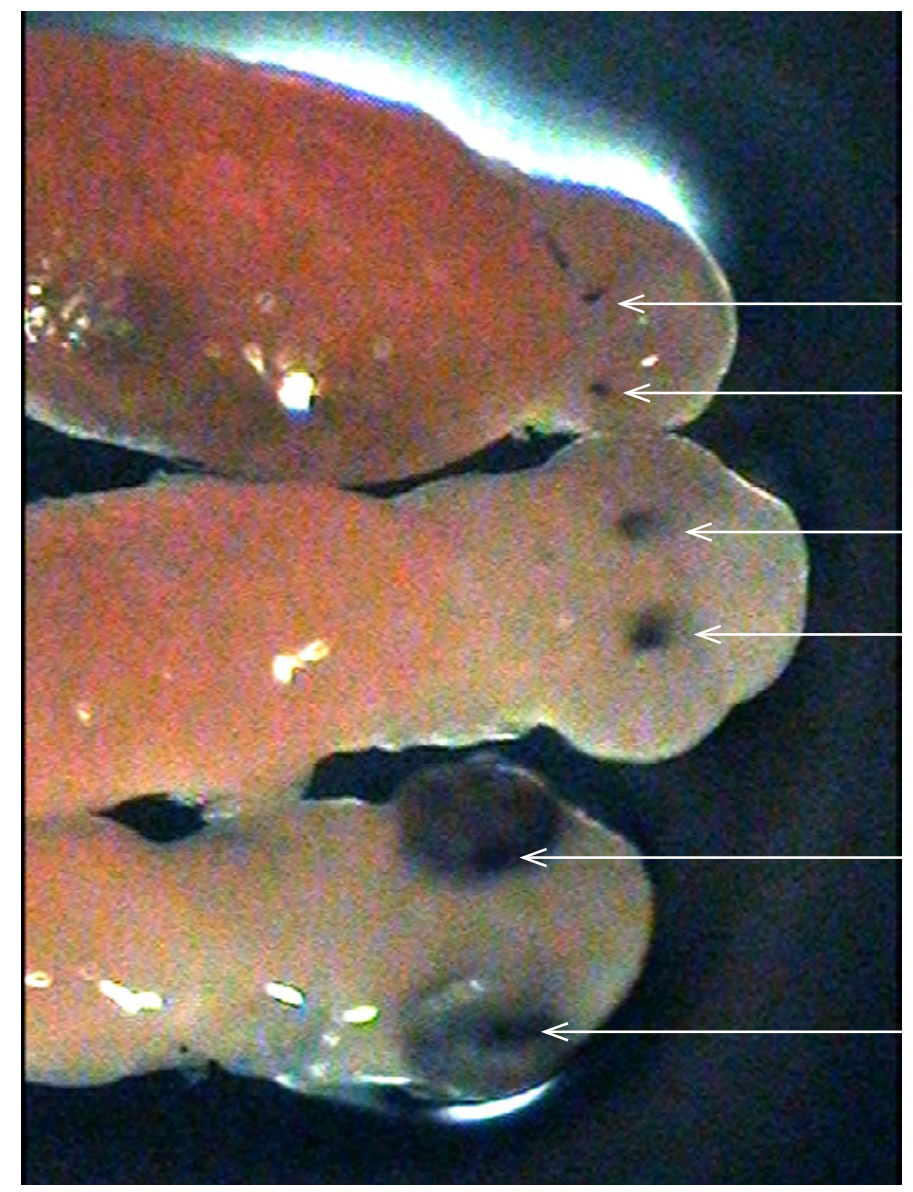

Figure 3. Ventral view of grass carp at three different early developmental stages. The uppermost larva is at the hatching stage, and the bottom larva is at the melanoid-eye stage. The middle larva is intermediate to the others. Arrows indicate the spots that are present on the ventral portion of the eyes of early larvae of grass, black, silver, and bighead carps. The spots are obscured as the eye becomes fully pigmented.

Pimephales genera, but the overall sizes of the larvae of these native fishes are much smaller than those of grass, black, silver, and bighead carps.

(4) Eye pigmentation: Prior to the complete pigmentation of the eye, there is a prominent dark spot on the inner ventral aspect of each eye in grass, black, silver, and bighead carps (fig. 3). Also described by Kryzhanovsky and others (1951; in Soin and Sukanhova, 1972), this useful diagnostic characteristic is easily visible from late embryonic stages until the eye is fully pigmented. At this time, we have not detected other species in our samples from the lower Missouri River and tributaries with a similar feature. In addition, a search of the literature on fishes of the Mississippi River basin has likewise not identified fish with a similar spot on the ventral portion of the eye. 

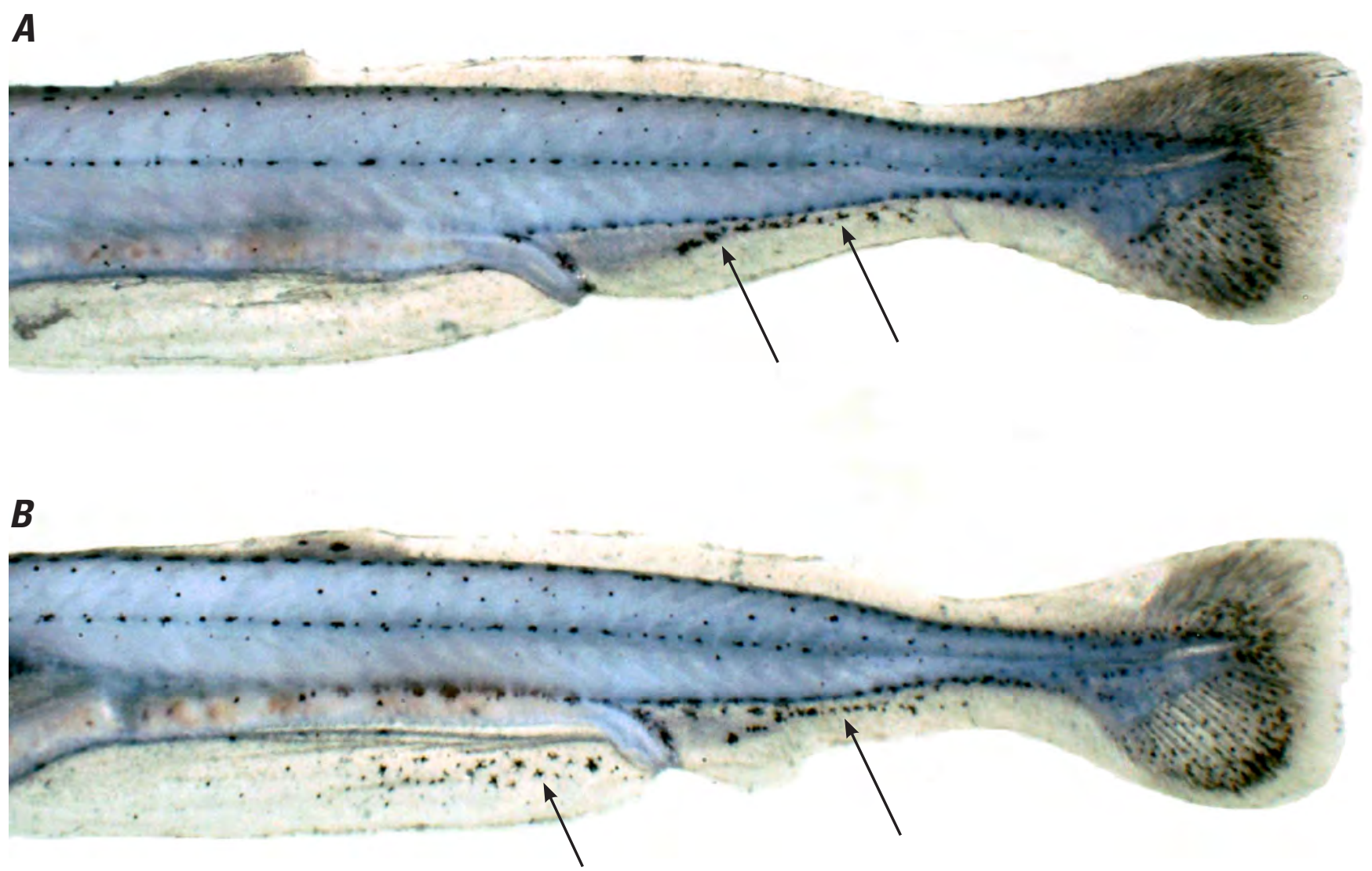

Figure 4. Melanophores (indicated by arrows) on the preanal and postanal finfolds of (A) bighead carp and (B) silver carp.

(5) Pigmentation of the preanal and anal finfolds: Bighead and silver carps develop melanophores on the preanal and anal finfolds (fig. 4) around the one-chamber-gas-bladder or dorsal-fin-differentiation stage. The melanophores remain visible until squamation. Similar pigmentation is not found in North American cyprinids, or in grass carp or black carp, which makes this an excellent diagnostic characteristic. The pattern of these pigments is also useful in discriminating between bighead carp and silver carp. However, we found that the melanophores were often difficult to discern in preserved samples.

\section{Acknowledgements}

We thank Bolu Yi, Zhishen Liang, Zhitang Yu, and Renduan Lin for permission to translate and republish the original document and Bolu Yi for his review of the translation. We thank Keyi Yi for facilitating our communications with Bolu Yi. Additional appreciation is extended to Kerry Reeves for his valuable assistance with larval fish identification and for reviewing an early version of the translation. We thank Joe Deters and Jessica Counihan for their work in larval fish identification. We thank Darrel Snyder, Thomas Simon, and James Fairchild for providing reviews of this document.

\section{References Cited}

Auer, N.A., ed., 1982, Identification of larval fishes of the Great Lakes basin with emphasis on the Lake Michigan drainage: Ann Arbor, Mich., Great Lakes Fishery Commission, Special Publication, p. 82-83.

Balon, E.K., 1984, Patterns in the evolution of reproductive styles in fishes, in Potts, G.W., and Wootten, R.J., eds,. Fish reproduction, strategies and tactics: New York, Academic Press, p. 35-53.

Fuiman, L.A., Conner, J.V., Lathrop, B.F., Buynak, G.L., Snyder, D.E., and Loos, J.J., 1983, State of the art of identification for cyprinid fish larvae from eastern North America: Transactions of the American Fisheries Society, v. 112, p. 319-332.

Institute of Hydrobiology, Chinese Academy of Science, 1973. Culture and Reproduction of Chinese freshwater fishes (2d ed.): Beijing, China, Science Press, 598 p. [In Chinese]

Institute of Hydrobiology, Chinese Academy of Science, 1976, Fishes in the Yangtze River: Beijing, China, Science Press, 220 p. [In Chinese] 
Kolar, C.S., Chapman, D.C., Courtenay, W.R., Housel, C.M., Williams, J.D., and Jennings, D.P., in press, Asian carps of the Genus Hypophthalmichthys (Pisces, Cyprinidae), a biological synopsis and environmental risk assessment: Bethesda, Md., American Fisheries Society Special Publication.

Kryzhanovsky, C.G., Smirnov, A.I., Soin, S.G., 1951, Development of fish from the Amur River: Papers from the Amur River ichthyological expedition, 1945-1949, v. 2, p. 73-84. [In Russian]

Kucera, C.J., Faulk, C.K., and Holt, G.J., 2002, The effect of spawning salinity on eggs of spotted seatrout (Cynoscion nebulosus, Cuvier) from two bays with historically different salinity regimes: Journal of Experimental Marine Biology and Ecology, v. 272, p. 147-158.

Li, S., Lu, W., Zhou, B., Xu, M., and Ren, M., 1990, Current situation of fisheries resources of silver, bighead, and grass carp in the Yangtze River, Pearl River, and Heilongjiang River: Freshwater Fisheries, v. 6, p. 15-20. [In Chinese]

Lovell, J.M., Findlay, M.M., Nedwell, J.R., and Pegg, M.A., 2006, The hearing abilities of the silver carp (Hypopthalmichthys molitrix) and bighead carp (Aristichthys nobilis): Comparative Biochemistry and Physiology, Part A-Molecular \& Integrative Physiology, v. 143, p. 286-291.

Nico, L.G., Williams, J.D., and Jelks, H.L., 2005, Black carp_-biological synopsis and risk assessment of an introduced fish: Bethesda, Md. American Fisheries Society Special Publication 31, $316 \mathrm{p}$.

Siefert, R.E., 1969, Characteristics for separation of white and black crappie larvae: Transactions of the American Fisheries Society, v. 98, p. 326-328.

Snyder, D.E., 1983, Fish eggs and larvae, in Nielson, L.A., and Johnson, D.L., eds., Fisheries techniques: Bethesda, Md., American Fisheries Society, p. 165-197.

Soin, S.G., and Sukhanova, A.I., 1972, Comparative morphological analysis of the development of the grass carp, the black carp, the silver carp and the bighead (Cyprinidae): Journal of Ichthyology, v. 12(1), p. 61-71.
Yi, B., Yu, Z., and Liang, Z., 1966, A comparative study of the embryonic development of grass carp, black carp, silver carp, big head carp and other fishes with drifting eggs in the Yangtze River, in Fisheries research committee of the western Pacific, 8th symposium, Beijing: Beijing, China, Science Press, p. 37-53. [In Chinese]

Yi, B., Liang, Z., Yu, Z., Lin, R., and He, M., 1988a, A comparative study of the early development of grass carp, black carp, silver carp and big head of the Yangtze River, in Yi, B., Yu, Z., and Liang, Z., eds., Gezhouba water control project and four famous fishes in Yangtze River: Wuhan, China, Hubei Science and Technology Press, p. 69-135. [In Chinese, English abstract].

Yi, B., Yu, Z., Liang, Z., Sujuan, S., Xu, Y., Chen, J., He, M., Liu, Y., Hu, Y., Deng, Z., Huang, S., Sun, J., Liu, R., and Xiang, Y., 1988b, The distribution, natural conditions, and breeding production of the spawning ground of four famous freshwater fishes on the main stream of the Yangtze River, in Yi, B., Yu, Z., and Liang, Z., eds., Gezhouba water control project and four famous fishes in the Yangtze River: Wuhan, China, Hubei Science and Technology Press, p. 1-46. [In Chinese, English abstract].

Yu, Z., Deng, Z., Xu, Y., Cai, M., Zhao, Y., Liang, Z., Wang, N., and Zeng, X., 1988, The present situation of the spawning grounds of the four Chinese domestic fishes in the Changjiang (Yangtze River) after construction of the Gezhouba water control project, in Yi, B., Yu, Z., and Liang, Z., eds., Gezhouba water control project and four famous fishes in the Yangtze River: Wuhan, China, Hubei Science and Technology Press, p. 1-68. [In Chinese, English abstract]

Wilson, E., 2006, Draft management and control plan for Asian carps in the United States: FR Doc. E6-17794, v. 71, no. 205 , Oct. 24 .

Zhang, Y., Tang, Y., Ouyang, H., 1989, Chinese pond aquaculture: Beijing, China, Science Press, 673 p. [In Chinese]

Zhong, L., Li, Y., Zhang, S., Liu, J., Chen, F., 1965, Biology and artificial reproduction of the four famous Chinese fishes: Beijing, China, Science Press, 171 p. [In Chinese] 
Early Development of Four Cyprinids Native to the Yangtze River, China

Page intentionally blank 


\section{A Study of the Early Development of Grass Carp, Black Carp, Silver Carp, and Bighead Carp in the Yangtze River, China}

By Bolu Yi, Zhishen Liang, Zhitang Yu, Renduan Lin, and Mingjue He

Translated by Duane C. Chapman and Ning Wang

Chapter 2 of

Early Development of Four Cyprinids Native to the Yangtze River, China

Edited by Duane C. Chapman

An identification guide translated from Chinese to English with approximately 200 original drawings. Original document published in Yi, B., Yu, Z., and Liang, Z., eds., 1988, Gezhouba water control project and four famous fishes in Yangtze River, China: Wuhan, China, Hubei Science and Technology Press, p. 69-135.

Data Series 239-2 


\section{Contents}

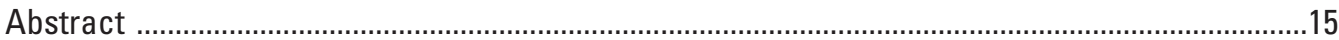

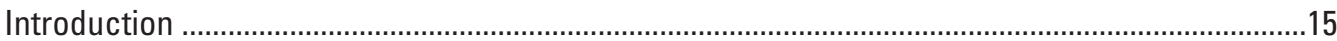

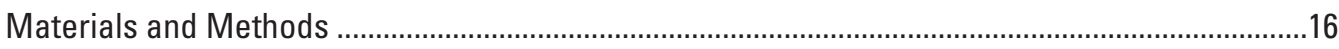

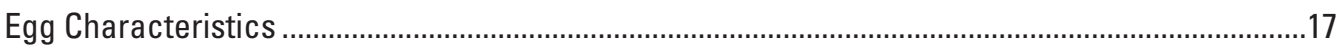

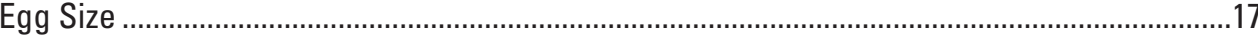

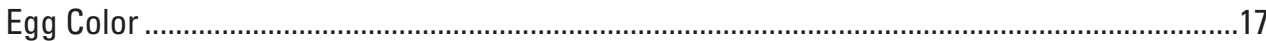

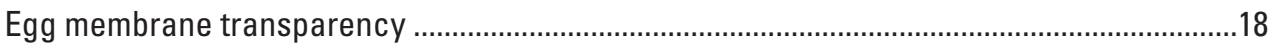

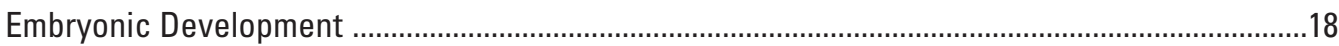

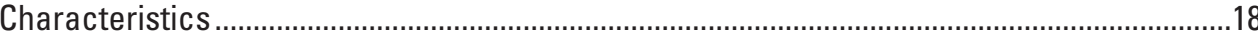

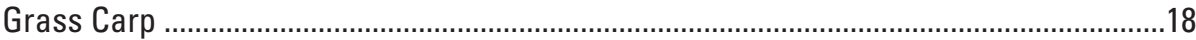

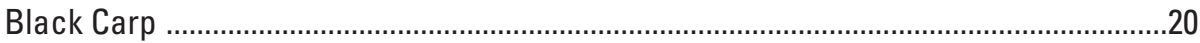

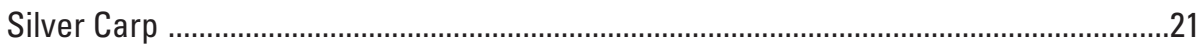

Bighead Carp ......................................................................................................21

Comparison of the Embryological Development of Grass, Black, Silver, and

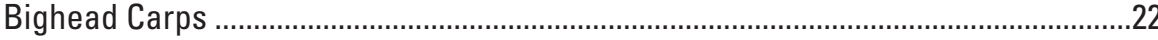

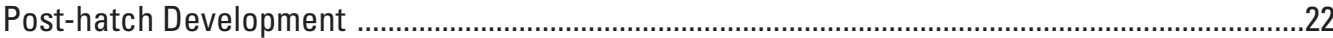

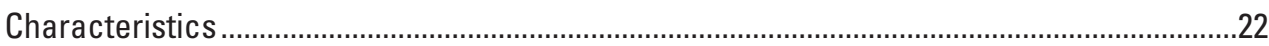

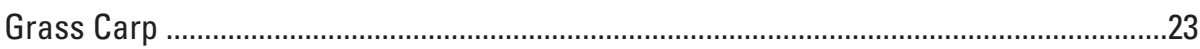

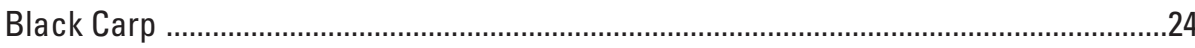

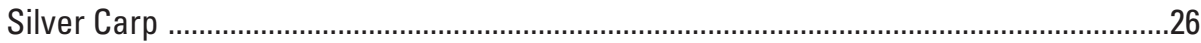

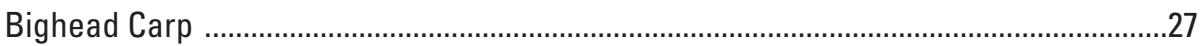

Comparison of Post-hatch Development of Grass, Black, Silver, and Bighead Carps ...........29

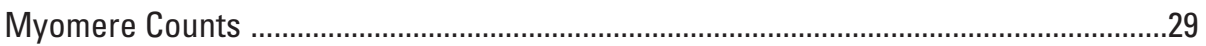

Relative Postanal Length .................................................................................................

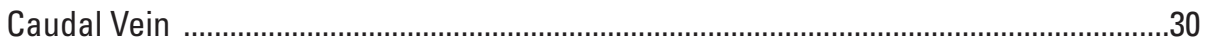

Pigmentation of the Dorsal Surface of the Head and Snout Shape …………….............30

Deep Head Pigmentation .........................................................................................

Pigment Around the Base of the Rudimentary Pectoral Fin ..............................................31

Pigmentation of the Caudal Fin .......................................................................................31

The Pigmentation of the Preanal and Anal Finfolds .....................................................31

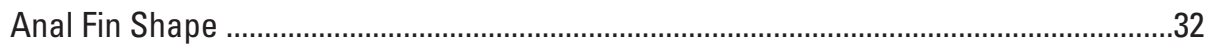

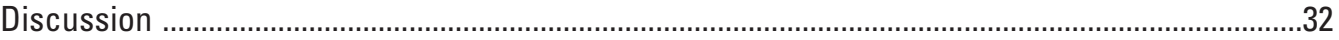

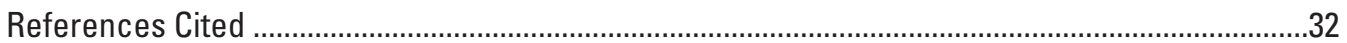

\section{Figures}

1-4. Drawings showing the stages of embryonic development-

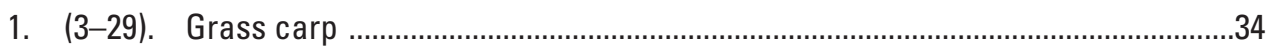

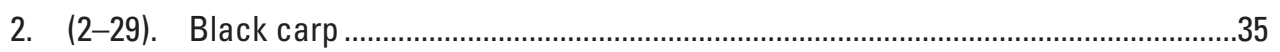

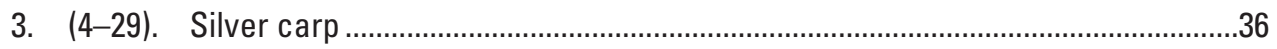

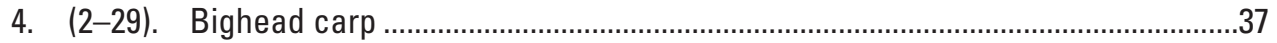

5. Drawings showing the stages of post-hatch development of grass carp (31-38) 
$(40-44)$

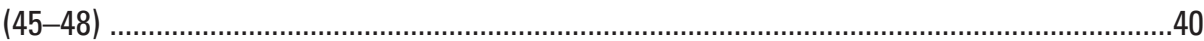

6. Drawings showing the stages of post-hatch development of black carp

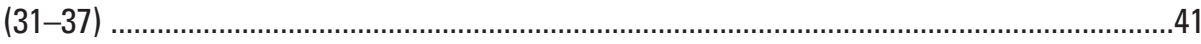

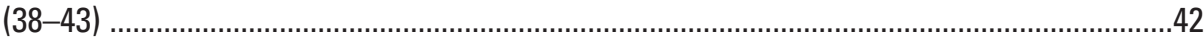

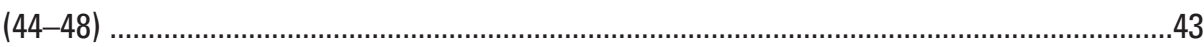

7. Drawings showing the stages of post-hatch development of silver carp

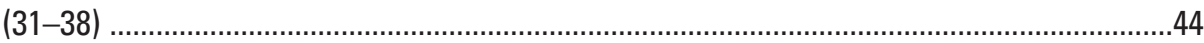

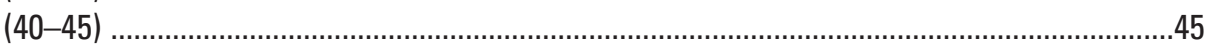

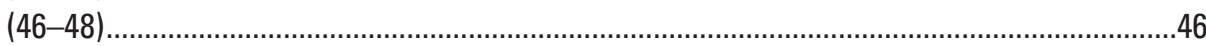

8. Drawings showing the stages of post-hatch development of bighead carp

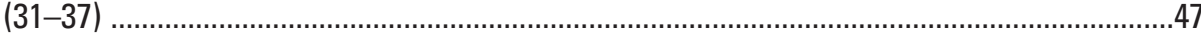

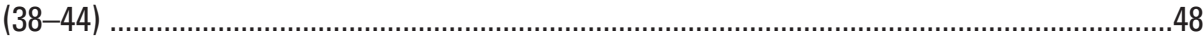

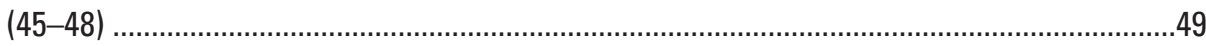

9. Drawings showing the different patterns of melanophores of eight cyprinids ...............50

10. Chart showing the primary diagnostic characteristics in the early development of grass, black, silver, and bighead carps collected from the Yangtze River. ..................51

\section{Tables}

1. The size-frequency distribution of the egg membranes of grass carp, black carp, silver carp, and bighead carp collected from the Yangtze River between 1961 and 1964, and between 1976 and 1978

2. Hues of the egg yolk of grass carp, black carp, silver carp, and bighead carp collected from the Yangtze River in 1964, 1976, and 1977

3. Stages of embryonic development, hours of development at $18-24^{\circ} \mathrm{C}$, and length of embryos of grass carp, black carp, silver carp, and bighead carp collected from the Yangtze River

4. Myomere counts in three early development stages of grass carp, black carp, silver carp, and bighead carp collected from the Yangtze River

5. Proportion of postanal length to total body length of yolk-sac larvae of grass carp, black carp, silver carp, and bighead carp collected from the Yangtze River

6. Melanophores of the dorsal surface of the head, and shape (as viewed dorsally) of the anterior margin of the snouts of grass carp, black carp, silver carp, and bighead carp at the gas-bladder-emergence stage

7. Number of lateral-line scales at the squamation stage of grass carp larvae originally collected from the Yangtze River and raised in containers with different water volumes 
Page intentionally blank 


\section{Chapter 2 \\ A Study of the Early Development of Grass Carp, Black Carp, Silver Carp, and Bighead Carp in the Yangtze River, China}

\author{
Bolu Yi' ${ }^{1}$ Zhishen Liang ${ }^{2}$, Zhitang Yư ${ }^{3}$, Renduan Lin $^{3}$, \\ and Mingjue $\mathrm{He}^{3}$
}

\section{Abstract}

The present paper describes the characteristics of 48 early developmental stages of the four famous domestic fishes in the Yangtze River in China-grass carp (Ctenopharyngodon idellus), black carp (Mylopharyngodon piceus), silver carp (Hypophthalmichthys molitrix), and bighead carp (Aristichthys nobilis). The paper compares the morphological similarities and differences among the four species with about 200 original drawings. The results of this paper were mainly based on continuous observations of the early development of eggs and larvae of the four species collected from the upstream and middle sections of the Yangtze River trunk stream ${ }^{4}$ between 1961 and 1963. In addition, some data and material collected during later studies of the four species in the Yangtze River and its tributary, the Han River, during spawning seasons between 1964 and 1966, between 1976 and 1978, and 1981 were used to confirm and supplement the previous results.

\section{Introduction}

Grass carp (Ctenopharyngon idellus), black carp (Mylopharyngodon piceus), silver carp (Hypophthalmichthys molitrix) and bighead carp (Aristichthys nobilis), known in China as "the four famous domestic fishes," are the primary economically-important freshwater fish in China, especially in the Yangtze River system. There was no record of the early development of these four fishes before the 1930s. Lin

\footnotetext{
${ }^{1}$ The College of Fisheries, Huazhong Agricultural University, Wuhan, 430070, China

${ }^{2}$ Institute of Environment Protection, Guangzhou, 510620, China

${ }^{3}$ Institute of Hydrobiology, Chinese Academy of Sciences, Wuhan, 430072, China

${ }^{4}$ Translator's note: definition of “trunk stream” in Chapman and Wang, this volume, chapter 1
}

$(1935)^{5}$ and Chen and Lin (1935) briefly described the eggs and larvae of grass carp. Li and He (1937) partly described the early development of silver carp as part of their fish culture studies. Afterwards, there were no more studies on the early development until the 1950s. Liu (1954) described some characteristics of the embryological development of grass carp. A few years later other researchers observed and recorded the embryological development of grass, silver, and bighead carps (Ye, 1958; Yu, 19595; Institute of Experimental Biology, 1962; Yang, 1962; Yuan, 1962; Zhong, 1962; Chen, 1963a,b; Shandong Institute of Freshwater Fisheries, 1963; Wu and Shi, 1964; Xie, 1964). Ye (1964) reported limited data on the embryological development of black carp. Outside of China, there were only a few reports on the early development of these four species in the early 50s (Verigin, 1950; Kryzhanovsky and others, 1951). However, in the above-mentioned studies, there was no detailed comparative description of the important characteristics of the four fishes and differences in their early development.

Since 1961, during studies of the potential effect of the Gezhouba Dam on the fisheries of the Yangtze River and determination of the spawning grounds of grass, black, silver, and bighead carps, we conducted thorough comparative studies on the early development of the four fishes. Identifying the developmental characteristics of these fishes was a prerequisite for identifying their spawning grounds. By knowing the common early developmental characteristics of the four fishes, it was possible to distinguish them from other co-occurring species with similar spawning habits and early life history. By determining various early development stages of the four fishes and the duration after fertilization, it was possible to locate the spawning grounds of these fishes. By determining the specific early development characteristics of each of the four species, it was possible to calculate the relative abundance of the four species, and the relative number of eggs/larvae produced between different spawning sites.

Most data were collected by the end of 1963 and a preliminary report was presented in the $8^{\text {th }}$ Symposium of West Pacific Fisheries Research Committee (Yi and others, 1966). In that report, which was written based on partially complete data, the reproduction and early development characteristics

\footnotetext{
${ }^{5}$ Translator's note: Lin (1935) and Yu (1959) were not listed in the References section of the original document.
} 
of the four fishes were described, and also were compared with six other species which have similar spawning requirements and early life history. A few years later, the figures of early development of the four fishes were published in the book "Culture and Reproduction of Chinese Freshwater Fish" (Chapter 4, "Reproduction of Cultured Fish," Institute of Hydrobiology, 1973) and in the book "Fishes of the Yangtze River" (Institute of Hydrobiology, 1976). This work from beginning to present lasted more than 20 years. Publication of the whole article has been delayed, but the intent was to continually add more information. For example, the study "Prediction of Timing of the Availability in Hatching of Larvae of the Four Fishes in the Yangtze River" was conducted between 1964 and 1968. During this study, eggs and larvae of the four fishes were collected, and the data and material were used to confirm and supplement our previous data. Some authors of the present paper participated in the study "The Juvenile Fish of Economical Importance of the Yangtze River" (1974 and 1975), the investigation "Fisheries Resources of the Han River" (1976-1978), and the study "The Present Situation on the Spawning Grounds of the Four Famous Domestic Fishes in the Yangtze River after Construction of the Gezhouba Water Control Project" (1981). Some results from these studies were also used to supplement current data and figures of early developmental stages of the four fishes.

The following people also participated in data collection and larvae culture for this research project: Sujuan Shan, Yungan Xu, Youliang Liu, Yizhi Hu, Jiangyi Sun, Jingxing Chen, Shangwu Huang, Zhonglin Deng, Henian Huang, Chungsheng Zhou, Yang Xiang, Zhigao Yang, Xiangjian Wei, and Ning Wang. We appreciate their efforts.

\section{Materials and Methods}

Eggs and larvae were mainly collected between 1961 and 1963 in the trunk stream of the Yangtze River. During the entire reproduction season in 1961, the collection and observation of eggs and larvae were conducted at the Yichang spawning reach, which included a $35-\mathrm{km}$ gorge section between the towns of Letianxi and Nanjinguan, located upstream of Yichang ${ }^{6}$, and the future site of the Gezhouba Dam (three km below Nanjinguan). In May and June of 1962, collections were performed in middle Yangtze River near the city of Huangshi and upper Yangtze River in Wuanxian County. In the first half of July 1961 and the first half of May 1962, our research vessel continually traveled back and forth between Wuhan and Yichang and between Wuhan and Hukou to collect eggs and larvae. We collected additional eggs and larvae between Huangshi and Hukou in 1963 and near Janli in 1964. Also, we

\footnotetext{
${ }^{6}$ Translator's note: For a map of locations, see Chapman and Wang, this volume, chapter 1 .
}

collected eggs and larvae, observed their characteristics, and made additional illustrations of the early development stages in the Yangtze River in 1965, 1966, 1974, and 1981, and in the Han River in 1976 and 1978.

The data from the collections above represent the morphological characteristics of early development of fishes in the middle and upper sections of the trunk stream of the Yangtze River. No obviously different characteristics were found between various sections of the Yangtze River or its tributaries.

Three conditions had to be satisfied when observing the embryological development of fish eggs collected from the field: (1) The fertilized eggs must have been released from a female which had eggs of the right stage of development and the eggs must develop normally, (2) the early embryos of four fishes could be collected at the same time and same location, and (3) the eggs of the four species could be compared under the same conditions.

The eggs were collected quantitatively by using a D-frame net and a conical net. The D-frame opening had a radius of $0.5 \mathrm{~m}$ and opening area of $0.393 \mathrm{~m}^{2}$. The length of the cloth portion of the D-frame net was $2 \mathrm{~m}$, followed by a box-shaped collection chamber. The conical net was used to collect eggs and larvae near the bottom of the river. The diameter of the opening of the conical net was $0.7 \mathrm{~m}$. The opening area was $0.385 \mathrm{~m}^{2}$. The net could be lowered to near the bottom using a long rope. The eggs and larvae collected were observed and identified under a dissecting scope immediately after collection and illustrated at that time. They were then placed into Petri dishes for rearing so that they could be repeatedly observed and illustrated. For observation of hatched larvae, several drops of a 5 to 10 percent solution of urethane were added into the observation chamber to temporarily immobilize the fish. Additional water was added to prevent mortality as needed based on the temperature, the blood circulation rate of the larvae, and the time needed to finish the illustration.

Between 1961 and 1964, 1,192 fish were collected and observed. Of these, 578 were grass carp, 337 were black carp, 199 were silver carp, and 78 were bighead carp. A total of 2,608 eggs were used to confirm and supplement between 1976 and 1978. Of that number, 977 were grass carp, 791 were black carp, 695 were silver carp, and 145 were bighead carp. From the 3,800 eggs randomly collected from the Yangtze River, the number of grass carp collected was highest $(1,555)$, and the bighead carp the lowest. These data possibly indicate a rough ratio of populations of the four fish in the Yangtze River. The ratio of grass carp: black carp: silver carp: bighead carp was 7:5:4:1 (table 1).

From the collected eggs of the four species, about 50 were used for drawing the pictures of the consecutive embryo stages. The eggs collected in April and May 1961 were held until hatching and then reared until November in order to identify the species. In the following two years, we repeated 
the observations and the illustrations of the developmental stages to fill remaining data gaps. Therefore, the 48 illustrated developmental stages of each species were first based on two or three organisms. Afterwards, more eggs and larvae were observed and used to perfect the illustrations and confirm that the illustrations were representative of the species. The shape and the size of the egg membrane of the four fishes were compared based on about 3,800 collected eggs.

\section{Egg Characteristics}

After mature eggs of the four species are released and fertilized, the vacuole is broken and fluid is released. Water enters the egg membrane, causing the egg to expand and creat-

Table 1. The size-frequency distribution of the egg membranes of grass carp, black carp, silver carp, and bighead carp collected from the Yangtze River between 1961 and 1964, and between 1976 and 1978.

$[\mathrm{mm}$, millimeters $]$

\begin{tabular}{lrrrrr}
\hline $\begin{array}{c}\text { Diameter of } \\
\text { egg membrane } \\
\text { (mm) }\end{array}$ & \multicolumn{5}{c}{ Number of eggs } \\
\hline & $\begin{array}{c}\text { Grass } \\
\text { carp }\end{array}$ & $\begin{array}{c}\text { Black } \\
\text { carp }\end{array}$ & $\begin{array}{c}\text { Silver } \\
\text { carp }\end{array}$ & $\begin{array}{c}\text { Bighead } \\
\text { carp }\end{array}$ & \multicolumn{1}{c}{ Total } \\
\hline $3.5-3.6$ & 3 & 0 & 4 & 0 & 7 \\
$3.7-3.8$ & 6 & 0 & 3 & 0 & 9 \\
$3.9-4.0$ & 20 & 0 & 22 & 0 & 42 \\
$4.1-4.2$ & 47 & 0 & 44 & 0 & 91 \\
$4.3-4.4$ & 55 & 8 & 47 & 0 & 110 \\
$4.5-4.6$ & 98 & 55 & 94 & 0 & 247 \\
$4.7-4.8$ & 125 & 70 & 93 & 0 & 288 \\
$4.9-5.0$ & 192 & 115 & 112 & 15 & 434 \\
$5.1-5.2$ & 276 & 111 & 129 & 10 & 526 \\
$5.3-5.4$ & 256 & 117 & 130 & 15 & 518 \\
$5.5-5.6$ & 233 & 202 & 111 & 34 & 580 \\
$5.7-5.8$ & 141 & 142 & 59 & 44 & 386 \\
$5.9-6.0$ & 88 & 143 & 35 & 48 & 314 \\
$6.1-6.2$ & 7 & 80 & 7 & 18 & 112 \\
$6.3-6.4$ & 5 & 56 & 4 & 19 & 84 \\
$6.5-6.6$ & 2 & 23 & 0 & 17 & 42 \\
$6.7-6.8$ & 1 & 6 & 0 & 3 & 10 \\
Total & 1,555 & 1,128 & 894 & 223 & 3,800 \\
Percentage & 40.9 & 29.7 & 23.5 & 5.9 & 100 \\
\hline & & & & & \\
\hline
\end{tabular}

ing a space between the plasmolemma and the egg membrane. The eggs are slightly demersal and drift with the current. The eggs do not float; they will sink under still water conditions. These eggs may be called "drifting eggs."

\section{Egg Size}

There are more than 20 fishes with semi-buoyant drifting eggs in the Yangtze River. Of these, water-hardened eggs of the grass, black, silver, and bighead carp were the largest. The diameter of most egg membranes of the four species were between 4.9 to $6.0 \mathrm{~mm}$ after water-hardening (table 1). However, the frequency of distribution of egg membrane sizes was different among the four species. The variation in grass carp egg diameters was largest. Among 1,555 grass carp eggs, the diameters were between 3.5 to $6.7 \mathrm{~mm}$ (range 3.2 $\mathrm{mm}$ ); most of the eggs ( 70.6 percent; $\mathrm{n}=1,098$ ) were between 4.9 to $5.8 \mathrm{~mm}$. There were no small eggs in black carp; the diameters were between 4.3 to $6.8 \mathrm{~mm}$ (range $2.5 \mathrm{~mm}$ ) and most eggs (73.6 percent, $\mathrm{n}=1128$ ) were between 4.9 to 6.0 $\mathrm{mm}$. Eggs of silver carp were the smallest compared to the other three species, but the size range was large (3.5 to 6.4 $\mathrm{mm}$, range $2.9 \mathrm{~mm})$; most of the eggs $(74.8$ percent, $\mathrm{n}=894)$ were between 4.5 and $5.6 \mathrm{~mm}$. The egg diameters of bighead carp were between 4.9 to $6.7 \mathrm{~mm}$ and the range was small ( 1.8 $\mathrm{mm}$ ); most of the eggs (73.1 percent, $\mathrm{n}=223$ ) were between 5.5 to $6.4 \mathrm{~mm}$. Among all four species, most of the eggs ( 72.6 percent, $\mathrm{n}=3,800$ ) were between 4.9 and $6.0 \mathrm{~mm}$ in diameter. There were few eggs with diameters larger than 6.6 or less than 3.9 ( 0.68 percent).

From the frequency distribution of egg diameters of the four species, the egg size of bighead carp was the largest, then the black carp, then grass carp, then silver carp. The mean and standard deviation of the egg size were $5.82 \pm 0.42,5.51 \pm$ $0.51,5.18 \pm 0.48,5.05 \pm 0.52$ for bighead, black, grass, and silver carps, respectively. On the other hand, we often found overlaps in the ranges of egg sizes for the four species, which caused difficulty in using egg size to identify the species. Based on frequency distribution, eggs with diameters between 4.9 and $5.2 \mathrm{~mm}$ were most likely to be grass carp or silver carp, between 5.3 to $5.6 \mathrm{~mm}$ were likely to be grass, silver or black carp; between 5.7 and $6.2 \mathrm{~mm}$ were likely to be black or bighead carp. Eggs larger than $6.2 \mathrm{~mm}$ generally were black carp or bighead carp. Eggs with a diameter of less than 4.9 $\mathrm{mm}$ were unlikely to be bighead carp; eggs less than $4.3 \mathrm{~mm}$ generally were grass or silver carp, but were unlikely to be black carp. When examining the eggs, one can use size along with other characteristics to make a decision as to the species.

\footnotetext{
${ }^{7}$ Translators' note: The authors of the original document inserted the English words "drifting eggs" here. Eggs with these characteristics are often termed "semibuoyant" in North American literature.
} 


\section{Egg Color}

The yolk sac of the four species often exhibited different shades of yellow. The color range between dark yellow to light yellow can be described in four categories of loquat-yellow, apricot-yellow, butter-yellow, and cream-colored. The most easily distinguished colors were loquat-yellow ${ }^{8}$ and creamcolored. Apricot-yellow and butter-yellow were difficult to distinguish. The yolk sac of grass carp was relatively darker than the other three fish. Among the 379 grass carp eggs, 63.6 percent were loquat-yellow and 23.2 percent apricotyellow. Most of the black carp $(n=263)$ were apricot-yellow (65.4 percent) and loquat-yellow (19.8 percent). The yolk sac of silver carp had a high degree of variance in color; however apricot-yellow was most prominent (49.5 percent; $\mathrm{n}=186$ ). Bighead carp had the lightest colored yolk sacs, with 61.5 percent butter-yellow and 10 percent cream-colored $(n=83$; table 2).

\section{Egg membrane transparency}

After water-hardening, there were substantial differences in the egg membrane transparency of the four species. The egg of the grass carp was obviously transparent to the unaided human eye. Egg membranes of silver and bighead carps were thicker than those of grass carp and were relatively transparent, although not quite as transparent as those of grass carp. The black carp egg membrane was relatively thick and slightly sticky; often small particles stuck to the surface, which made the egg membrane slightly opaque. The embryos of black carp could only be clearly distinguished only by using a dissecting microscope.

${ }^{8}$ Translator's note: The names of the colors are not direct translations from the original document. These colors were suggested by the first author of the document (Bolu Yi) as appropriate color names for this translation.

\section{Embryonic Development}

\section{Characteristics}

The early development of grass, black, silver, and bighead carps had two primary periods, embryonic and posthatch. Before hatching, the embryos were observed in the dishes and the water was renewed a few times every day. The water temperature ranged from 18.0 to $24.2^{\circ} \mathrm{C}$. Under these conditions, the larvae of the four species hatched in about $1 \frac{1}{2}$ days (usually 33-34 hours). Similar to other cyprinids with drifting eggs, there were 30 embryonic development stages and the time between stages differed. The egg size changed between stages. From the two-cell stage to the heartbeat stage, the length of the embryo increased continually (table 3 ). The characteristics of various stages of embryonic development are described as follows:

\section{Grass Carp}

The youngest eggs collected were at the 4-cell stage (fig. 1-3). The color of divided cells was light yellow, while the yellow color of the yolk was darker. The cytoplasm was widely distributed. Cells divided vertically four times until the 64-cell stage. From the 8-cell stage through the 32-cell stage (fig. 1-4 to 1-6), cells were large and arranged regularly; the cytoplasm diminished and streamed toward the animal pole. At the 64-cell stage (fig. 1-7), cells became smaller and were arranged irregularly; the cross-section width of the blastodisc was almost equal to that of the yolk. Cells divided horizontally between the 64-cell stage and the 128-cell stage (fig. 1-8). At the morula stage (fig. 1-9), the cells became smaller and cytoplasm continued to move toward the animal pole. At the earlyblastula stage (fig. 1-10), the blastodisc appeared mound-like. At the mid-blastula stage (fig. 1-11), the crowded cells expanded over the yolk and the blastodisc began flattening. At the late-blastula stage (fig. 1-12), the blastodisc flattened more, the whole egg looked round, and the cytoplasm disappeared.

Table 2. Hues of the egg yolk of grass carp, black carp, silver carp, and bighead carp collected from the Yangtze River in 1964, 1976, and 1977.

\begin{tabular}{lcccccccc}
\hline \multirow{2}{*}{ Color } & \multicolumn{2}{c}{ Grass carp } & \multicolumn{2}{c}{ Black carp } & \multicolumn{2}{c}{ Silver carp } & \multicolumn{2}{c}{ Bighead carp } \\
\cline { 2 - 8 } & Number & Percent & Number & Percent & Number & Percent & Number & Percent \\
\hline Loquat-yellow & 241 & 63.6 & 52 & 19.8 & 38 & 20.4 & 0 & 0 \\
Apricot-yellow & 88 & 23.2 & 172 & 65.4 & 92 & 49.5 & 25 & 30.1 \\
Butter-yellow & 18 & 4.8 & 11 & 4.2 & 42 & 22.6 & 51 \\
Cream-colored & 32 & 8.4 & 23 & 10.6 & 14 & 7.5 & 7 & 8.5 \\
Total & 379 & & 258 & & 186 & & 83 \\
\hline
\end{tabular}


Table 3. Stages of embryonic development, hours of development at $18-24^{\circ} \mathrm{C}$, and length of embryos of grass carp, black carp, silver carp, and bighead carp collected from the Yangtze River.

[mm, millimeter; hr:min, hour and minutes; -, no data]

\begin{tabular}{|c|c|c|c|c|c|c|c|c|c|}
\hline \multirow[b]{2}{*}{ No. } & \multirow[b]{2}{*}{ Stage } & \multicolumn{2}{|c|}{ Grass carp } & \multicolumn{2}{|c|}{ Black carp } & \multicolumn{2}{|c|}{ Silver carp } & \multicolumn{2}{|c|}{ Bighead carp } \\
\hline & & Length & Time & Length & Time & Length & Time & Length & Time \\
\hline & & $(\mathrm{mm})$ & (hr:min) & $(\mathrm{mm})$ & (hr:min) & $(\mathrm{mm})$ & (hr:min) & $(\mathrm{mm})$ & (hr:min) \\
\hline 1 & 1 -cell & - & - & - & - & - & - & - & - \\
\hline 2 & 2-cell & - & - & 1.75 & $0: 50$ & - & - & 1.85 & $0: 55$ \\
\hline 4 & 8-cell & 1.57 & $1: 20$ & 1.78 & $1: 25$ & 1.80 & $1: 20$ & 1.91 & $1: 12$ \\
\hline 5 & 16-cell & 1.88 & $1: 40$ & 1.80 & $1: 45$ & 1.90 & $1: 45$ & 1.93 & $1: 24$ \\
\hline 6 & 32-cell & 1.90 & $2: 05$ & 1.80 & $2: 00$ & 1.93 & $1: 57$ & 1.95 & $2: 00$ \\
\hline 7 & 64-cell & 1.88 & $2: 45$ & 1.88 & $2: 15$ & 1.93 & $2: 30$ & 1.97 & $2: 20$ \\
\hline 10 & Early blastula & 1.92 & $4: 50$ & 2.10 & $4: 48$ & 1.94 & $4: 55$ & 2.10 & $4: 10$ \\
\hline 11 & Mid-blastula & 1.90 & $5: 55$ & 2.00 & $5: 38$ & 1.93 & $5: 20$ & 2.00 & $5: 30$ \\
\hline 12 & Late blastula & 1.80 & $7: 35$ & 1.90 & $7: 43$ & 1.92 & $6: 40$ & 1.90 & $7: 20$ \\
\hline 13 & Early gastrula & 1.80 & $8: 55$ & 1.80 & $9: 38$ & 1.92 & $8: 40$ & 1.85 & $8: 10$ \\
\hline 14 & Mid-gastrula & 1.80 & $9: 40$ & 1.80 & $11: 41$ & 1.90 & $10: 15$ & 1.85 & $9: 55$ \\
\hline 15 & Late gastrula & 1.80 & $10: 30$ & 1.80 & $12: 35$ & 1.90 & $12: 50$ & 1.90 & $11: 20$ \\
\hline 16 & Neurula & 1.80 & $11: 15$ & 1.80 & $13: 40$ & 2.00 & $14: 10$ & 2.00 & $12: 45$ \\
\hline 21 & Olfactory placode & 1.95 & $19: 15$ & 2.20 & $18: 10$ & 2.20 & $18: 25$ & 2.26 & $17: 45$ \\
\hline 22 & Tail bud & 2.00 & $19: 45$ & 2.30 & 19:00 & 2.50 & $19: 30$ & 2.32 & 19:05 \\
\hline 23 & Otic capsule & 2.40 & $20: 30$ & 2.50 & $19: 50$ & 2.60 & $20: 45$ & 2.56 & $19: 35$ \\
\hline 24 & Tail vesicle & 2.71 & $21: 20$ & 2.70 & $21: 20$ & 2.80 & $22: 00$ & 3.00 & $22: 00$ \\
\hline 25 & Caudal fin & 3.10 & $22: 45$ & 2.80 & $22: 50$ & 3.20 & $22: 35$ & 3.00 & $24: 28$ \\
\hline 26 & Lens formation & 3.20 & $23: 15$ & 3.00 & $23: 25$ & 3.65 & $23: 00$ & 3.80 & $25: 20$ \\
\hline 27 & Muscular effect & 3.30 & $23: 50$ & 3.50 & $24: 15$ & 3.90 & $24: 25$ & 4.40 & $26: 25$ \\
\hline 28 & Heart rudiment & 4.00 & $27: 32$ & 4.00 & $28: 10$ & 4.10 & $28: 20$ & 5.20 & $28: 40$ \\
\hline 29 & Otolith appearance & 4.80 & $31: 30$ & 4.70 & $31: 48$ & 4.30 & $30: 00$ & 5.80 & $32: 30$ \\
\hline 30 & Heart pulsation & 5.50 & $33: 35$ & 5.80 & $34: 35$ & 5.40 & 34.15 & 6.30 & $33: 00$ \\
\hline
\end{tabular}


At the early-gastrula stage (fig. 1-13), the blastodisc began to invaginate, the germ ring formed, the dorsal lip appeared, and the blastoderm covered about one-half of the yolk. At the mid-gastrula stage (fig. 1-14), the germ ring and the enlarged region of the blastoderm thickened, the embryonic shield formed, the lower part of the yolk cell shrank, and the margin of the blastoderm covered about two-thirds of the yolk cell. At the late-gastrula stage (fig. 1-15), the embryonic shield developed, the rudiment of the embryo became evident, the blastoderm covered about four-fifths of the yolk, and the yolk was pear-shaped. At the neurula stage (fig. 1-16), the blastoderm covered almost the whole yolk, leaving only the yolk plug uncovered, and the embryo thickened substantially. The blastopore-closure stage (fig. 1-17) began one half-hour later and the embryo lengthened. At the somite-appearance stage (fig. 1-18), one to three pairs of somites appeared at the middle part of the embryo, the brain rudiment thickened, and the blastopore was still visible. At the optic-primordium stage (fig. 1-19), the optic primordium was a long oval shape, the lower edge appeared to have fine crenulations, the embryo embraced about five-sixths of the yolk, two to three oil droplets appeared on the yolk cell, and the somite number increased to four or five pairs. At the optic-vesicle stage (fig. 1-20), the optic primordium enlarged slightly and became more visible, the embryo encircled most of the yolk so that the head and tail were in close proximity, the somite number was six or seven pairs, and the notochord was clearly visible. At the olfactory-placode stage (fig. 1-21), the olfactory placode was barely visible above the optic vesicle and the somite number was nine pairs. At the tail-bud stage (fig. 1-22), the tail was more prominent, the brain rudiment differentiated substantially, and the somites numbered 10 to 15 pairs. At the otic-capsule stage (fig. 1-23), the otic capsule was clearly visible, the optic vesicle enlarged and became elliptical, the somites numbered 16 to 20 pairs, the yolk sac elongated, the distance between the head and tail increased, and an obvious bump appeared at the brain area. At the tail-vesicle stage (fig. 1-24), the tail extended outward, a vesicle appeared on the tail bud, the end of the yolk-sac showed sky-blue color, the somites numbered 21 or 22 pairs, the embryo elongated, and a constriction appeared in the posterior region of the yolk where the tail bud ended. At the caudal-fin stage (fig. 1-25), the embryo elongated further, the rudimentary caudal fin formed, the tail vesicle moved to the end of the tail, the eye was almost round, the yolk-sac looked like a kidney, and the somites numbered about 25 pairs. At the lens-formation stage (no figure), the eye lens formed, the otic vesicle appeared, and the somites numbered 26 pairs. The muscular-effect stage started about one-half hour later (fig. 1-27). The tail vesicle disappeared, the embryo was light yellow, the spontaneous myotomal constrictions produced a slight lashing motion, the brain developed further, the bump was more prominent, the embryo and the yolk continued elongating, the end of the yolk remained sky blue, and the myomeres numbered 27 . At the heartrudiment stage (fig. 1-28), the embryo and the yolk elongated further, the caudal fin extended, the embryo lashed from side to side occasionally, the heart rudiment appeared between the head and the yolk, and the somites numbered 31 pairs. At the otolith-appearance stage (fig. 1-29), the embryo straightened but the head was still curved around the anterior yolk-sac. The embryo moved continuously, the yolk-sac was wider in the anterior than the posterior portion, the otoliths appeared, and the somites numbered 33 to 35 pairs. The heart-pulsation stage (no figure), was the last stage of embryonic development. The heart began to pulsate, the embryo rotated continuously, and the somites numbered 36 to 41 pairs, the egg membrane softened, and the embryo was ready to hatch.

\section{Black Carp}

The youngest eggs collected were at the 2-cell stage (fig. 2-2). The cell was dark yellow and the yolk was light yellow. The grey cytoplasm concentrated near the center of the yolk. Sometimes one or two cells divided earlier than others at the 8-cell stage (fig. 2-4). The cytoplasm diminished gradually at the 16-cell stage (fig. 2-5). At the 32- and 64-cell stages (fig. 2-6 and 2-7), the sizes of cells were different and cells at the periphery of the blastodisc were smaller. After a horizontal division, the 128-cell stage began (fig. 2-8). The blastodisc appeared mound-like and several oil droplets appeared on the yolk. At the morula stage (fig. 2-9), the blastodisc was highly raised above the yolk surface and the cross-sectional width of the blastodisc was obviously smaller than that of the yolk. At the early-blastula stage (fig. 2-10), the cells became still smaller and the cytoplasm almost disappeared. At the midblastula stage (fig. 2-11), the blastodisc began flattening and formed a half-sphere. At the late-blastula stage (fig. 2-12), the blastodisc gradually expanded over the yolk. At the early-gastrula stage (fig. 2-13), the germ ring appeared, the blastoderm covered about half of the yolk cell, and the whole egg was round. At the mid-gastrula stage (fig. 2-14), the dorsal lip and embryonic shield appeared and the margin of the blastoderm covered about two-thirds of the yolk cell. At the late-gastrula stage (fig. 2-15), the embryonic body was clearly visible, the head was slightly enlarged, the blastoderm covered about 5/6 of the yolk, and the yolk cell was pear-shaped. At the neurula stage (fig. 2-16), the head part was clearly visible, the blastoderm covered almost the whole yolk cell leaving only the yolk plug uncovered, and the embryo thickened substantially. At the blastopore-closure stage (fig. 2-17), the embryo elongated and the front part of the head was slightly enlarged. At the somite-appearance stage (fig. 2-18), somites numbered one to five pairs: one pair appeared every 10 minutes or so. At the optic-primordium stage (fig. 2-19), the optic primordium was a long oval shape with a crenulated ventral margin. The un-encircled margin of the yolk was a straight line, and the somites numbered 6 to 10 pairs. At the optic-vesicle stage (fig. 2-20), a bump appeared obviously at the brain area, the somites numbered 11 to 12 pairs, and the notochord was clearly visible. At the olfactory-placode stage (fig. 2-21), the olfactory placode was barely visible above the optic vesicle and the somites numbered 13 to 14 pairs. At the tail-bud stage 
(fig. 2-22), the brain rudiment differentiated substantially, the eyes enlarged, and the somites numbered 15 to 16 pairs. At the otic-capsule stage (fig. 2-23), the otic capsule appeared, the tail bud extended outward further, the yolk between the head and tail began to invaginate, and the somites numbered 17 to 18 pairs. At the tail-vesicle stage (fig. 2-24), the bump on the brain area was highly raised (a unique characteristic of black carp), a vesicle appeared on the tail bud, and the somites numbered 19 or 20 pairs. At the caudal-fin stage (fig. 2-25), the embryo and the yolk elongated, the yolk sac was kidneyshaped, the caudal fin formed, the tail vesicle moved to the end of the tail, and the somites numbered 21 to 23 pairs. At the lens-formation stage (no figure), the eye lens formed, the tail vesicle was still visible, and the somites numbered 24 pairs. At the muscular-effect stage (fig. 2-27), the tail vesicle disappeared, the olfactory vesicle formed, the eyes were round, the embryo lashed slightly, the yolk continued to elongate with an obvious constriction in the posterior portion of the yolk, the end of the yolk was grey-blue, and the somites numbered about 25 pairs. At the heart-rudiment stage (fig. 2-28), the embryo elongated further, the caudal fin extended, the embryo lashed occasionally but was relatively inactive, the posterior portion of the yolk sac was narrow, the heart rudiment appeared between the head and the yolk, and the somites numbered 26 to 30 pairs. At the otolith-appearance stage (fig. 2-29), the embryo straightened and moved continuously, the yolk sac was wider in the anterior than the posterior portion, and the somites numbered 31 to 34 pairs. At the heart-pulsation stage (no figure), the heart began to pulsate, the embryo rotated continuously, the egg membrane softened, and the somites numbered 35 to 38 pairs. The embryo was ready to hatch.

\section{Silver Carp}

The youngest eggs collected were at the 8-cell stage (fig. $3-4)$. The cells were orange and the yolk was light yellow. The grey cytoplasm was widely distributed in the yolk. At the 16- to 64-cells stages (fig. 3-5 to 3-7), the cytoplasm diminished gradually. At the 128-cell stage (fig. 3-8), the cell color lightened, and the cytoplasm almost disappeared. The blastodisc appeared mound-like and several oil droplets appeared on the yolk cell. At the morula stage (fig. 3-9), cells became smaller, the blastodisc was highly raised above the yolk, and the cytoplasm disappeared. At the early-blastula stage, the blastodisc formed a half-sphere. At the mid-blastula stage (fig. 3-12), the blastodisc began flattening. At the lateblastula stage, the blastodisc flattened more and gradually expanded over the yolk. At the early-gastrula stage (fig. 313 ), the germ ring was visible, the blastoderm covered about one-third of the yolk cell, and the whole egg appeared round. At the mid-gastrula stage (fig. 3-14) the blastoderm covered about half of the yolk. At the late-gastrula stage (fig. 3-15), the embryo head enlarged, and the blastoderm covered about three-fourths of the yolk. At the neurula stage (no figure), the head part was clearly visible and the blastoderm covered almost the whole yolk, leaving only the yolk plug uncovered.
At the blastopore-closure stage (fig. 3-17), the front part of the embryo head was square and the yolk was round. At the somite-appearance stage (fig. 3-18), somites numbered one to three pairs and the optic primordium was dimly visible. At the optic-primordium stage (fig. 3-19), the optic primordium was a long oval shape and clearly visible, the embryo embraced about three-fourths of the yolk, the un-encircled margin of the yolk was convex, and the somites numbered four to six pairs. At the optic-vesicle stage (fig. 3-20), the eyes enlarged and the somites numbered seven to nine pairs. At the olfactoryplacode stage (fig. 3-21), the olfactory placode was barely visible above the optic vesicle, the somite number was 10-13 pairs, and the notochord was clearly visible. At the tail-bud stage (fig. 3-22), the eyes enlarged and were shaped like a watermelon seed, the brain rudiment differentiated slightly, the tail bud appeared, and the somites numbered 14 to 16 pairs. At the otic-capsule stage (fig. 3-23), the tail bud was clearly visible, the otic capsule appeared, the yolk elongated, the portion of the yolk between the head and tail began invagination, and the somites numbered 17 to 19 pairs. At the tail-vesicle stage (fig. 3-24), the tail bud expanded outward further, the tail vesicle appeared, the bump on the brain area enlarged, the yolk elongated and became kidney-shaped, and the somites numbered 20 or 21 pairs. At the caudal-fin stage (fig. 3-25), the caudal fin expanded outward, the embryo and the yolk elongated, and the somites numbered 22 or 23 pairs. At the lens-formation stage (fig. 3-26), the eyes were round, the olfactory vesicle was clearly visible, the embryo elongated, the yolk invaginated further, and the somites numbered 24 or 25 pairs. At the muscular-effect stage (fig. 3-27), the embryo continued elongating and lashed slightly, the tail vesicle disappeared, the bump on the brain area enlarged but was not highly raised, the end of the yolk was colorless, and the somites numbered about 26 to 28 pairs. At the heart-rudiment stage (no figure), the heart rudiment appeared, the embryo lashed occasionally, and the somites numbered 29 to 30 pairs. At the otolith-appearance stage (fig. 3-29), the embryo elongated further, the embryo moved continuously, the otolith appeared, and the somites numbered 31 to 35 pairs. At the heart-pulsation stage (no figure), the heart began to pulsate, the embryo rotated continuously, the egg membrane softened, and the somites numbered 36 or 37 pairs. The embryo was ready to hatch.

\section{Bighead Carp}

At the 2-cell stage (fig. 4-2), the cytoplasm was widely distributed in the yolk. Cells divided vertically five times until the 64-cell stage (fig. 4-3 to 4-7); the cytoplasm diminished gradually. The cells were light yellow and the yolk was even lighter in color. The cross-section width of the animal pole was smaller than that of the yolk. After one horizontal celldivision, the 128-cell stage (no figure), started. At the morula stage (fig. 4-9), the blastodisc was highly raised above the yolk. At the early-blastula stage (fig. 4-10), the blastodisc remained high and the cells became smaller. At the mid- 
blastula stage (fig. 4-11), the blastodisc began flattening. At the late-blastula stage (fig. 4-12), the blastodisc gradually expanded over the yolk and the cytoplasm almost disappeared. At the early-gastrula stage (fig. 4-13), the whole egg looked round, the germ ring formed, the dorsal lip appeared, and the blastoderm covered about one-third of the yolk. At the midgastrula stage (fig. 4-14), the blastoderm covered about twothirds of the yolk, and the embryonic shield appeared. At the late-gastrula stage (fig. 4-15), the blastoderm covered about five-sixths of the yolk, and the rudimentary embryo was visible. At the neurula stage (fig. 4-16), the head part enlarged, and the blastoderm covered almost the whole yolk, leaving only the yolk plug uncovered. At the blastoporeclosure stage (no figure), the front part of the embryo head was slightly curved. At the somite-appearance stage (no figure), somites numbered one to three pairs, the head was round but the front margin of the head was flat. At the opticprimordium stage (fig. 4-19), the optic primordium was dimly visible and was a long oval shape with a slightly crenulated lower margin. The embryo embraced about three-fourths of the yolk. No oil droplets appeared on the yolk. The somites numbered four to six pairs. At the optic-vesicle stage (no figure), the eyes enlarged and the somites numbered seven to 10 pairs. At the olfactory-placode stage (fig. 4-21), the eyes continued enlarging, the lower edge of the eye was still slightly crenulated, the olfactory placode appeared, the notochord was clearly visible, and the somites numbered 11-14 pairs. At the tail-bud stage (fig. 4-22), the optic vesicle was large and clearly visible, the tail bud appeared, the yolk elongated, and the somites numbered 15 to 17 pairs. At the otic-capsule stage (no figure), the yolk between the head and tail began invagination, and the somites numbered 18 or 19 pairs. At the tail-vesicle stage (fig. 4-24), the otic capsule was clearly visible, the tail bud expanded outward, the tail vesicle appeared, the embryo became thicker, the yolk elongated and looked like a kidney, and the somites numbered 20 or 21 pairs. At the caudal-fin stage (no figure), the caudal fin expanded outward, and the somites numbered 22 or 23 pairs. At the lensformation stage (fig. 4-26), the olfactory vesicle was clearly visible, the lens formed, the embryo and the yolk elongated, a bump on the brain area was slightly raised, the tail vesicle disappeared, and the somites numbered 24 pairs. At the muscular-effect stage (no figure), the embryo lashed slightly, the end of the yolk was light grey-blue, and the somites numbered about 25 to 27 pairs. At the heart-rudiment stage (no figure), the embryo lashed occasionally, the somites numbered 28 to 29 pairs. At the otolith-appearance stage (fig. 4-29), the otolith appeared, the embryo elongated further, the tail was relative long and often moved to one side, the embryo rotated occasionally. While the anterior half of the yolk-sac was oval and wide, the posterior half was narrow. The somites numbered 30 to 32 pairs. At the heart-pulsation stage (no figure), the heart began to pulsate, the embryo rotated continuously, and the somites numbered 33 or 35 pairs. The embryo was ready to hatch.

\section{Comparison of the Embryological Development of Grass, Black, Silver, and Bighead Carps}

Although the reproductive habits among the four species are similar and the general characteristics of eggs and embryological development are also similar, speciesspecific differences in morphology and time of organ differentiation could be found by careful observation of the various stages. Through comprehensive observation, some diagnostic characteristics of eggs were distinguished among species.

Before the blastula stage, there was no obvious difference between the developing eggs of the four species. At the blastula stage, when the blastoderm margin covered one-half to two-thirds of the yolk surface, the form of the yolk was different among species. The upper part of the covered yolk of grass carp had a greater diameter than that of the lower part (fig. 1-14); in black carp, the upper part of the covered yolk was the same size as the lower part (fig. 2-14); in silver carp, the entire yolk had a round shape (fig. 3-14); and in bighead carp, the yolk was relatively wide (fig. 4-14). At the blastoporeclosure stage, when the embryo began to form, the head of grass carp was smoothly curved (fig 1-17). The black carp head was somewhat wider in the vertical aspect and the anterior margin was straight (fig. 2-17). The silver carp head was square (fig. 3-17). These characteristics were obvious.

At the somite-appearance stage, the optic rudiment of the silver carp appeared (fig. 3-18), while that of the bighead carp did not appear until the olfactory-placode stage (fig. 4-21). From the optic- rudiment stage to the otic-capsule stage, there were oil droplets on the yolk of the grass carp (fig. 1-19 to 1-23). The black carp also had these oil droplets until the otolith-appearance stage (fig. 2-20 to 2-29). There were no oil droplets on the yolk sac of silver and bighead carps. At that time, the embryo lengthened and embraced the yolk. The shape of the un-encircled margin of the yolk was different between species. The un-encircled margin of the yolk was short and slightly convex in grass carp (fig. 1-19 to 1-21); nearly straight in black carp (fig. 2-19 to 2-21); more convex in silver carp than in grass carp, (fig. 3-19 to 3-21); and gradually changing from convex to straight in bighead carp (fig. 4-19 to 4-21).

From the otic-capsule stage to the heart-pulsation stage, the head of the embryo gradually developed a bump (fig. 10A). The bump on black carp was largest (fig. 10A2), followed by the grass carp (fig. 10A1). The bump on silver and bighead carps was not obvious (fig. 10A3, 4); especially the bighead carp which only had a small wave shape.

At the otolith-appearance stage, the yolk sac lengthened with the development of the embryo, and the anterior portion was wider than the posterior portion. However, there were differences among species. The anterior one-third of the yolk sac of grass carp was round, and the remainder was narrow and straight (fig. 1-29). In black carp (fig. 2-29), the yolk sac gradually narrowed toward the vent. In silver carp (fig. 3-29), the front two-thirds of the yolk sac was wide and the posterior 
one-third was narrow with an obvious concavity between these two parts. In bighead carp (fig. 4-29), the front half of yolk sac was extremely large and the posterior half was very narrow with a deep constriction between the two halves.

\section{Post-hatch Development}

\section{Characteristics}

There were 18 stages between hatching and the juvenile stage when the lateral line scales were complete. During these stages, the fish underwent the change from endogenous to exogenous nutrition. During post-hatch development, the various organs gradually differentiated and became identifiable. There were many characteristics that were similar between the four species, but there were certain obvious differences.

\section{Grass Carp}

(1) Hatching stage (fig. 5-31): Total length was $6.0 \mathrm{~mm}$ at 37 hours post-fertilization. The tail length was 24 percent of the total length. The body was transparent and the heart was at the top of the anterior edge of the yolk sac. The posterior aorta, the main vein, the caudal vein, and myomere blood vessels were differentiated. The blood color was apricotyellow. The yolk sac was a lengthened teardrop shape with a bright-blue color on the posterior end. Below the eye, there was a triangular black spot. The eye diameter was $0.35 \mathrm{~mm}$. The myomere numbering was $8+22+13=43$. The larvae remained on their side at the bottom of the container most of the time, but occasionally they darted to the surface.

(2) Rudimentary-pectoral-fin stage (fig. 5-32): Total length was $6.8 \mathrm{~mm}$ at 47 hours post-fertilization. The rudimentary pectoral fin was crescent-shaped and located below myomeres two or three. The heart moved slightly ventrally and was located anterior to the middle of the yolk sac. The Cuvierian duct appeared. The caudal vein was large and wide. The black spot below the eye became oval. The heartbeat was 182 times per minute (at $26.8^{\circ} \mathrm{C}$ ). The larva swam actively.

(3) Gill-arch stage (fig. 5-33): Total length was $7.0 \mathrm{~mm}$ at 51 hours post-fertilization. The body color was butter-yellow. The tail length was 27 percent of total length. Ventral to the otic capsule and posterior to the eye, four gill arches appeared. The head extended straight out from the body. The indentation of the mouth appeared. The pectoral fin enlarged. The blood vessels were clearly evident. The caudal vein expanded and was apricot-yellow. The diameter of the eye was about 0.40 $\mathrm{mm}$ and the myomere numbering was $8+22+14=44$.

(4) Xanthic-eye stage (fig. 5-34): Total length was 7.2 $\mathrm{mm}$ at 62 hours post-fertilization. Yellow pigmentation of the eye appeared. The caudal vein was thick and the color was loquat-yellow. The mouth was slightly open. The rudiments of the gill filaments appeared. The myomere numbering was $8+22+15=45$. Viewed dorsally, there were clear embryonic hairs $^{9}$ on the sides of the embryo.

(5) Gill-filament stage (fig. 5-35): Total length was 7.5 $\mathrm{mm}$ at 73 hours post-fertilization. The gill filaments were clear and the operculum appeared. The blue color of the posterior end of the yolk sac disappeared. The caudal vein and the Cuvierian duct narrowed.

(6) Melanoid-eye stage (fig. 5-36): Total length was 7.7 $\mathrm{mm}$ at 83 hours post-fertilization. Black pigment appeared in the eye at the top front and later extended all the way around. The black spot below the eye disappeared. The operculum was clearly evident. The rudimentary cleithrum appeared. The yolk sac became narrow and elongated. Two or three stellate melanophores appeared on the anterior portion of the yolk sac. There were four or five stellate melanophores at the ventral edge of the myomeres in front of the vent. The caudal vein became thinner. The diameter of the eye was $0.42 \mathrm{~mm}$.

(7) Gas-bladder-emergence stage (fig. 5-37): Total length was $8.13 \mathrm{~mm}$ at 98 hours post-fertilization. Tail length was about 30 percent of total length. The gas bladder began to appear. The yolk sac continued to elongate. The gut was continuous, the mouth moved forward, and the gill filaments grew longer. The otic capsule enlarged to almost the diameter of the eye. The pectoral fins extended; near the insertion of the fin there was one stellate melanophore. From the dorsal view, the anterior margin of the head was flattened and there were eight stellate melanophores. From the dorsal surface of the gas bladder, there were two lines of pigment between the gut and myomeres. The pigment lines extended to the caudal end of the vertebral column. (With the naked eye, one black line was visible. Fish caught at this stage directly from the river were less pigmented than those raised in the lab.) The body was lemon-yellow and the eye was orange-yellow with a blue tint on the edge. The caudal vein was intense orange-yellow. Myomere numbering was $9+21+15=45$. Some embryonic hairs were still visible.

(8) One-chamber-gas-bladder stage (fig. 5-38): Total length was $8.55 \mathrm{~mm}$ at 139 hours post-fertilization. The inside of the gut appeared wavy, gut folds appeared, and feeding began. The yolk sac was mostly gone, as this was the period of mixed endogenous and exogenous nutrition. The mouth was terminal. The nares moved to the dorsal surface of the head. The body was lemon-yellow, covered by many melanophores; on the body side, there were four lines of pigment and another one along the gut. Many stellate melanophores were visible in the dorsal view of the head. The stellate melanophore on the pectoral fin enlarged. Many melanophores were grouped together inside the deep posterior portion of the head. From the dorsal view these melanophores appeared vase-shaped (fig. 9a). There were a few melanophores below the caudal end of the notochord. (The larvae caught from the river at this stage had a lighter body color. Except for the melanophores on the dorsal body and the pectoral fin, the melanophores on the

\footnotetext{
${ }^{9}$ Translator's note: Assumed to be neuromast cupulae.
} 
other parts of the body were not obvious.) The caudal vein was orange-yellow. At this time the fish could swim normally.

(9) Yolk-absorption stage (no figure): Total length was $8.62 \mathrm{~mm}$ at 167 hours post-fertilization. The yolk sac was exhausted. The gut folds were more developed. The fish began to feed on plankton. The anterior margin of the head was flattened. The pigment on the body side and dorsal head surface increased, but the deep pigment inside the head did not change. The stellate melanophores on the pectoral fin numbered two or three. There were two or three stellate melanophores on the lower caudal finfold.

(10) Dorsal-fin-differentiation stage (fig. 5-40): Total length was $8.7 \mathrm{~mm}$ at 190 hours post-fertilization. The dorsal margin of the anterior part of the dorsal finfold had a sigmoid shape. The melanophores on the pectoral fins formed an arch shape. There were stellate melanophores and some small melanophores on the lower part of the caudal fin; with the naked eye these together appeared as a gray spot. Myomere numbering was $10+20+15=45$.

(11) Notochord-tip-lifting stage (fig. 5-41): Total length was $9.20 \mathrm{~mm}$ at 215 hours post-fertilization. The anterior portion of the dorsal finfold had a pronounced triangular form, which was the rudimentary dorsal fin. The end of the vertebral column curved upward. The caudal finfold began to differentiate; the edge was crenulated. There were 12 initial rays in the caudal fin. The anal finfold began to differentiate. The caudal vein was still visible and was loquat-yellow. The pigment on the surface of the head between the eyes increased. Also, pigment appeared on the maxillary. The anterior margin of the dorsal finfold moved backward. Myomere numbering was $11+19+15=45$. The operculum enlarged and covered the entire gill chamber.

(12) Two-chamber-gas-bladder stage (fig. 5-42): Total length was $10.16 \mathrm{~mm}$ at 253 hours post-fertilization. The anterior gas bladder appeared and formed a ball shape. The posterior gas bladder moved backward, lengthened, and tapered towards the rear. On the rudimentary dorsal fin and anal fin, there were six or seven initial rays and several stellate melanophores. The caudal fin continued to differentiate; 16 rays were apparent. The vertebrae were clearly visible. Myomere numbering was $12+18+15=45$.

(13) Pelvic-fin-bud stage (fig. 5-43): Total length was $10.68 \mathrm{~mm}$ at 302 hours post-fertilization. The tail length was about 31.5 percent of total length. The pelvic fin bud appeared in the midpart of the preanal finfold. The rudimentary dorsal fin grew larger; the numbers of rays and melanophores increased. The dorsal finfold shrank. The numbers of rays and melanophores on the anal finfold increased. The caudal fin was forked; between the rays there were melanophores. The mandible and maxillary were developed. The mouth was terminal. The anterior gas bladder enlarged and became oval. The pattern of the deep pigment in the head changed. Below the end of the urostyle, there was a large and obvious stellate melanophore. Myomere numbering was $13+17+15=45$.

(14) Dorsal-fin-formation stage: At the beginning of this stage (fig. 5-44a), total length was $11.8 \mathrm{~mm}$ at 15 days post- fertilization. The dorsal fin was separate from the dorsal finfold (ray numbering $=\mathrm{ii}, 7$ ). The anal fin extended and the number of rays increased. The pelvic fin bud enlarged. At the end of the dorsal-fin-formation stage (fig. 5-44b), total length was $12.5 \mathrm{~mm}$ at 18 days post-fertilization. The dorsal fin was thoroughly formed (ray numbering $=$ iii, 7). The anal fin enlarged (ray numbering $=\mathrm{ii}, 8$ ). The dorsal finfold and anal finfold shrank to the caudal peduncle. The pelvic fin enlarged; three or four rays appeared. The ribs and vertebral processes began to appear. The myomeres further developed from a single chevron shape to chevrons both above and below the lateral line. Myomere numbering was $14+16+15=45$. The operculum became thicker.

(15) Anal-fin-formation stage (fig. 5-45): Total length was $14.9 \mathrm{~mm}$ at 21 days post-fertilization. The anal fin was formed (ray numbering $=$ iii, 8 ). The anal finfold continued to shrink. The caudal fin was thoroughly developed. The pelvic fin lengthened and the preanal finfold shrank.

(16) Pelvic-fin-formation stage (fig.5-46): Total length was $16.2 \mathrm{~mm}$ at 24 days post-fertilization. The pelvic fin formed. The preanal finfold remained only in a narrow strip. The pectoral fin continued to develop; the stellate melanophores on the base of the fin reduced. The whole body was pigmented.

(17) Squamation stage (fig. 5-47). Total length was between 21 to $32 \mathrm{~mm}$ at 44 to 58 days post-fertilization. The morphology was similar to that of an adult fish; very little remained of the preanal finfold. Lateral line scales and several rows of scales above and below it developed from the front to the back. The growth of scales depended on environmental conditions (table 7). ${ }^{10}$

(18) Juvenile stage (fig. 5-48): Total length was about 35 $\mathrm{mm}$. This stage lasted from 63 to 92 days post-fertilization. Squamation was complete. The lateral line scales numbered 39. Other than the larger eyes, the fish resembled an adult fish.

\section{Black Carp}

(1) Hatching stage (fig. 6-31): Total length was $6.7 \mathrm{~mm}$ at hatching, which occurred at 43 hours post-fertilization. The tail length was 26.5 percent of the total length. The anterior part of the yolk sac was large and wide, and the posterior part of the yolk sac was long and thin, becoming a lengthened teardrop shape. The posterior end of the yolk sac had a slightly blue color. The heart was at the bottom of the anterior edge of the yolk sac. The caudal vein was not clear. The embryo color was apricot-yellow. The head was angled downward. The diameter of the eye was $0.37 \mathrm{~mm}$. At the lower edge of the eye there was a black spot. The myomere numbering was $7+19+14=40$. The larvae rested on their side on the bottom of the container, occasionally darting to the surface.

\footnotetext{
${ }^{10}$ Translator's note: tables 4, 5, and 6 are first referenced later in the original document than this reference to table 7 . Table 7 is again referenced, and discussed in more detail, later in the document.
} 
(2) Rudimentary-pectoral-fin stage (fig. 6-32): Total length was $7.0 \mathrm{~mm}$ at 48 hours post-fertilization. The tail length was 27.5 percent of the total length. The embryo was butter-yellow. The rudimentary pectoral fin was crescentshaped and located below myomeres two to three. The heart moved slightly ventrally, and was now located anterior to the middle of the anterior edge of the yolk sac. The Cuvierian ducts were clear. The heartbeat was 154 times per minute at $26.8^{\circ} \mathrm{C}$ or 200 times per minute at $27.7^{\circ} \mathrm{C}$. The bottom edge of caudal vein was crenulated and tapered posteriorly along the anal finfold, the end curving upward into the tenth postanal myomere. The eye diameter was $0.41 \mathrm{~mm}$. The myomere numbering was $8+18+14=40$. The larvae rested on their side on the bottom of the container, but occasionally darted to the surface.

(3) Gill-arch stage (fig. 6-33): Total length was $7.38 \mathrm{~mm}$ at 56 hours post-fertilization. The tail length was about 30 percent of total length. Four gill arches appeared. The caudal vein margin was wavy and very clear. The anterior portion of the yolk sac shrank slightly. The myomere numbering was $8+18+15=41$.

(4) Xanthic-eye stage (fig. 6-34): Total length was 7.5 $\mathrm{mm}$ at 70 hours post-fertilization. The yellow pigmentation of the eye appeared. The head extended straightly; the mouth opened and began slight movements. The rudiments of the gill filaments appeared. The rudimentary pectoral fin expanded to a semi-circular shape. The larvae rested on their side on the bottom of the container and were not active.

(5) Gill-filament stage (fig. 6-35): Total length was $7.66 \mathrm{~mm}$ at 79 hours post-fertilization. The gill filaments appeared. The head grew straight out from the body. The yolk sac became a lengthened tear-drop shape. The otic capsule enlarged and was about one-half the eye size. The larvae were still not active, but occasionally swam without vertical orientation.

(6) Melanoid-eye stage (fig. 6-36): Total length was 8.0 $\mathrm{mm}$ at 89 hours post-fertilization. The black spot at the lower edge of the eye disappeared. Black pigments gradually appeared around the edge of the eye and often displayed gold-yellow or blue colors. The lower jaw shook continuously and the pectoral fins quivered. The otic capsule continued to enlarge. The gill filaments became evident. The larvae laid on their side or swam unbalanced, occasionally swimming normally.

(7) Gas-bladder-emergence stage (fig. 6-37): Total length was $8.14 \mathrm{~mm}$ at 109 hours post-fertilization. The gas bladder began to appear. The gut was now continuous. The otic capsule enlarged almost to the size of the eye. Pectoral fins started to move at this stage. The mouth occupied a more forward position. The yolk sac shrank to a baseball-bat shape. From the dorsal view, the snout was curved with the central portion prominent. Along the dorsal surface of the gas bladder and the gut, there was a pigment line that extended to the caudal vein (with the naked eye, one black line was visible; darker than that of grass carp). There was a large black stellate melanophore below the tail myomeres on the caudal finfold. The caudal vein was clear and orange-yellow. Myomere numbering was $9+17+15=41$. Head and body sides had embryonic hair. The larva swam normally, maintaining vertical orientation.

(8) One-chamber-gas-bladder stage (fig. 6-38): Total length was $8.55 \mathrm{~mm}$ at 140 hours post-fertilization. The inside of the gut appeared wavy because of the development of the gut folds. Feeding began. The yolk sac remained only as a small strip. The dorsal margin of the body was slightly arched at the beginning of the dorsal finfold. Initial rays appeared on the caudal finfold. From the dorsal view of the melanophores inside the head, there were two short pigment lines near otic capsule and two large stellate melanophores above the base of pectoral fin, which formed two " $\backslash /$ " shapes (fig. 9b). On the surface of the head there was no pigment, while the sides of the body were covered by a few melanophores. There were also a few melanophores at and below the urostyle.

(9) Yolk-absorption stage (fig. 6-39): Total length was $9.35 \mathrm{~mm}$ at 174 hours post-fertilization. The tail length was 32 percent of the total length. The yolk was exhausted. At the junction of the lower lobe of the caudal finfold and the caudal vein, there was a lemon-yellow lymph node. Initial rays appeared in the ventral half of the caudal finfold. The gas bladder enlarged; the anterior margin was rounded and the posterior part was more pointed. There were some melanophores on the dorsal surface of the head, but no pigment between the eyes. There was a faint pigment line on the upper body side. Some small melanophores appeared at the posterior end of the vertebral column. The pigments inside the head and on the lower part of the caudal finfold were the same as in the one-chamber-gas-bladder stage (the melanophores of the larvae caught directly from the river looked like small dots). The mouth was terminal; there were a few melanophores on the upper jaw. The operculum completely covered the gills. Myomere numbering was $10+16+15=41$.

(10) Dorsal-fin-differentiation stage (fig. 6-40): Total length was $10.0 \mathrm{~mm}$ at 197 hours post-fertilization. The dorsal margin of the anterior part of the dorsal finfold had a sigmoid shape. Nine initial rays appeared in the caudal finfold with melanophores between the rays. The pectoral fins enlarged; there was no pigment on the base of pectoral fins. The otic capsule became triangular. There were two pigment lines on the upper body side. The melanophores on the upper jaw increased. The stellate melanophore on the low part of the caudal fin was more obvious.

(11) Notochord-tip-lifting stage (fig. 6-41): Total length was $10.7 \mathrm{~mm}$ at 226 hours post-fertilization. The anterior portion of the dorsal finfold had a pronounced triangular form. The caudal finfold began to differentiate; the margin of the fin was crenulated. There were 12 rays in the caudal fin. The vertebrae were partially formed. On the dorsal surface of the head, there were few or no melanophores between the eyes. Some individuals had a small melanophore on the base of the pectoral fin. Myomere numbering was $10+16+15=41$.

(12) Two-chamber-gas-bladder stage (fig. 6-42): Total length was $11.3 \mathrm{~mm}$ at 285 hours post-fertilization. The anterior gas bladder chamber appeared, forming a yellow, slightly transparent ball. As time progressed, more and more melano- 
phores covered the upper part of the gas bladder, which was often grayish silver in color. The dorsal fin began to separate from the dorsal finfold, and had seven initial rays and a large stellate melanophore. The vertebrae differentiated. Myomere numbering was $11+15+15=41$ and the myomeres further developed from a single chevron to a double chevron shape.

(13) Pelvic-fin-bud stage (fig. 6-43): Total length was $12.0 \mathrm{~mm}$ at 324 hours post-fertilization. The pelvic fin bud appeared in the mid-part of the preanal finfold. The melanophores inside the head changed shape from that shown in fig. $10, \mathrm{D}, 18$ to that in fig. 10, D, 22. The caudal fin began differentiation. The dorsal and anal fins extended. The gas bladder enlarged. Embryonic hairs disappeared.

(14) Dorsal-fin-formation stage: Total length ranged between 13.0 to $14.4 \mathrm{~mm}$ at 15 to 18 days post-fertilization. At the beginning of this stage (fig. 6-44a), the dorsal fin was separate from the dorsal finfold (dorsal fin ray numbering $=$ ii, 7). The caudal fin had 18 rays. The pectoral fin was curved convexly. The pelvic fin bud enlarged slightly; rays began appearing. At the end of the dorsal-fin-formation stage (fig. 6-44b), the dorsal fin formed completely (ray numbering = iii, 7). The anal fin enlarged rapidly (ray numbering $=i i, 8$ ). The dorsal finfold and anal finfold began to disappear. The caudal fin was forked deeply. The pelvic fin enlarged; rays were obvious. The stellate melanophore below the urostyle was very obvious. There were few melanophores on the body. The operculum became thicker. The ribs and vertebral processes began to appear.

(15) Anal-fin-formation stage (fig. 6-45): Total length was $14.9 \mathrm{~mm}$ at 22 days post-fertilization. The anal fin was formed completely (ray numbering $=$ iii, 8). Rays appeared in the pectoral fin. The pelvic fin lengthened and the preanal finfold shrank. There were no or few melanophores between the eyes on the dorsal surface of the head. The snout and mouth became even more pointed.

(16) Pelvic-fin-formation stage (fig. 6-46): Total length was $16.1 \mathrm{~mm}$ at 25 days post-fertilization. The pelvic fin formed and had eight rays. The preanal finfold shrank further. Rays in the pectoral fin were obvious. Several of the anterior rays became branched and extended on the anal fin. The gas bladders enlarged.

(17) Squamation stage (no figure): Total length was between 20 to $27 \mathrm{~mm}$. This stage lasted from 35 to 60 days post-fertilization. For the larvae raised in a container, the number of scales increased with increasing body length. When total lengths of the fish were 20,21, 23, and $27 \mathrm{~mm}$, the numbers of lateral line scales were 2, 4, 9, and 13 respectively (observed in 1961 in Yichang).

(18) Juvenile stage (fig. 6-48; 69 days old): Total length was about $35.5 \mathrm{~mm}$. The juvenile stage lasted 60 to 83 days post-fertilization. Squamation was complete. All fins developed completely. Other than the larger eyes, the juvenile resembled an adult fish. The lateral line scales numbered 43 . The large stellate melanophore below the urostyle was still obvious. The anal fin was relatively large; branched rays are long.

\section{Silver Carp}

(1) Hatching stage (fig. 7-31): Total length was $6.1 \mathrm{~mm}$ at 38 hours post-fertilization. Tail length was 28.5 percent of the total length. Unlike grass and black carps, the head of silver carp did not curve and extend downwards, and instead extended obliquely forward from the body. The yolk sac was light in color and slightly transparent. The anterior portion of yolk sac was large and oval; the posterior portion was a narrow and lengthened tear-drop shape. Body was butter-yellow. The heart was at the top of the anterior edge of the yolk sac. The caudal vein was not very obvious. The otic capsule was relatively small. The eye diameter was $0.37 \mathrm{~mm}$. A black spot appeared at the lower edge of the eye about 10 minutes after hatching. The myomere numbering was $6+19+14=39$. Larvae usually rested on their side on the bottom of the container, but occasionally they swam actively.

(2) Rudimentary-pectoral-fin stage (fig. 7-32): Total length was $6.3 \mathrm{~mm}$ at 48 hours post-fertilization. The tail length was 29.5 percent of total length. The head extended straight out from the body. The rudimentary pectoral fin was located below myomeres two to three. The heart moved to the anterior edge of the yolk sac. Cuvierian ducts were located on the anterior tip of yolk sac. The myomere numbering was $7+18+14=39$. The larvae still usually rested on the bottom but occasionally swam.

(3) Gill-arch-stage (fig. 7-33): Total length was $6.83 \mathrm{~mm}$ at 53 hours post-fertilization. The tail length was about 31 percent of total length. Four gill arches appeared. Cuvierian ducts were now located on the front side of yolk sac. The yolk sac shrank and became a lengthened tear-drop shape. The eye diameter was $0.4 \mathrm{~mm}$. The myomere numbering was $7+18+15=40$.

(4) Xanthic-eye-stage (fig. 7-34): Total length was $7.2 \mathrm{~mm}$ at 63 hours post-fertilization. Tail length was about 32 percent of total length. Yellow pigmentation of the eye appeared; it was apricot-yellow. There was a small black spot on the front edge of the eyes. Blood vessels between myomeres were obvious. The indentation of the mouth appeared. The myomere numbering was $8+17+15=40$. The larvae still laid on the bottom and occasionally swam.

(5) Gill-filament stage (fig. 7-35): Total length was 7.55 $\mathrm{mm}$ at 74 hours post-fertilization. The tail length was about 33 percent of total length. The gill filaments extended. The head and body straightened. Melanophores on the front edge of eyes increased. The mouth was open. The lower jaw began movement.

(6) Melanoid-eye stage (fig. 7-36): Total length was 8.0 $\mathrm{mm}$ at 92 hours post-fertilization. Melanophores extended all the way around the eye. The otic capsule enlarged and was about $1 / 2$ of the eye diameter. The rudimentary pectoral fin base appeared. The mouth moved forward and was located below the front margin of the eye.

(7) Gas-bladder-emergence stage (fig. 7-37): Total length is $8.24 \mathrm{~mm}$ at 106 hours post-fertilization. Tail length was about 34 percent of total length. The gas bladder began to 
appear. There were melanophores on the gas bladder. The gut was now continuous. The mouth continued to move forward. The otic capsule enlarged to a size slightly smaller than that of the eye. The yolk sac remained only as a narrow strip. On the front tip of the yolk sac there were several stellate melanophores. From the dorsal view, the tip of the snout was round and there were several stellate melanophores on the surface of the head and between the eyes. There was a faint line of pigment along the upper edge of myomeres. On the posterior part of the fish body there was a short pigment line along the lower edge of myomeres. The body was butter-yellow. The caudal vein was apricot-yellow. Larvae were able to swim normally.

(8) One-chamber-gas-bladder stage (fig. 7-38): Total length was $8.5 \mathrm{~mm}$ at 146 hours post-fertilization. The gas bladder appeared and was oval or olive shape. The maxillary differentiated. The mouth was terminal. Feeding began. The inside of the gut appeared wavy due to the development of the gut folds. Very little yolk sac remained. The pectoral fin enlarged and covered the front third of the gas bladder. The otic capsule continued to enlarge, and was triangular and equal in size to the eye. Dorsal and anal finfolds began to separate from the caudal finfold. The body was covered by many melanophores. Pigment density increased on the dorsal surface of the head and between the eyes. From the dorsal view, two pigment lines appeared between the otic capsule and the cleithrum and formed a U shape (fig. 9c). There were four lines of pigment on the body side. Seven or eight melanophores of various sizes were visible on the preanal finfold. Around the posterior end of the notochord in the caudal finfold there was a group of melanophores that appeared as two large black points when viewed with the naked eye. There were also a few small melanophores on the anterior part of the anal finfold. The myomere numbering was $8+16+16=40$.

(9) Yolk-absorption stage (no figure): Total length was $8.7 \mathrm{~mm}$ at 168 hours post-fertilization. The yolk sac was exhausted. Pigment was distributed as in the previous stage, but melanophores were darker and denser. Myomere numbering was $9+15+16=40$.

(10) Dorsal-fin-differentiation stage (fig. 7-40): Total length was $9.0 \mathrm{~mm}$ at 212 hours post-fertilization. The dorsal margin of the anterior part of the dorsal finfold had a sigmoid shape. There were a few small melanophores on the dorsal finfold. The posterior tip of the notochord curved slightly upward. The large stellate melanophores on the preanal finfold increased. There were also one or two stellate melanophores on the anal finfold. The two groups of melanophores on the caudal fin were even darker.

(11) Notochord-tip-lifting stage (fig. 7-41): Total length was $9.4 \mathrm{~mm}$ at 240 hours post-fertilization. Tail length was about 36 percent of total length. The end of the notochord curved upward obviously. The anterior portion of the dorsal finfold continued to differentiate and melanophores increased. The posterior margin of the caudal finfold was crenulated; there were eight initial rays in the caudal fin. The two groups of melanophores on the caudal finfold dispersed and three stellate melanophores were visible above and below the notochord tip. The operculum completely covered the gills. Melanophores on the anal finfold increased and extended to the entire finfold. Two small stellate melanophores appeared on the base of the pectoral fin. Myomere numbering was $9+15+16=40$.

(12) Two-chamber-gas-bladder stage (fig. 7-42): Total length was $10.32 \mathrm{~mm}$ at 279 hours post-fertilization. The anterior gas bladder appeared, forming a ball. The mouth was terminal and angled upward. Five rays were now visible in the dorsal fin. The posterior margin of the caudal fin was crenulated. There were 11 or 12 initial rays in the caudal fin with melanophores between the rays. The vertebral column was developing. Six rays appeared in the anal fin. Melanophores on the dorsal surface of the head increased. Below the tip of the notochord in the caudal fin there were two groups of small melanophores. Myomere numbering was $10+14+16=40$.

(13) Pelvic-fin-bud stage (fig. 7-43): Total length was $11.2 \mathrm{~mm}$ at 312 hours post-fertilization. The pelvic fin bud appeared near the mid-part of the preanal finfold. The caudal fin was forked with 16 rays. The rudimentary dorsal fin grew larger with nine initial rays. The dorsal finfold shrank. The anal fin differentiated obviously with seven initial rays. The myomeres further developed from a single chevron to a double chevron. Body height increased obviously. The vertebral column was fully formed.

(14) Dorsal-fin-formation stage (fig. 7-44): Total length was $14.1 \mathrm{~mm}$ at 19 days post-fertilization. The dorsal fin was separate from the dorsal finfold (ray numbering $=\mathrm{ii}, 7$ ). The anal fin extended obviously but had not yet separated from the anal finfold (anal fin ray numbering = ii, 12). The caudal fin was deeply forked, and had 16 branched rays and three unbranched rays both in the upper and lower portions of the fin. The pelvic fin bud extended. Initial rays start to appear in the pectoral fin. Melanophores on the preanal finfold were even darker and their branches shrank in size. Myomere numbering was $11+13+16=40$. The ribs and large dorsal and ventral vertebral processes appeared on the vertebrae.

(15) Anal-fin-formation stage (fig. 7-45): Total length was $15.7 \mathrm{~mm}$ at 22 days post-fertilization. The anal fin (ray numbering iii, 12) was separated from the anal finfold. The dorsal fin had iii, 7 rays. The pelvic fin lengthened and extended beyond the preanal finfold. The preanal finfold was still large; on the posterior two-thirds there were many melanophores.

(16) Pelvic-fin-formation stage (fig. 7-46): Total length was $17.0 \mathrm{~mm}$ at 25 days post-fertilization. The pectoral fin formed (ray numbering $=\mathrm{i}, 8$ ). The preanal finfold shrank slightly. The pelvic fin formed completely. The mouth opening was large, terminal, and strongly upturned. The upper side of the body was more pigmented than in previous stages.

(17) Squamation stage (fig. 7-47; 40-d old). Total length was about $20.0 \mathrm{~mm}$. The squamation stage lasted from 34 to 55 days post-fertilization. Scales at the anterior end of the body appeared first and scale development progressed towards 
the rear of the body. There were 50 lateral line scales. The end of the pectoral fin did not reach the base of the pelvic fin. The preanal finfold gradually shrank.

(18) Juvenile stage (fig. 7-48): Total length was about $34 \mathrm{~mm}$. The stage lasted from 60 to 90 days post-fertilization. The fish resembled adult fish. The lateral line scales developed completely and numbered 101 . The preanal finfold remained only as a narrow strip, on which there were some melanophores. The preanal finfold eventually developed into the full keel.

\section{Bighead Carp}

(1) Hatching stage (fig. 8-31): Total length was $7.0 \mathrm{~mm}$ at 39 hours post-fertilization. The body was large compared to the other three species. The tail length was relatively long and about 32 percent of the total length. The head extended straight forward from the body. The anterior half of yolk sac was large and oval; the posterior half was a narrow and lengthened tear-drop shape. The heart was at the top of the anterior edge of the yolk sac. Eye diameter was $0.39 \mathrm{~mm}$. A black spot appeared below the eye. Caudal vein was large and flat. Myomere numbering was $6+17+15=38$.

(2) Rudimentary-pectoral-fin stage (fig. 8-32): Total length was $7.1 \mathrm{~mm}$ at 49 hours post-fertilization. The rudimentary pectoral fin was located below myomeres two to three. The caudal vein was wide and long. The Cuvierian ducts appeared on the anterior tip of yolk sac. Blood color was apricot-yellow. Body color was butter-yellow and head color was lighter.

(3) Gill-arch stage (fig. 8-33): Total length was $7.5 \mathrm{~mm}$ at 59 hours post-fertilization. The tail length was 33 percent of total length. Four gill arches appeared. The head extended straight out from the body. The indentation of the mouth appeared. The caudal vein and Cuvierian ducts were obvious. The yolk sac shrank and the anterior portion narrowed. Myomere numbering was $7+16+15=38$.

(4) Xanthic-eye stage (fig. 8-34): Total length was 7.8 $\mathrm{mm}$ at 65 hours post-fertilization. Yellow pigmentation of the eye appeared. The mouth was open and could move. The lower edge of the caudal vein was crenulated.

(5) Gill-filament stage (fig. 8-35): Total length was 8.1 $\mathrm{mm}$ at 76 hours post-fertilization. The body was relatively thick. The tail length was about 34.5 percent of total length. The eye diameter was $0.42 \mathrm{~mm}$. The gill filaments appeared. The otic capsule and rudimentary pectoral fin enlarged. The blood systems were obvious.

(6) Melanoid-eye stage (fig. 8-36): Total length was 8.3 $\mathrm{mm}$ at 98 hours post-fertilization. The eye diameter was 0.44 $\mathrm{mm}$. Melanophores appeared around the eye. The caudal vein was wide, long, and dark yellow. Myomere numbering was $8+15+16=39$. Normal swimming began.

(7) Gas-bladder-emergence stage (fig. 8-37): Total length was $9.2 \mathrm{~mm}$ at 111 hours post-fertilization. Tail length was about 36 percent of total length (the largest percentage among the four fishes). The snout was blunt. The initial gas bladder appeared. The gill filaments extended. The gut was continuous. The caudal vein was narrowing slightly but still visible. The otic capsule enlarged. From the dorsal view there were some stellate melanophores between the posterior edge of eyes and otic capsule (fig. 9d). There were separate faint pigment lines along the upper body side and vertebral column. There was also a distinct pigment line along the ventral edge of myomeres starting from the dorsal margin of the initial gas bladder. There were several large stellate melanophores in the region of the heart and top front yolk sac. Myomere numbering was $8+15+16=39$. The larvae swam normally.

(8) One-chamber-gas-bladder stage (fig. 8-38): Total length was $9.4 \mathrm{~mm}$ at 135 hours post-fertilization. The gas bladder appeared and was oval. The inside of the gut appeared wavy (gut folds appeared). The yolk sac shrank and became a curved strip. The size of the otic capsule was equal to the eye size. The upper jaw formed. Pigment density increased on the dorsal surface of the head but there was no pigment between eyes (fig. 9d). There were four incomplete pigment lines on the body side. Some melanophores appeared on the anterior portion of the yolk sac. Two or three stellate melanophores appeared on the anal finfold. The melanophores on the lower part of the caudal finfold linked as a curve line. From the dorsal view, two pigment lines appeared between the otic capsule and cleithrum and form a ") (" shape (fig. 9d). The preanal finfold extended forward to below the posterior margin of the gas bladder. The myomere numbering was $9+14+16=39$.

(9) Dorsal-fin-differentiation stage (fig. $8-39^{11}$ ): Total length was $9.7 \mathrm{~mm} 166$ hours post-fertilization. Tail length was about 37 percent of total length. The dorsal margin of the anterior part of the dorsal finfold had a sigmoid shape. A narrow strip of yolk sac still remained. There were four pigment lines; three of them along the upper body side. The notochord and the ventral edge of myomeres are relatively obvious. One short line on the anal finfold became slightly curved. Melanophores on the lower part of the caudal fin did not change.

(10) Yolk-absorption stage (fig. 8-40): Total length was $10.0 \mathrm{~mm}$ at 202 hours post-fertilization. The yolk sac was exhausted. The dorsal fin further differentiated. There were some melanophores on the dorsal fin. The posterior margin of the caudal finfold began to become crenulated. The melanophores on the lower part of the caudal fin dispersed. Nine initial rays appeared in the caudal fin. The preanal finfold enlarged. Six or seven small stellate melanophores appeared on the posterior portion of the preanal finfold. The size and number of stellate melanophores on the anal finfold increased. The anal finfold extended to the edge of lower part of the caudal fin. A few larvae had one or two stellate melanophores on the base of the pectoral fin. Myomere numbering was $10+13+16=39$.

\footnotetext{
${ }^{11}$ Translator's note: In bighead carp only, the dorsal-fin-differentiation stage is listed as stage 39 and the yolk-absorption stages as stage 40. In the other three species, these are reversed. Although there is no discussion of this reversal in the original document, it does not appear to be an error, judging from the illustrations.
} 
(11) Notochord-tip-lifting stage (fig. 8-41): Total length was $10.8 \mathrm{~mm}$ at 216 hours post-fertilization. The dorsal fin further differentiated and had three initial rays. The posterior margin of the caudal finfold became crenulated. The caudal finfold had 14 initial rays. Eight initial rays appear in the anal fin, which was differentiating. The end of the the notochord curves upward. The mouth was terminal and angled upward. Melanophores appeared between the eyes on the dorsal surface of the head. Melanophores on the posterior portion of the preanal finfold increased. There were one or two stellate melanophores on the base of the pectoral fin. Myomere numbering was $11+12+16=39$.

(12) Two-chamber-gas-bladder stage (fig. 8-42): Total length was $11.0 \mathrm{~mm}$ at 275 hours post-fertilization. The anterior gas bladder appeared, forming a sphere. The differentiating dorsal fin had five initial rays. The posterior edge of the caudal fin became crenulated with three curves. There were 12 or 13 initial rays in the caudal fin. Rays started to appear in the pectoral fin. The vertebrae formed.

(13) Pelvic-fin-bud stage (no figure): Total length was $12.5 \mathrm{~mm}$ at 339 hours post-fertilization. The pelvic fin bud appeared. The dorsal fin lengthened, but was still connected with the dorsal finfold. The dorsal fin had eight rays. The caudal fin was forked with 16 rays. The anal fin had 10 initial rays. The pigment distribution was the same as in the twochamber-gas-bladder stage. Myomeres further developed from a single chevron to a double chevron shape. Myomere numbering was $11+12+17=40$.

(14) Dorsal-fin-formation stage (fig. 8-44): Total length was $14.8 \mathrm{~mm}$ at 19 days post-fertilization. The dorsal fin was separate from the dorsal finfold (ray numbering $=$ iii, 7 ). The caudal fin also formed and had 16 branched rays and three unbranched rays both in the upper and lower portions of the fin. The anal fin began to separate from the anal finfold (ray numbering = iii, 12). The preanal finfold increased in size; the melanophores on the fold increased and enlarged. The pelvic fin bud extended. The pectoral fin enlarged and rays began to appear. Ribs and vertebral processes appeared on the vertebrae.

(15) Anal-fin-formation stage (fig. 8-45): Total length was $17.3 \mathrm{~mm}$ at 23 days post-fertilization. The anal fin formed (ray numbering = iii,13). The preanal finfold was short and deep. The pelvic fin bud was still small and had not extended beyond the fold.

(16) Pelvic-fin-formation stage (fig. 8-46): Total length was $19.0 \mathrm{~mm}$ at 27 days post-fertilization. The pelvic fin formed (ray numbering $=\mathrm{i}, 8$ ). The preanal finfold was short and deep; there were still many melanophores on the fold. Rays on the pectoral fin were forming. The mouth opening was large, terminal, and strongly upturned. The head was relatively large, the length being over one-quarter of the total body length.

(17) Squamation stage (fig. 8-47; 45-d old). Total length was $24.5 \mathrm{~mm}$. This stage lasted from 35 to 57 days postfertilization. Lateral line scales and scales on the body sides formed, but there were no scales on the dorsal and ventral parts. The preanal finfold shrank. There were many melanophores on the preanal finfold between the base of the pelvic fin and vent. The pectoral fin was fully formed and the distal end of the fin extended to the anterior margin of the preanal finfold.

(18) Juvenile stage (fig. 8-48): Total length was about $36 \mathrm{~mm}$ at about 70 days post- fertilization. Squamation was complete. The anal fin enlarged. The preanal finfold shrank further, later becoming the keel. The distal end of the pectoral fin extended over the anterior margin of the preanal finfold. The fish resembled an adult fish.

\section{Comparison of Post-hatch Development of Grass, Black, Silver, and Bighead Carps}

The grass, black, silver, and bighead carps are taxonomically related and their reproductive habits are similar. However, each species had some distinguishing characteristics; some of these were obvious and some subtle. The differences were more obvious when the species could be directly compared. Although the organ morphology was similar, there were differences in 1) morphometrics, 2) the position of body structures, and 3) the timing of development of the different structures. By comparison and identification of these subtle differences, the

Table 4. Myomere counts in three early development stages of grass carp, black carp, silver carp, and bighead carp collected from the Yangtze River.

\begin{tabular}{|c|c|c|c|c|c|c|c|c|c|c|c|c|}
\hline \multirow{3}{*}{ Species } & \multicolumn{4}{|c|}{ Hatching stage } & \multicolumn{4}{|c|}{ Gas-bladder-emergence stage } & \multicolumn{4}{|c|}{ 2-chamber-gas-bladder stage } \\
\hline & \multicolumn{2}{|c|}{ Preanal } & \multirow{2}{*}{$\begin{array}{l}\text { Post- } \\
\text { anal }\end{array}$} & \multirow[b]{2}{*}{ Total } & \multicolumn{2}{|c|}{ Preanal } & \multirow{2}{*}{$\begin{array}{l}\text { Post- } \\
\text { anal }\end{array}$} & \multirow[b]{2}{*}{ Total } & \multicolumn{2}{|c|}{ Preanal } & \multirow{2}{*}{$\begin{array}{l}\text { Post- } \\
\text { anal }\end{array}$} & \multirow[b]{2}{*}{ Total } \\
\hline & $\begin{array}{l}\text { Pre- } \\
\text { dorsal }\end{array}$ & Middle & & & $\begin{array}{l}\text { Pre- } \\
\text { dorsal }\end{array}$ & Middle & & & $\begin{array}{l}\text { Pre- } \\
\text { dorsal }\end{array}$ & Middle & & \\
\hline Grass carp & $8^{1}$ & 22 & 13 & 43 & 9 & 21 & 15 & 45 & 12 & 18 & 15 & 45 \\
\hline Black carp & 7 & 19 & 14 & 40 & 9 & 17 & 15 & 41 & 11 & 15 & 15 & 41 \\
\hline Bighead carp & 6 & 17 & 15 & 38 & 8 & 15 & 16 & 39 & 11 & 12 & 16 & 39 \\
\hline
\end{tabular}

${ }^{1}$ See Chapter 1 for a description of the myomere numbering conventions used in this table. 
larvae could be identified to species. From hatching to the one-chamber-gas-bladder stage, the morphology of the larva was more complicated compared to that of the embryonic stages. There were more characteristics to compare. From the yolk-absorption stage to squamation, the organs of the larvae differentiated. During this period it was easier to identify the differences between the species. Sometimes diagnostic characters were subtle or consisted of subtle differences that caused difficulty in determining species. Under these conditions, it was necessary to make determinations using multiple characteristics to identify the fish.

\section{Myomere Counts}

The myomere counts of the four fishes were close, but slightly different (table 4). The total grass carp myomere number was three or four more than that of black carp; black carp had one more myomere than silver carp, and silver carp had one more than bighead carp. During the hatching period, grass, black, silver, and bighead carps had 43, 40, 39, and 38 myomeres, respectively. Larvae often had one more or less myomere. By the gas-bladder-emergence stage, the number of myomeres increased to 45, 41, 40, or 39 for the four fishes, respectively. The total number of preanal myomeres (predorsal and central combined) were 30, 26, 25, and 23 for the grass, black, silver, and bighead carps, respectively. Grass carp had the most and bighead carp the least, and the number did not change during later development. However, because the anterior margin of the dorsal fin gradually moved backward, the number of predorsal myomeres increased gradually, and central myomere counts reduced correspondingly. The number of postanal myomeres increased from 13,14, 14, 15 to 15, 15, 15,16 between hatching- and gas-bladder-emergence stages of the four species, respectively. In contrast to the situation with predorsal myomeres, the grass carp had the fewest postanal myomeres and the bighead had the most. The increase in the total number of myomeres during development resulted from an increase in postanal myomeres. The quickest method of identification of larvae was the central myomere count. However, black and silver carps were the same in this respect. In this case, one can refer to the predorsal myomere count, which differed between the two species, or use other obvious characteristics.

\section{Relative Postanal Length}

From the hatching stage to the gas-bladder-emergence stage, the relation between postanal length and total length was obviously different among the four species (table 5). Postanal to total length ratio was largest in the bighead carp, then silver carp, then black carp, then grass carp. The data in table 5 shows that postanal length grew most rapidly at the rudimentary-pectoral-fin stage.

\section{Caudal Vein \\ (fig. 10B, 5-8)}

The caudal vein was located along the base of the postanal finfold. It was the most diagnostic morphological characteristic of the larval circulatory system over the period from the rudimentary-pectoral-fin stage to the gasbladderemergence stage. There were different characteristics of the caudal vein between the four species. The caudal vein of grass carp was the most obvious because it was bigger and the blood was loquat-yellow. With the naked eye the caudal vein looked like a thin red line. The caudal vein of the black carp was not straight, but wavy with little blood in the vein. The color was first apricot-yellow and then changed to lemon-yellow over time. The caudal vein of silver carp was shorter, narrower, and butter-yellow or apricot-yellow. In the bighead carp, the caudal vein was long and wide. The under edge of the caudal vein was not very straight, and often was apricot-yellow.

\section{Pigmentation of the Dorsal Surface of the Head and Snout Shape}

\section{(fig. 10C, 9-16; table 6)}

At the gas-bladder-emergence stage, the larva could orient itself and swim normally. It was possible to observe the pigment distribution on the dorsal surface of the head, as well as the snout shape to identify the species (table 6). After the pelvic-fin bud-stage, the head pigmentation did not change, except there was some development of pigment on the dorsal surface of the head of the black carp, and between the eyes of the bighead carp.

Table 5. Proportion in percent of postanal length to total body length of yolk-sac larvae of grass carp, black carp, silver carp, and bighead carp collected from the Yangtze River.

\begin{tabular}{lcccc}
\hline \multicolumn{1}{c}{ Stages } & Grass carp & Black carp & Silver carp & Bighead carp \\
\hline Hatching & $23.0-25.0$ & $25.5-27.0$ & $28.0-29.0$ & $30.0-32.0$ \\
Rudimentary pectoral fin & $26.0-29.0$ & $27.5-31.0$ & $29.5-33.5$ & $32.5-35.0$ \\
Gas bladder emergence & $29.5-30.5$ & $30.5-31.5$ & $33.5-34.5$ & $35.5-36.5$ \\
One-chamber gas bladder & $30.0-31.0$ & $31.5-32.5$ & $34.0-35.0$ & $36.0-37.0$ \\
\hline
\end{tabular}


Table 6. Melanophores of the dorsal surface of the head, and shape (as viewed dorsally) of the anterior margin of the snouts of grass carp, black carp, silver carp, and bighead carp at the gasbladder-emergence stage.

\begin{tabular}{|c|c|c|}
\hline Species & Melanophores distribution & $\begin{array}{c}\text { Shape of the } \\
\text { snout }\end{array}$ \\
\hline Grass carp & $\begin{array}{l}\text { Melanophores on dorsal surface of } \\
\text { head, some between eyes }\end{array}$ & Flat \\
\hline Black carp & $\begin{array}{l}\text { No melanophores on dorsal surface } \\
\text { of head }\end{array}$ & Arc \\
\hline Silver carp & $\begin{array}{l}\text { Melanophores on dorsal surface of } \\
\text { head, some between eyes }\end{array}$ & Obtuse \\
\hline Bighead carp & $\begin{array}{l}\text { Melanophores on dorsal surface of } \\
\text { head, but none between eyes }\end{array}$ & Obtuse \\
\hline
\end{tabular}

Deep Head Pigmentation

(fig. 9a-h and fig. 10D, 17-24)

During the developmental stages from the one-chamber gas bladder to the two-chamber gas bladder, there were large interconnected patterns of stellate melanophores close to the otic capsule and gill arch in the inner part of the head, and anterior and dorsal to the pectoral fin base. Viewed dorsally through the transparent top of the head, these pigments made patterns that were diagnostic to species. The pigment pattern of grass carp resembled a short, wide, flower vase (fig. 9a). The pigment pattern of black carp resembled two " /" shapes (fig. 9b). The pigment pattern of silver carp was U-shaped (fig. 9c). The pigment pattern of bighead carp formed two roughly parallel lines (fig. 9d). These patterns were obvious when observing the swimming larvae in a dish of shallow water.

There are some other cyprinid fishes with drifting eggs, which also had different pigment patterns within their heads (fig. 9e-h). Some of them were similar to grass carp, black carp, silver carp, or bighead carp; however, differences were visible with close observation. For example, the pigment pattern of Rhinogobio typus resembled inverted parenthesis over a "I/" shape (fig. 9e). The pigment pattern of Parabramis pekinensis also resembled two stacked " $/$ " shapes, but was smaller than those of black carp (fig. 9f). The pigment pattern of Ochetobius elongatus resembled inverted parenthesis over two large stellate melanophores (fig. 9g). The pigment pattern of Elopichthys bambusa was a short " $\backslash /$ " anterior to two parallel lines (fig. 9h). Generally, the pigment patterns of these other cyprinids could be easily discriminated from those of grass carp, black carp, silver carp, or bighead carp. Also, the general shape, color, and size of the other cyprinids were quite different from the four famous domestic fishes. At the later developmental stages of the four species, after about the pelvic-fin-bud stage, the pigment patterns changed and become more similar to each other. This made identification using these parameters more difficult.

\section{Pigment Around the Base of the Rudimentary Pectoral Fin (fig. 10E, 25-36).}

The presence, absence, or abundance of stellate melanophores on the base of the rudimentary pectoral fin of larvae and juvenile also could be used as a characteristic to identify the species. At the gas-bladder-emergence stage, only the grass carp had one or two melanophores on the pectoral fin. The other three species had none (fig. 10E, 25-28). From the one-chamber-gas-bladder stage to the dorsal-fin-differentiation stage, the number of stellate melanophores on the rudimentary pectoral fin of grass carp increased to two or three (fig. 10E, 29). At this same stage, the rudimentary pectoral fin of bighead carp had one stellate melanophore, and black and silver carps had none (fig. 10E, 30-32). After the notochord-tiplifting stage, all four fishes had stellate melanophores on the base of the rudimentary pectoral fin, but the number was different: the grass carp had three or four, the black carp had one, the silver carp had two, and the bighead carp had one or two (fig. 10E, 33-36).

\section{Pigmentation of the Caudal Fin (fig. 10F, 37-40)}

From the one-chamber-gas-bladder stage to the dorsalfin-differentiation stage, the pigment on the caudal fin of the four species had different characteristics. Some of them could be seen by the naked eye and proved to be a rapid and efficient way to identify the species. There was a small grouping of melanophores on the anterior ventral portion of the caudal fin of the grass carp. With the naked eye, this grouping appeared as a large black point. Similar to grass carp, silver carp also had the black point on the anterior ventral portion of the caudal fin, but silver carp had another black point on the dorsal portion of the caudal fin (two points visible by the naked eye). Black carp had a very obvious single large dark stellate melanophore on the anterior ventral portion of the caudal fin. Bighead carp had some melanophores on the ventral portion of the caudal fin, which connected in a curved line.

\section{The Pigmentation of the Preanal and Anal Finfolds (fig. 10G, 41-48).}

During and after the one-chamber-gas-bladder stage, some stellate melanophores appeared on the preanal and anal finfolds of silver and bighead carps, but the grass and black carps did not have them. This was an important and stable characteristic to identify the species. The melanophores of silver and bighead carps had different characteristics. The melanophores of the silver carp were distributed on the posterior two-thirds of the preanal finfold at the one-chambergas-bladder stage. The stellate melanophores were large and 
had many branches. However, the stellate melanophores of bighead carp appeared at the dorsal-fin-differentiation stage and they were few in number. The abundance of melanophores increased gradually in the anterior direction on the preanal finfold; melanophores were distributed over the posterior half of the preanal finfold. The stellate melanophores were small and darkly pigmented. Until the appearance of scales, when the preanal finfold was mostly reduced, the melanophores of silver carp were still more abundant than those of bighead carp. In contrast, the melanophores of the anal finfolds of bighead carp appeared at the one-chamber-gas-bladder stage, and gradually formed a dark wavy line. Melanophores on the anal finfold of silver carp appeared later at the dorsal-fin-differentiation stage. The number of melanophores were few and the color light.

\section{Anal Fin Shape}

(fig. 10H, 49-52)

By the juvenile stage, the scales and fins were similar in shape to the adult fishes. The shape of the anal fin differed between species. The base of the grass and black carps' anal fins were shorter than that of silver and bighead carps. The first two or three rays of the black carp anal fin were long, so that the posterior margin of the anal fin was somewhat pointed. By comparison, the anal fin of the grass carp was more rounded. The base of the silver carp anal fin was long, and the base of the bighead carp anal fin was longer yet.

\section{Discussion}

The spawning grounds of grass, black, silver, and bighead carps were widely distributed in the upper- and middle-streams of the Yangtze River and its main tributaries. At each spawning ground or some spawning areas, "pure" early-stage eggs of the four fish could generally be collected at the same time. After they developed and grew, hybrids were never found. This may have contributed to the different fertilization process and time sequence between fish species (Wang and $\mathrm{Xu}, 1980$ ), which becomes a natural block of hybridization.

Overall, the morphology and structure of the four fishes were very similar during the early development. It was not easy to instantly identify the difference among the four species. These four cyprinid fishes, which have similar reproduction habits, have similar ontogeny. However, by observing individual structures closely, we found many obvious characteristics that were useful in species determination.

During the early development, grass and black carps showed differences from silver and bighead carps, such as presence or absence of melanophores on preanal and anal finfolds, and the relative length of the tail section. In addition, each species had unique characteristics, such as distribution and shapes of melanophores, which are clearly apparent at certain stages.

During the post-embryonic development, the growth and organ differentiation of larvae and juveniles were occasionally found to overlap (Yi and others, 1966). In addition, as mentioned before, the larvae and juveniles held under laboratory conditions grew slower than those living in the wild. However, the organ differentiations of yolk-sac larvae held in the laboratory did not progress at a slower rate. Their body color was generally darker than those in nature, probably due to different backgrounds and light intensities. The darker colors resulted from more melanophores and more highly-branched stellate melanophores. By contrast, larvae collected from rivers had few melanophores; their melanophores generally were not stellate, resulting in a light body color.

At the post-yolk-sac, larval, and juvenile periods, the laboratory-reared fish not only grew slower, their structures formed more slowly. For example, at the squamation stage, the larvae of the four species raised in the laboratory were one and half months old and had reached a total length ranging from 20.0 to $24.5 \mathrm{~mm}$; however, scales generally had not covered the whole body. In nature, it generally takes only three weeks for the fish to reach that body length and grow out all scales. An obvious difference between the laboratory and natural conditions is the water volume. There are relatively constant temperatures and dissolved oxygen, rich nutrition, and minerals in the natural water bodies providing much more favorable conditions than the water in the laboratory containers. Even in the laboratory under similar conditions, the different container sizes used to raise the larvae may also have led to different results. Table 7 shows the differences in the number of lateral line scales of the same size of grass carp larvae raised in different sizes of containers at the squamation stage. Obviously, a large container with more water volume provides more calcium, which supports scale formation and growth. Calcium can be absorbed by the fish through the body surface, mouth, and gill (Simkiss, 1974), especially during larval fish period.

Table 7. Number of lateral-line scales at the squamation stage of grass carp larvae originally collected from the Yangtze River and raised in containers with different water volumes.

\begin{tabular}{cccccccccccccc}
\hline Container size & \multicolumn{10}{c}{} & \multicolumn{10}{c}{ Total length of larvae (millimeters) } \\
\hline (Liter) & $\mathbf{2 1}$ & $\mathbf{2 2}$ & $\mathbf{2 3}$ & $\mathbf{2 4}$ & $\mathbf{2 5}$ & $\mathbf{2 6}$ & $\mathbf{2 7}$ & $\mathbf{2 8}$ & $\mathbf{2 9}$ & $\mathbf{3 0}$ & $\mathbf{3 1}$ & $\mathbf{3 2}$ \\
\hline 34 & 30 & 34 & 34 & 35 & 35 & 35 & 35 & 36 & 36 & 37 & 38 & 39 \\
18.5 & 5 & 10 & 15 & 18 & 20 & 23 & 25 & 27 & 30 & 33 & 35 & 38 \\
\hline
\end{tabular}




\section{References Cited}

Chen, Chungshou, and Shuyan Lin, 1935, Chinese larval fishes. Fisheries Report of Zhejiang Fisheries Experimental Station, 1(4). [In Chinese]

Chen, Zhenran, 1963a, Morphological characteristics of larval and juvenile grass carp Chinese Journal of Zoology, v. 1, p. 23-29. ]In Chinese]

Chen, Zhenran, 1963b, Morphological characteristics of early development of silver carp. Journal of Wuhan University (natural science edition), v. 2, p. 48-64. [In Chinese]

Institute of Experimental Biology, Chinese Academy of Science, 1962. Embryonic development of silver Carp. In Institute of Experimental Biology (ed.), Study on Artificial Reproduction of Cultured Fishes. 125-136. [In Chinese]

Institute of Hydrobiology, Chinese Academy of Science, 1973. Reproduction of cultured fishes in Fishes. In Institute of Hydrobiology (ed.), Culture and Reproduction of Chinese Freshwater Fishes (second edition). Science Press, Beijing. 96-107. [In Chinese]

Institute of Hydrobiology, Chinese Academy of Science, 1976. Fishes in the Yangtze River. Science Press, Beijing. 220 pp. [In Chinese]

Kryzhanovsky, C.G. A.I. Smirnov, S. G. Soin. 1951. Development of fish from the Amur River. Papers from the Amur River Ichthyological expedition, 1945-1949. Vol II: 73-84. [In Russian]

$\mathrm{Li}, \mathrm{Pu}, 1959$. Embryonic developmental stages of crucian carp and goldfish. Acta Zoologica Sinica, 11(2):145-157. [In Chinese]

Li, Xiangyuan and Xiazhong He, 1937. Study of silver carp and the experiment of their artificial fertilization and hatch. Quaternary Publication of Fish Culture, 1(3-4):1-21. Guangxi Fish Culture Experimental Station. [In Chinese]

Liu, Jiankang, 1954. Egg fertilization and hatch of Chinese freshwater fish. Biology Bulletin, 1954 (1):11-16. [In Chinese]

Rugh, R., 1962. Experimental Embryology. Burgess Publishing Company, Minnesota, USA.

Shangdong Freshwater Fisheries Institute, 1963. Embryonic development of grass carp. [In Chinese]
Simkiss, K., 1974. Calcium metabolism of fish in relation to aging. In T. Bagenal (ed.): Aging of Fish, Unwin Bros Ltd, London, 1-12.

Verigin, B.V. 1950. Biological characteristics of age and growth of silver carp (H. m Val.) Papers from the Amur River Ichthyological expedition, 1945-1949. Vol I: 303318. [In Russian]

Wang, Changxie, 1959. Species identification of larval fish in the middle stream of the Yangtze River. Acta Hydrobiologica Sinica, 3:315-344. (In Chinese)

Wang, Youlan and Guojiang Xu, 1980. Cytology study on egg cell fertilization of silver carp. Acta Hydrobiologica Sinica, 7(2):189-194. [In Chinese]

Wu, Hongtu and Youqi Shi, 1964. Embryonic development of bighead carp (Aristichthys nobilis). Journal of Harbin Normal University (natural science edition), 2:115-126. [In Chinese]

Xie, Yuhao, 1964. Post-hatch development of larval bighead carp and silver carp. Scientific Report of Liaoning Fisheries Research Institute. [In Chinese]

Yang, Yijuan, 1962. Preliminary observation of embryonic and post-hatch development of bighead carp. Journal of Jimei Fisheries College, 2:18-26. [In Chinese]

Luanzuo, 1958. Preliminary study on morphology of larval fish. Bulletin of Biology, 7:7-13. [In Chinese]

Ye, Luanzuo, 1964. Preliminary study on post-hatching development of black carp. Journal of Fisheries of China, 1:39-60. [In Chinese]

Yi, Bolu, Zhitang Yu and Zhishen Liang, 1966. A comparative study of the embryonic development of grass carp, black carp, silver carp, big head carp and other fishes with drifting eggs in the Yangtze River. 8th Symposium, Fisheries Research Committee of the Western Pacific, Beijing. Science Press, Beijing: 37-53. [In Chinese]

Yuan, Chuanbi, 1962. The method of distinguishing species differences among larvae of black carp, grass carp, silver carp, and bighead carp. Journal of Nanjing University (natural science edition), 1:75-90. [In Chinese]

Zhong, Lin, 1962. Growth and artificial reproduction of silver carp. 8th Symposium, Fisheries Research Committee of the Western Pacific, Beijing. Science Press, Beijing: 54-66. [In Chinese] 

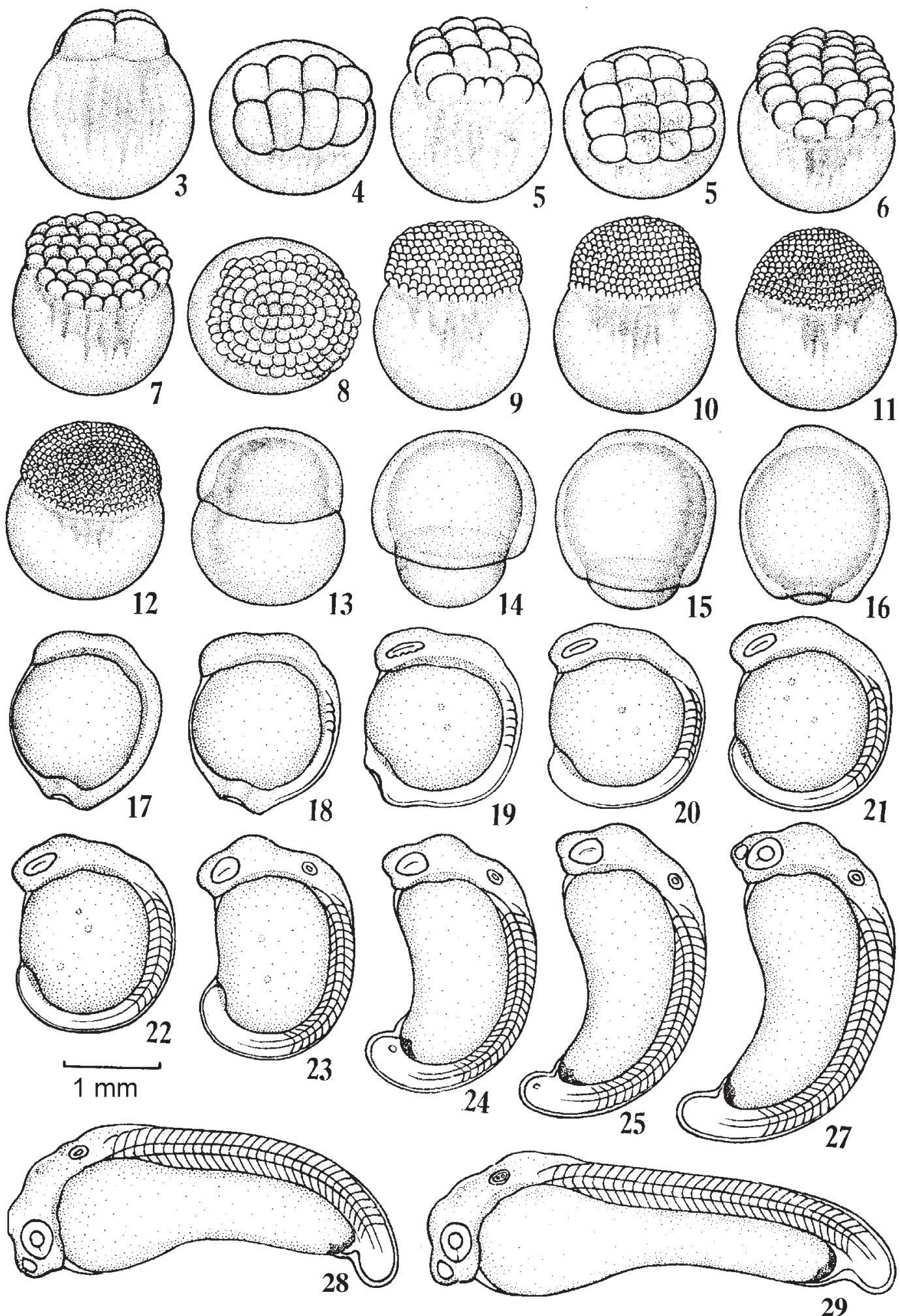

Figure 1 (3-29). The stages of embryonic development of grass carp: (3) 4-cell, (4) 8-cell, (5) 16-cell, (6) 32-cell, (7) 64-cell, (8) 128-cell, (9) morula, (10) early blastula, (11) mid-blastula , (12) late blastula, (13) early gastrula, (14) mid-gastrula, (15) late gastrula, (16) neurula, (17) blastopore closure, (18) somite appearance, (19) optic primordium, (20) optic vesicle, (21) olfactory placode, (22) tail bud, (23) otic capsule, (24) tail vesicle, (25) caudal fin, (27) muscular effect, (28) heart rudiment, and (29) otolith appearance. 


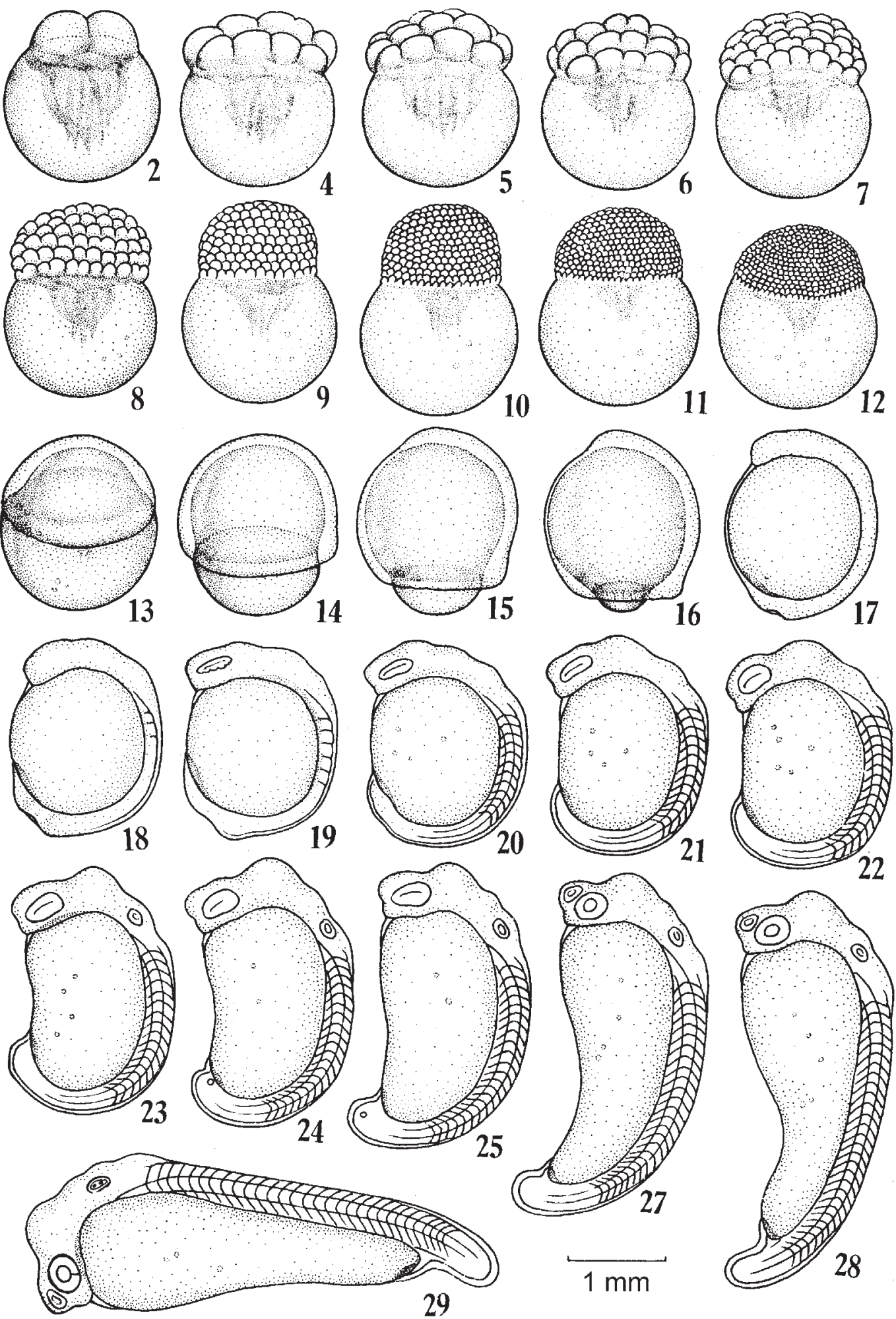

Figure 2 (2-29). The stages of embryonic development of black carp: (2) 2-cell, (3) 4-cell, (4) 8-cell, (5) 16-cell, (6) 32-cell, (7) 64-cell, (8) 128-cell, (9) morula, (10) early blastula, (11) mid-blastula, (12) late blastula, (13) early gastrula, (14) mid-gastrula, (15) late gastrula, (16) neurula, (17) blastopore closure, (18) somite appearance, (19) optic primordium, (20) optic vesicle, (21) olfactory placode, (22) tail bud, (23) otic capsule, (24) tail vesicle, (25) caudal fin, (27) muscular effect, (28) heart rudiment, and (29) appearance of otolith. 

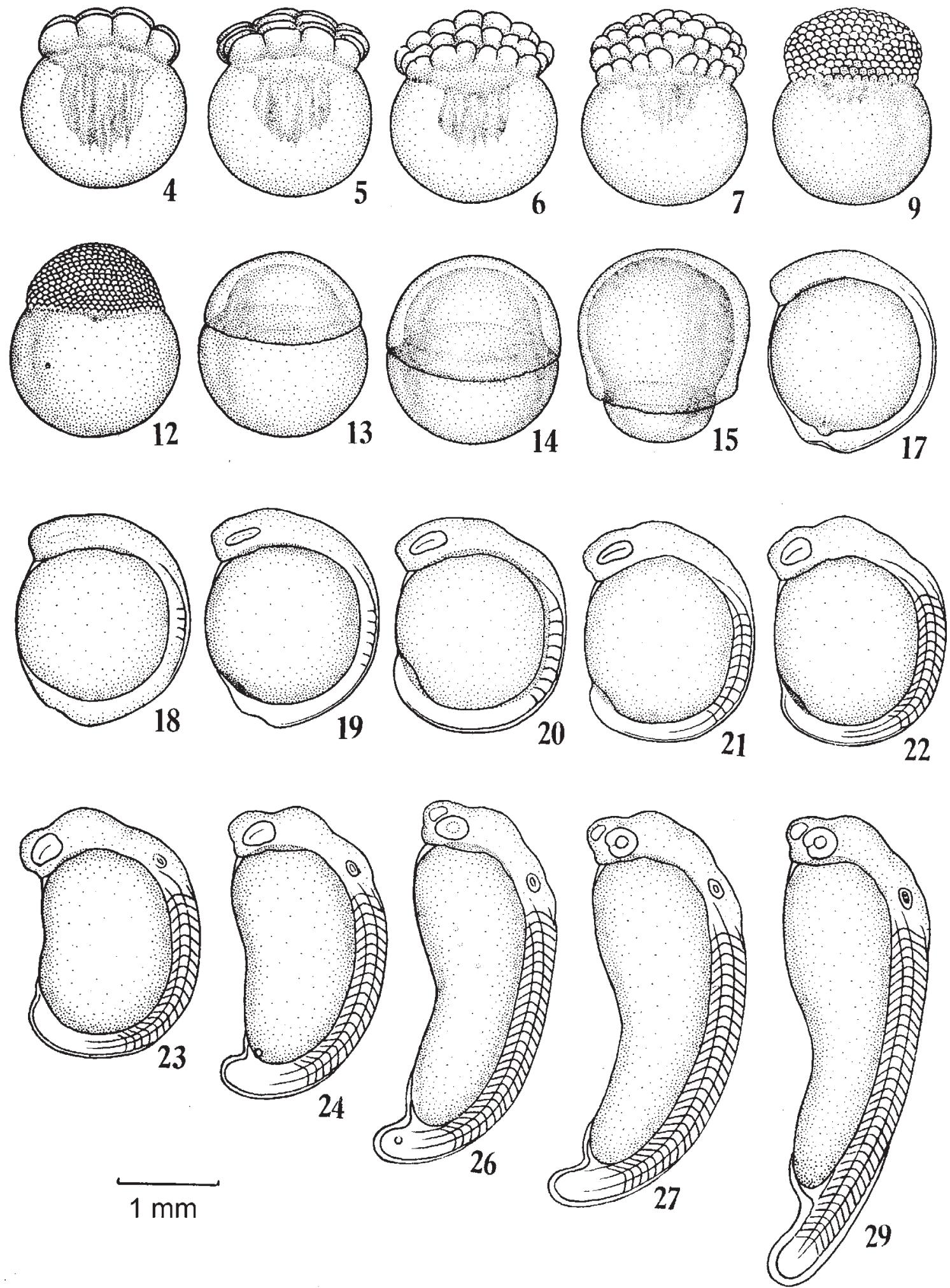

Figure 3 (4-29). The stages of embryonic development of silver carp: (4) 8-cell, (5) 16-cell, (6) 32-cell, (7) 64-cell, (8) 128-cell, (9) morula, (12) late blastula, (13) early gastrula, (14) mid-gastrula, (15) late gastrula, (17) blastopore closure, (18) somite appearance, (19) optic primordium, (20) optic vesicle, (21) olfactory placode, (22) tail bud, (23) otic capsule, (24) tail vesicle, (26) lens formation, (27) muscular effect, and (29) otolith appearance. 

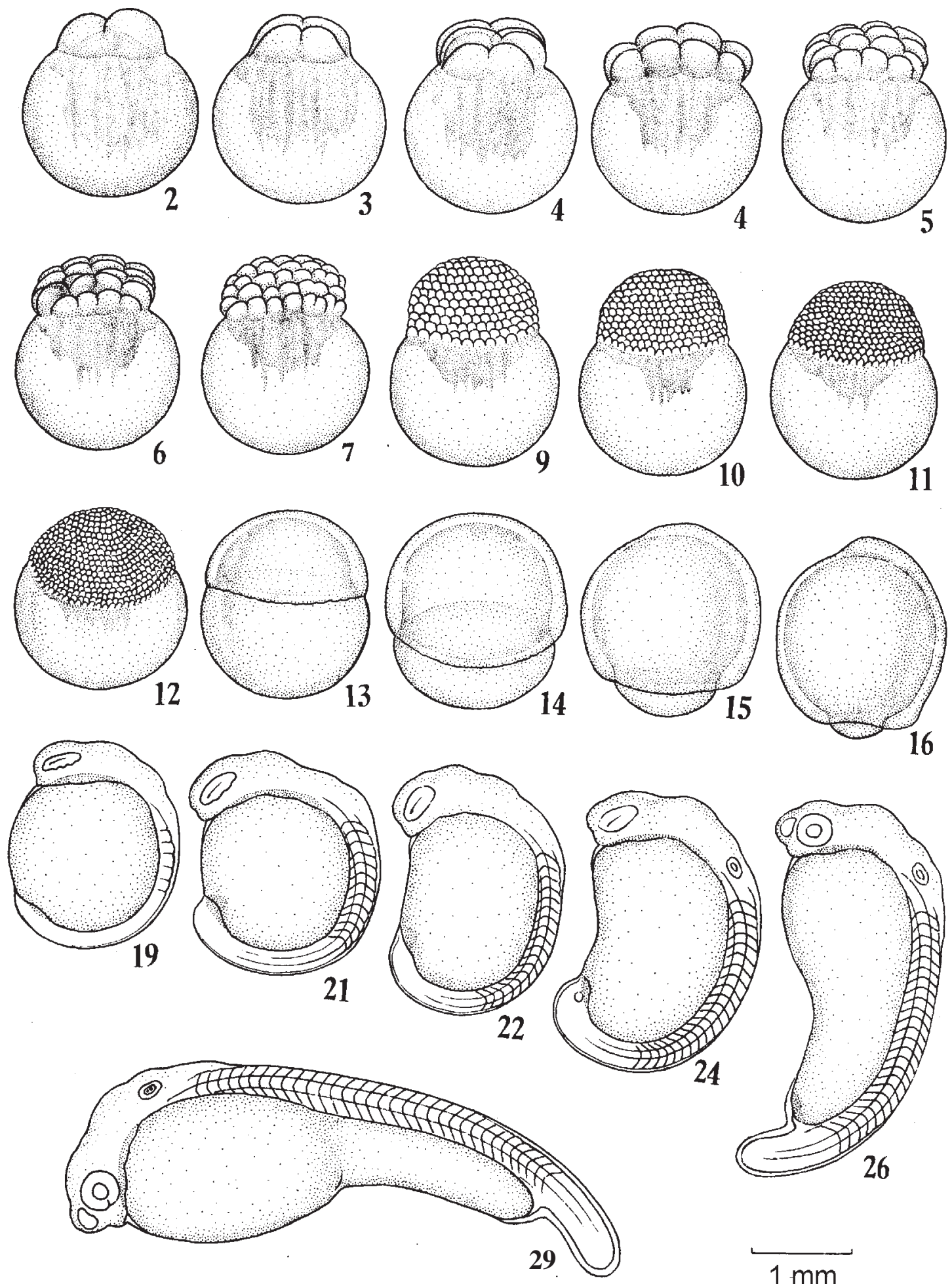

$1 \mathrm{~mm}$

Figure 4 (2-29). The stages of embryonic development of bighead carp: (2) 2-cell, (3) 4-cell, (4) 8-cell, (5) 16cell, (6) 32-cell, (7) 64-cell, (9) morula, (10) early blastula, (11) mid-blastula, (12) late blastula, (13) early gastrula, (14) mid-gastrula, (15) late gastrula, (16) neurula, (19) optic primordium, (21) olfactory placode, (22) tail bud, (24) tail vesicle, (26) lens formation, and (29) otolith appearance. 

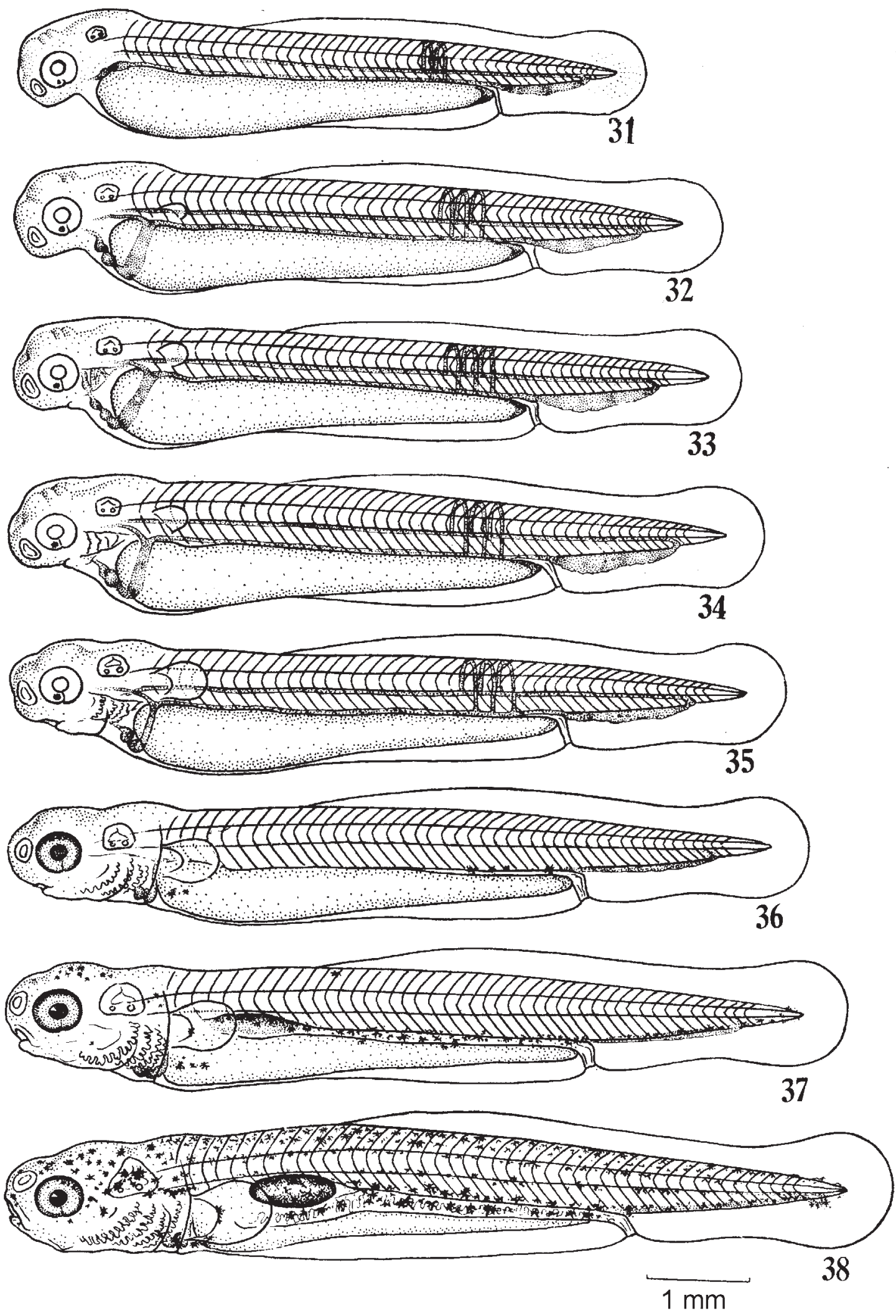

Figure 5 (31-38). The stages of post-hatch development of grass carp: (31) hatching, (32) rudimentary pectoral fin, (33) gill arch, (34) xanthic eye, (35) gill filaments, (36) melanoid eye, (37) gas bladder emergence, and (38) one-chamber gas bladder. 

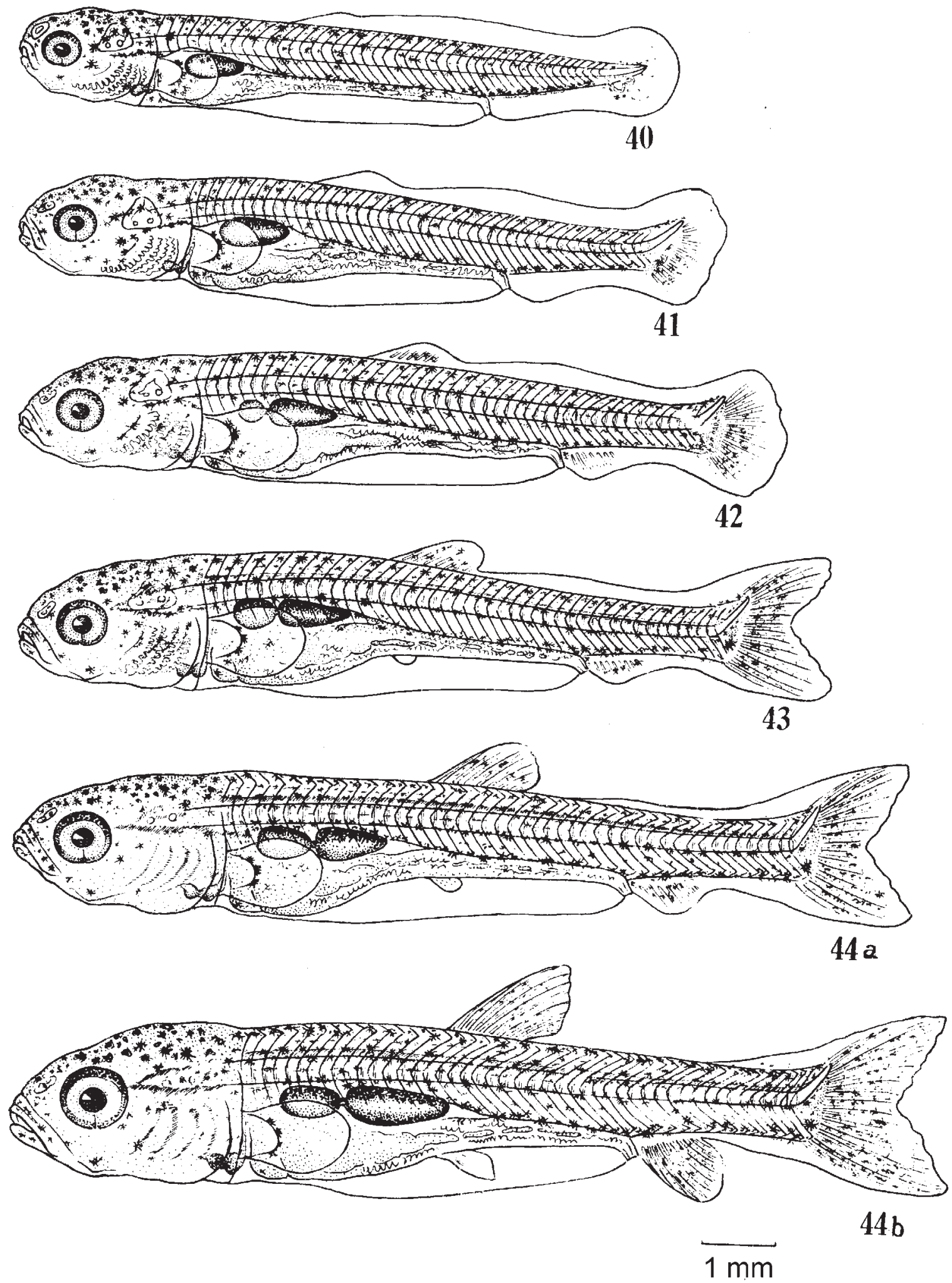

Figure 5 (40-44). The stages of post-hatch development of grass carp: (40) dorsal fin differentiation, (41) notochord tip lifting, (42) two-chamber gas bladder, (43) pelvic fin bud, (44a) early dorsal fin formation, and (44b) late dorsal fin formation. 

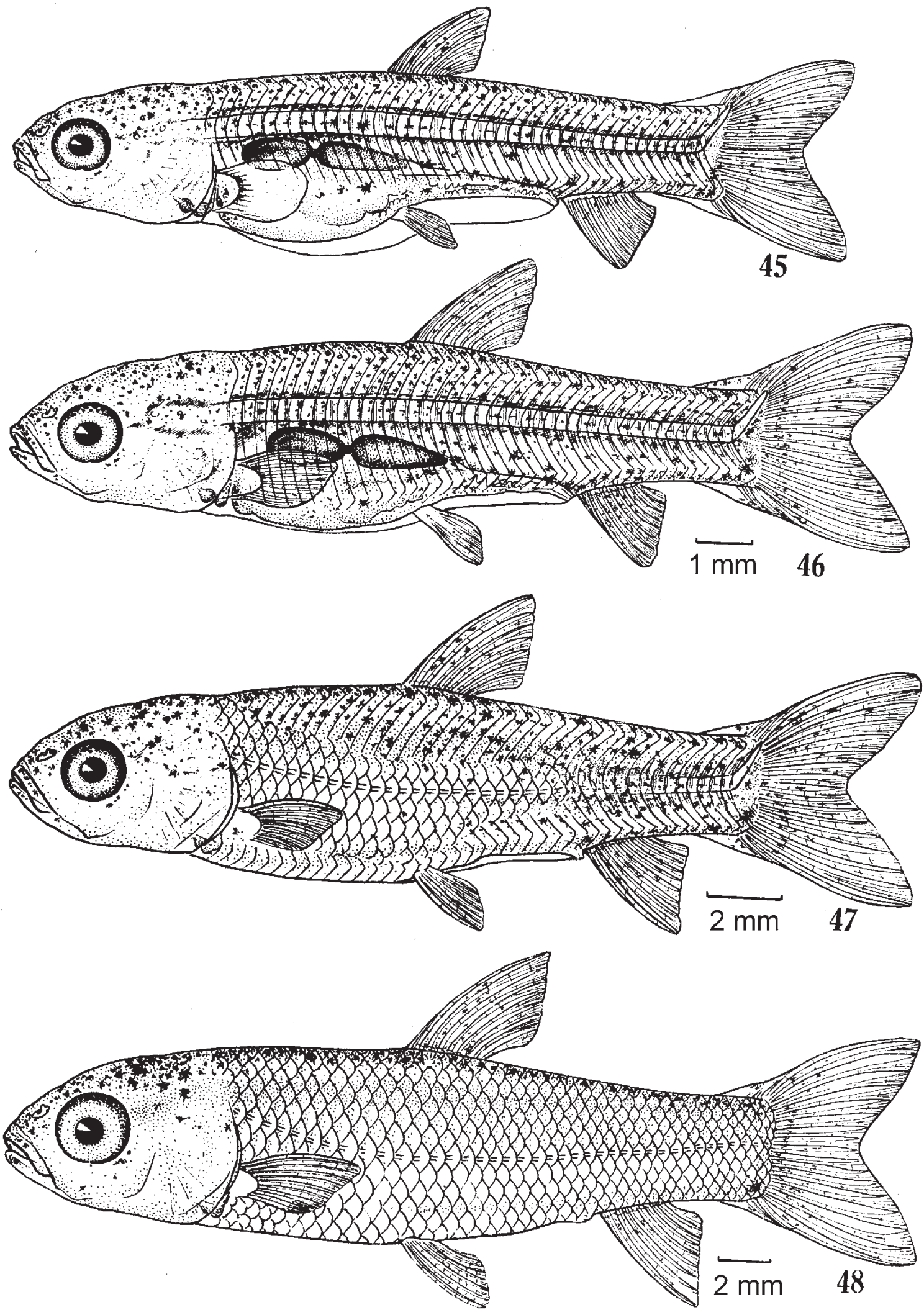

Figure 5 (45-48). The stages of post-hatch development of grass carp: (45) anal fin formation, (46) pelvic fin formation, (47) squamation, and (48) juvenile stage. 

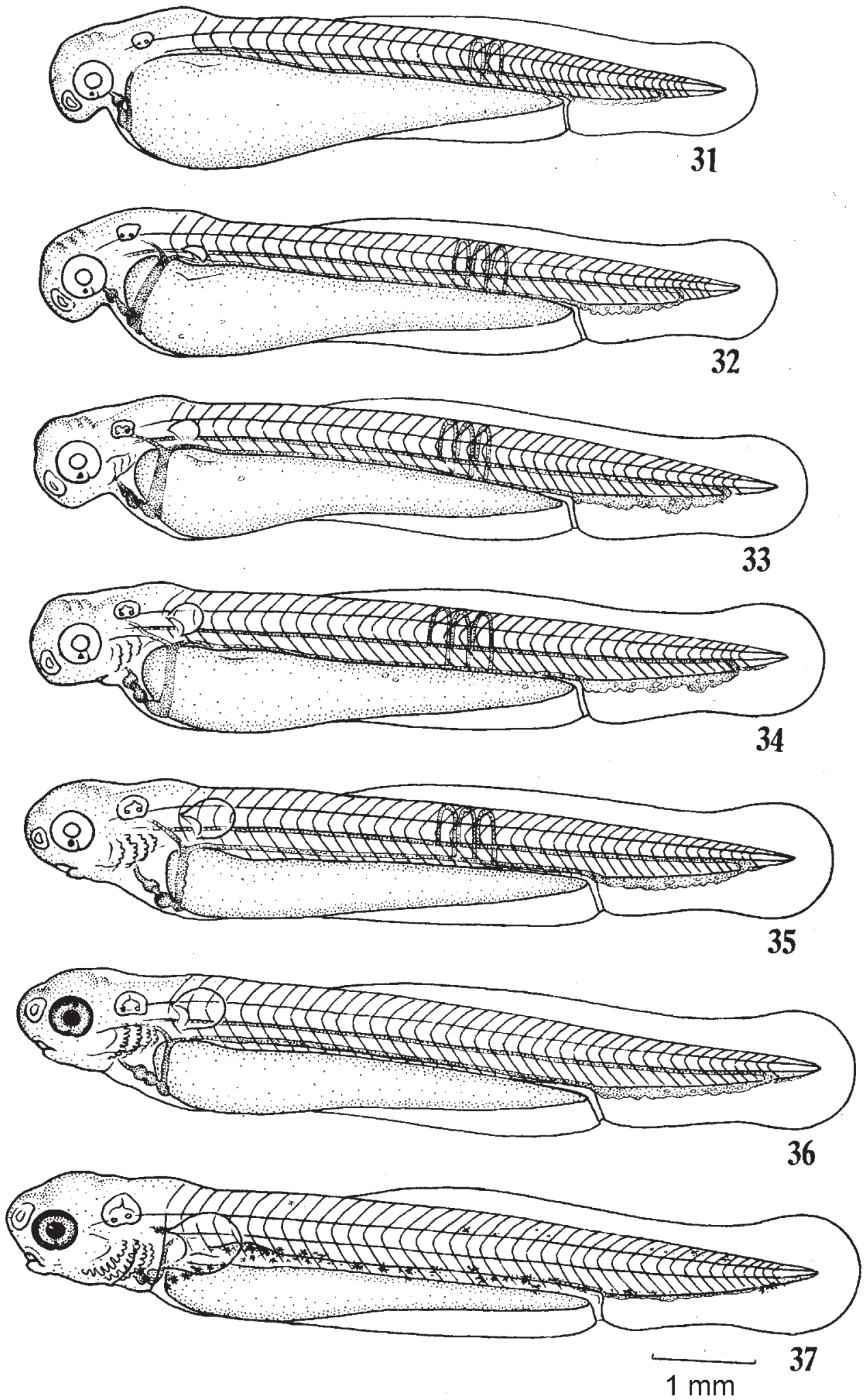

Figure 6 (31-37). The stages of post-hatch development of black carp: (31) hatching, (32) rudimentary pectoral fin, (33) gill arch, (34) xanthic eye, (35) gill filaments, (36) melanoid eye, and (37) gas-bladder emergence. 

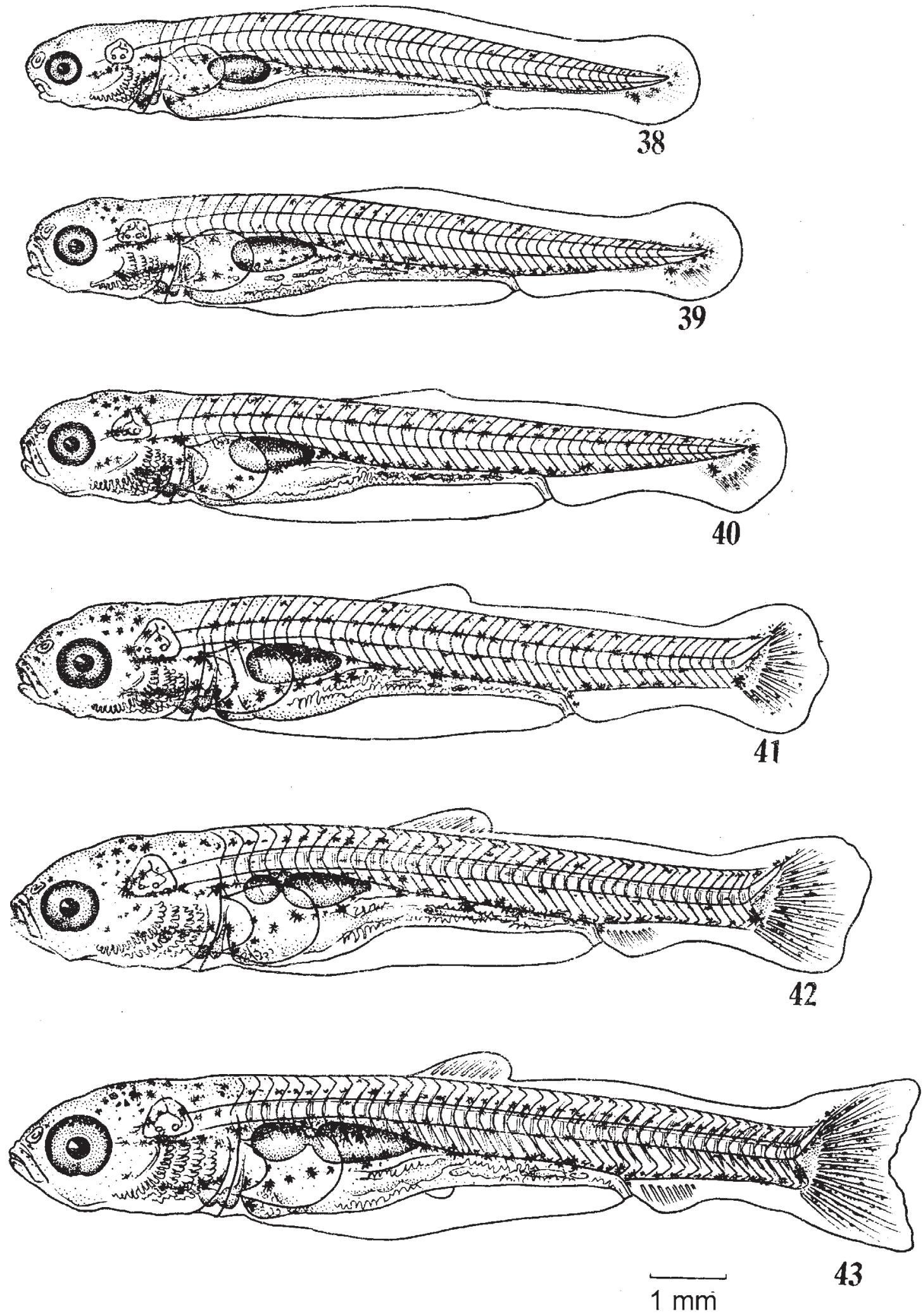

Figure 6 (38-43). The stages of post-hatch development of black carp: (38) one-chamber gas bladder, (39) yolk absorption, (40) dorsal fin differentiation, (41) notochord tip lifting, (42) two-chamber gas bladder, and (43) pelvic fin bud. 

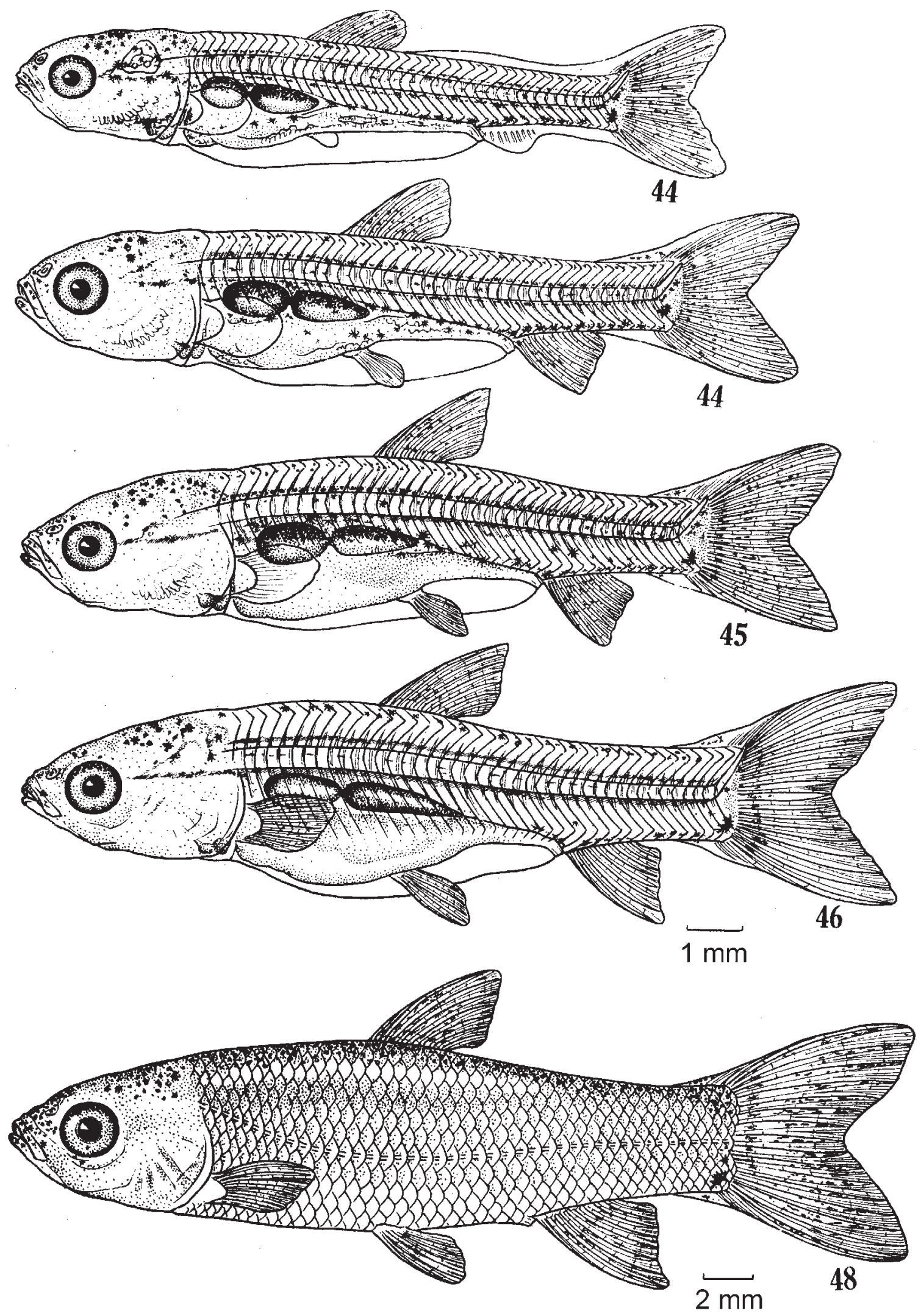

Figure 6 (44-48). The stages of post-hatch development of black carp: (44) dorsal fin formation, (45) anal fin formation, (46) pelvic fin formation, and (48) juvenile stage. 

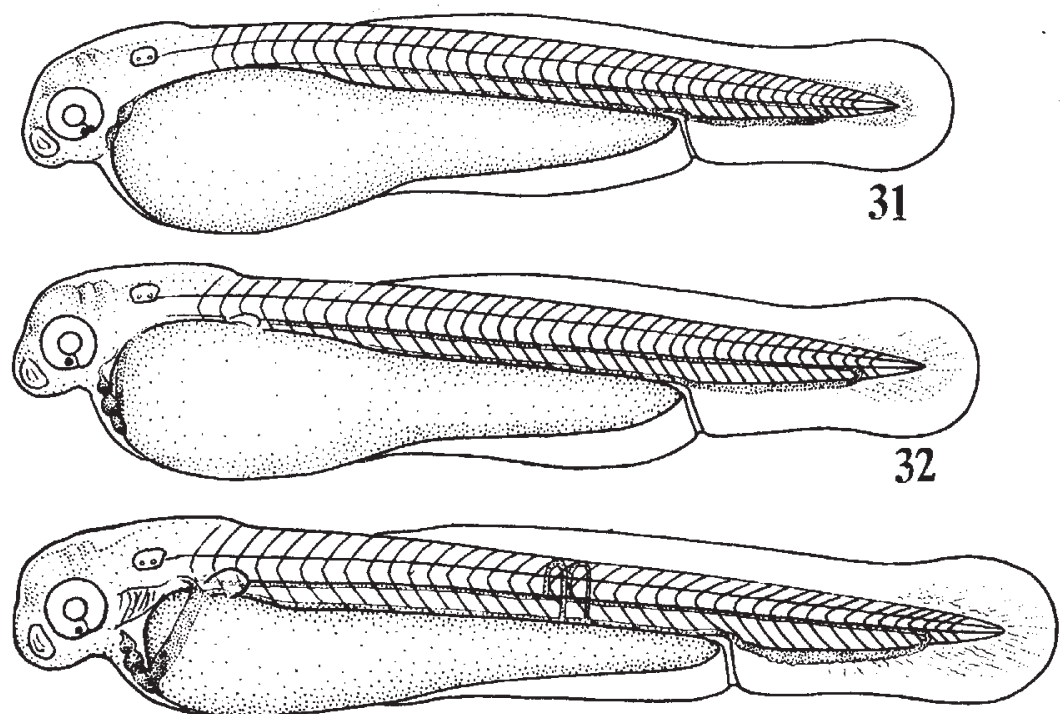

33
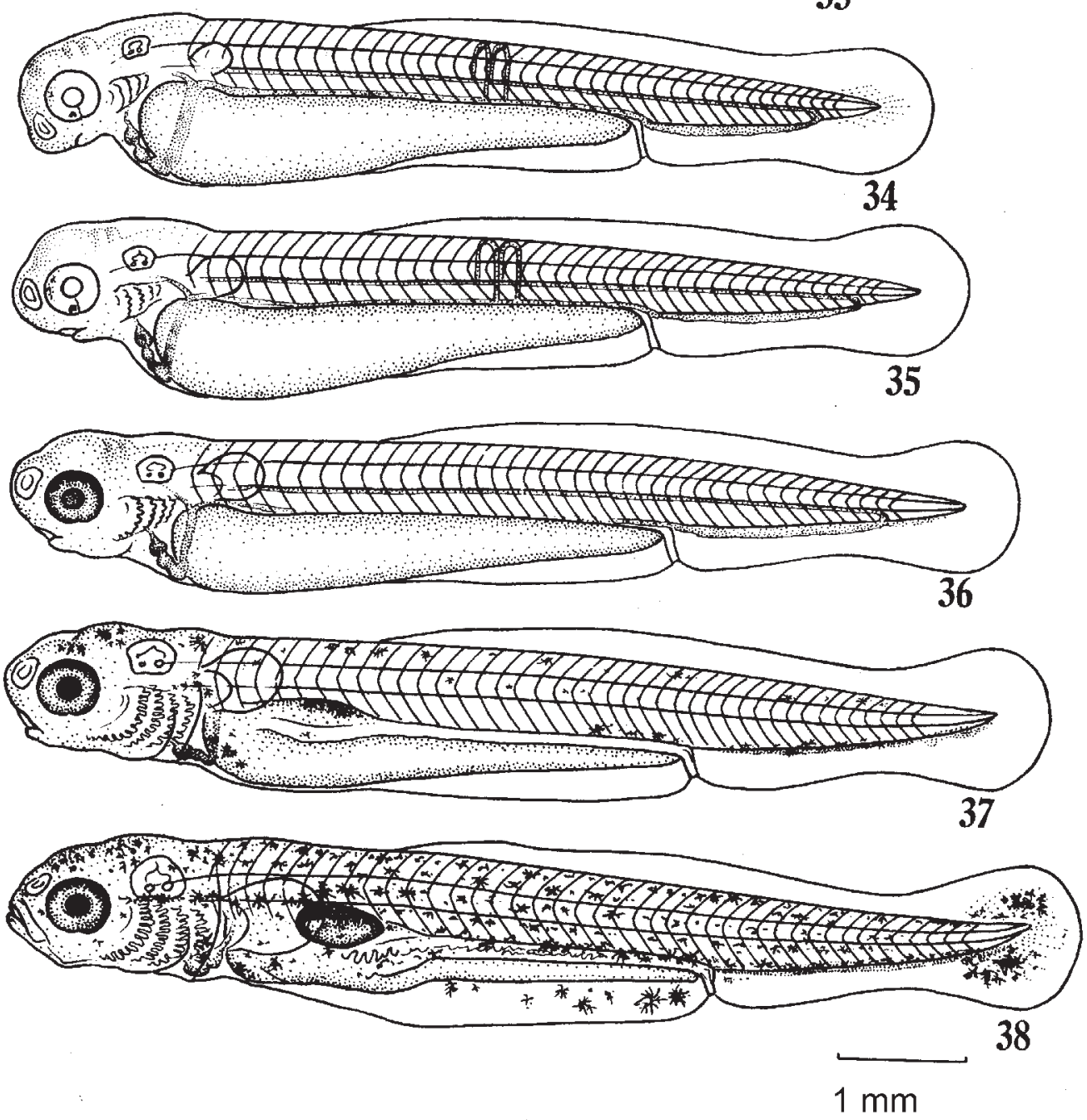

Figure 7 (31-38). The stages of post-hatch development of silver carp: (31) hatching, (32) rudimentary pectoral fin, (33) gill arch, (34) xanthic eye, (35) gill filaments, (36) melanoid eye, (37) gas bladder emergence, and (38) one-chamber gas bladder. 

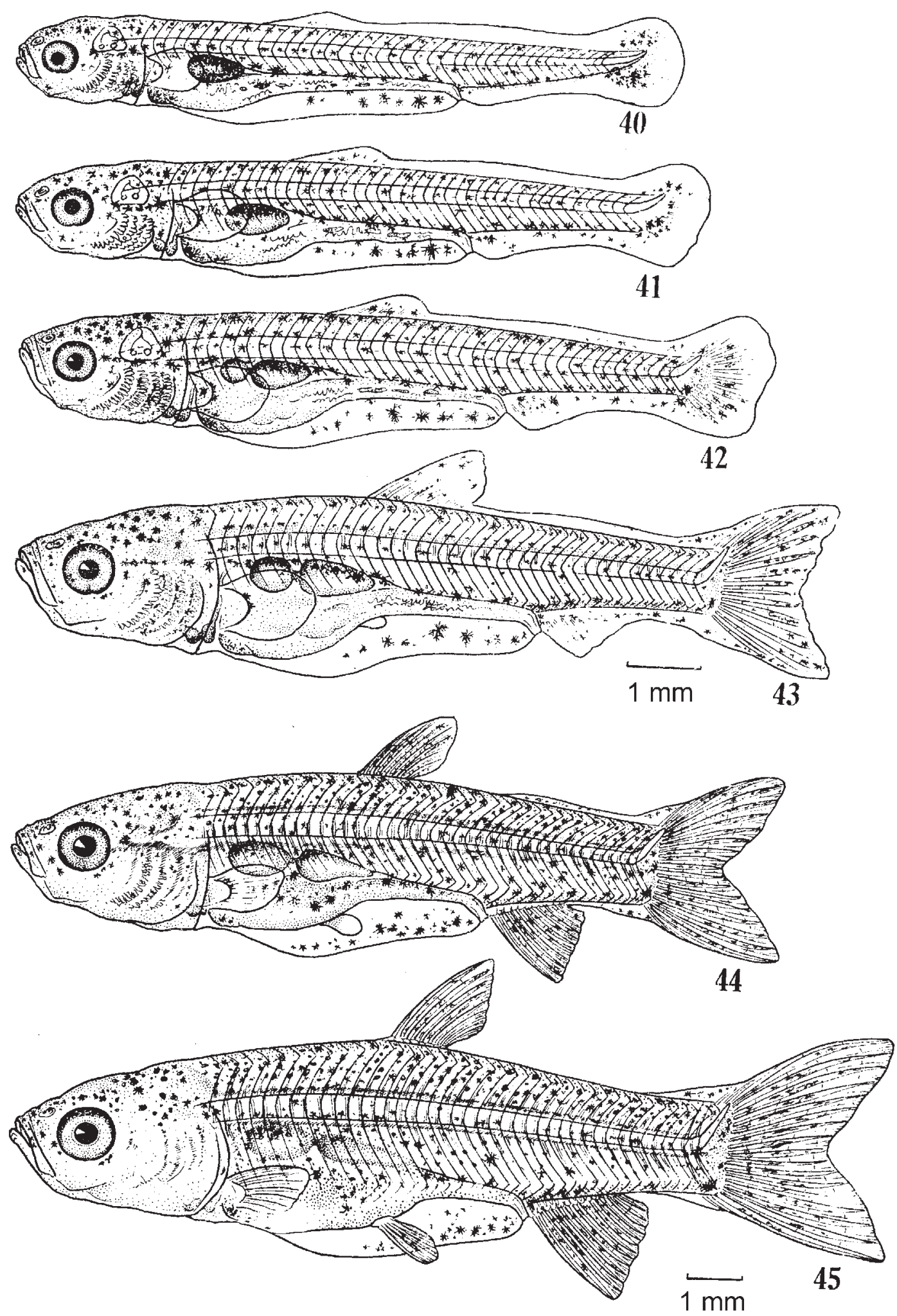

Figure 7 (40-45). The stages of post-hatch development of silver carp: (40) dorsal fin differentiation, (41) notochord tip lifting, (42) two-chamber gas bladder, (43) pelvic fin bud, (44) dorsal fin formation, and (45) anal fin formation. 

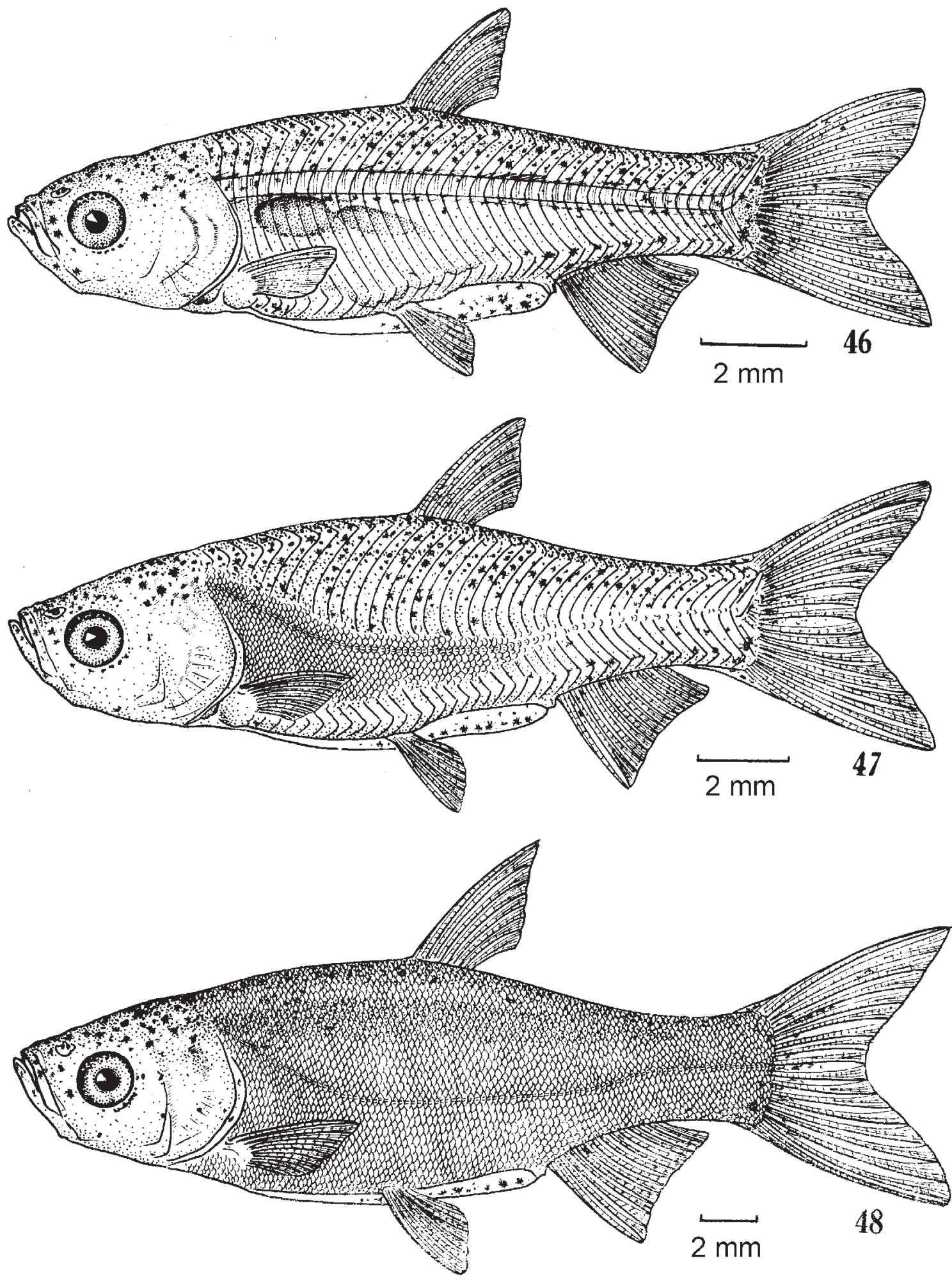

Figure 7 (46-48). The stages of post-hatch development of silver carp: (46) pelvic fin formation, (47) squamation, and (48) juvenile stage. 

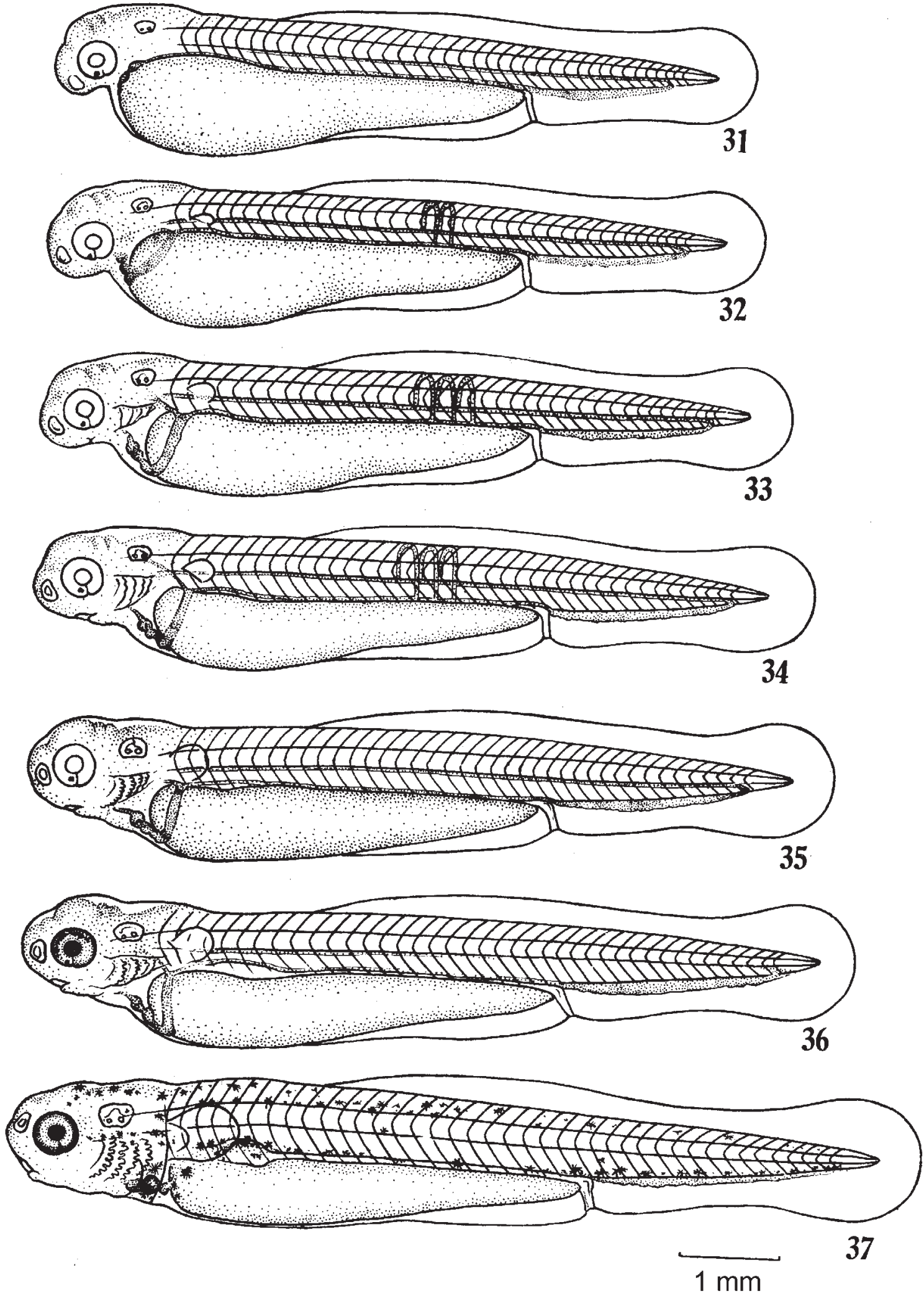

Figure 8 (31-37). The stages of post-hatch development of bighead carp: (31) hatching, (32) rudimentary pectoral fin, (33) gill arch, (34) xanthic eye, (35) gill filaments, (36) melanoid eye, and (37) gas-bladder emergence. 

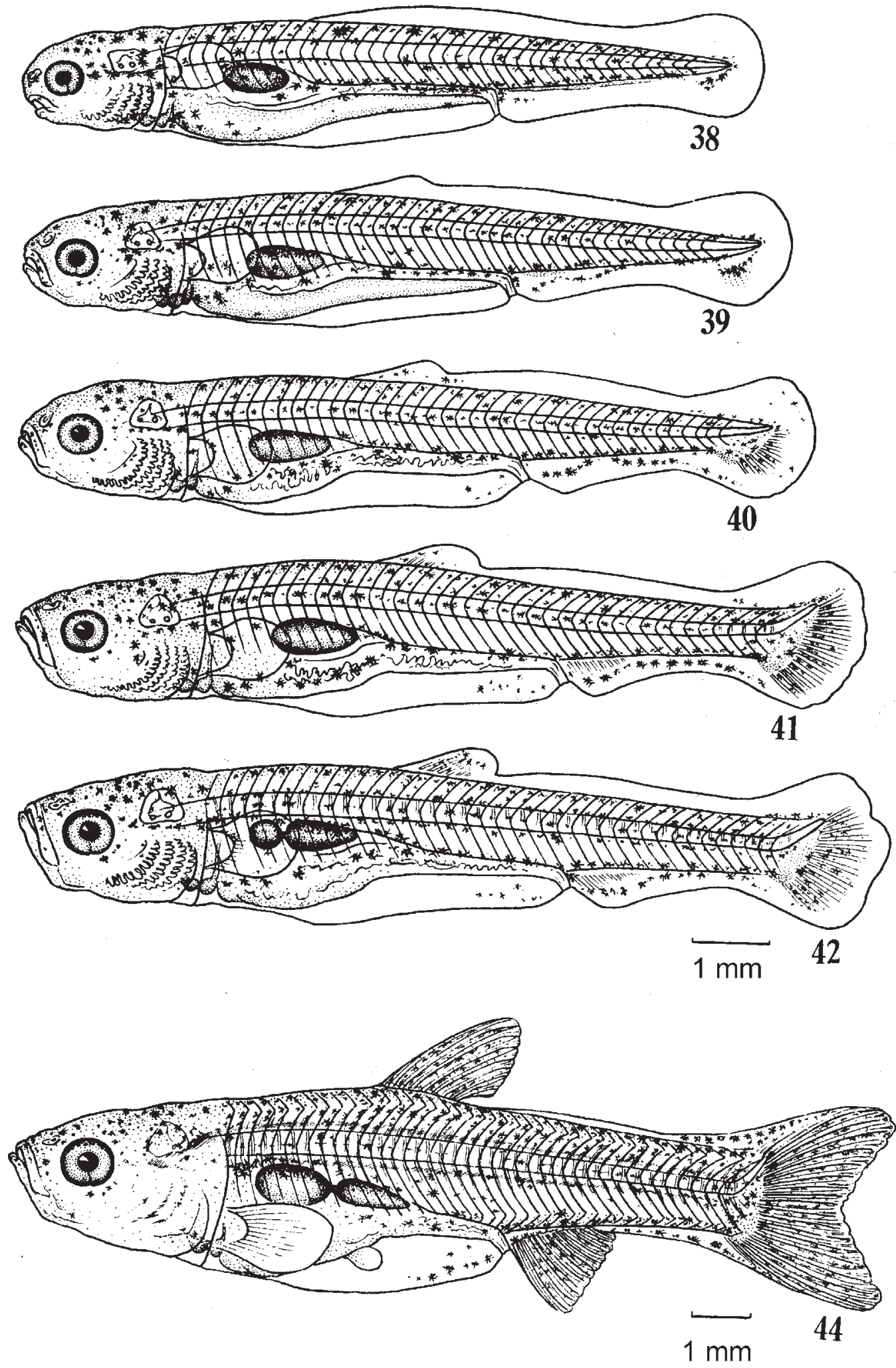

Figure 8 (38-44). The stages of post-hatch development of bighead carp: (38) one-chamber gas bladder, (39) dorsal fin differentiation, (40) yolk absorption, (41) notochord tip lifting, (42) twochamber gas bladder, and (44) dorsal fin formation. 


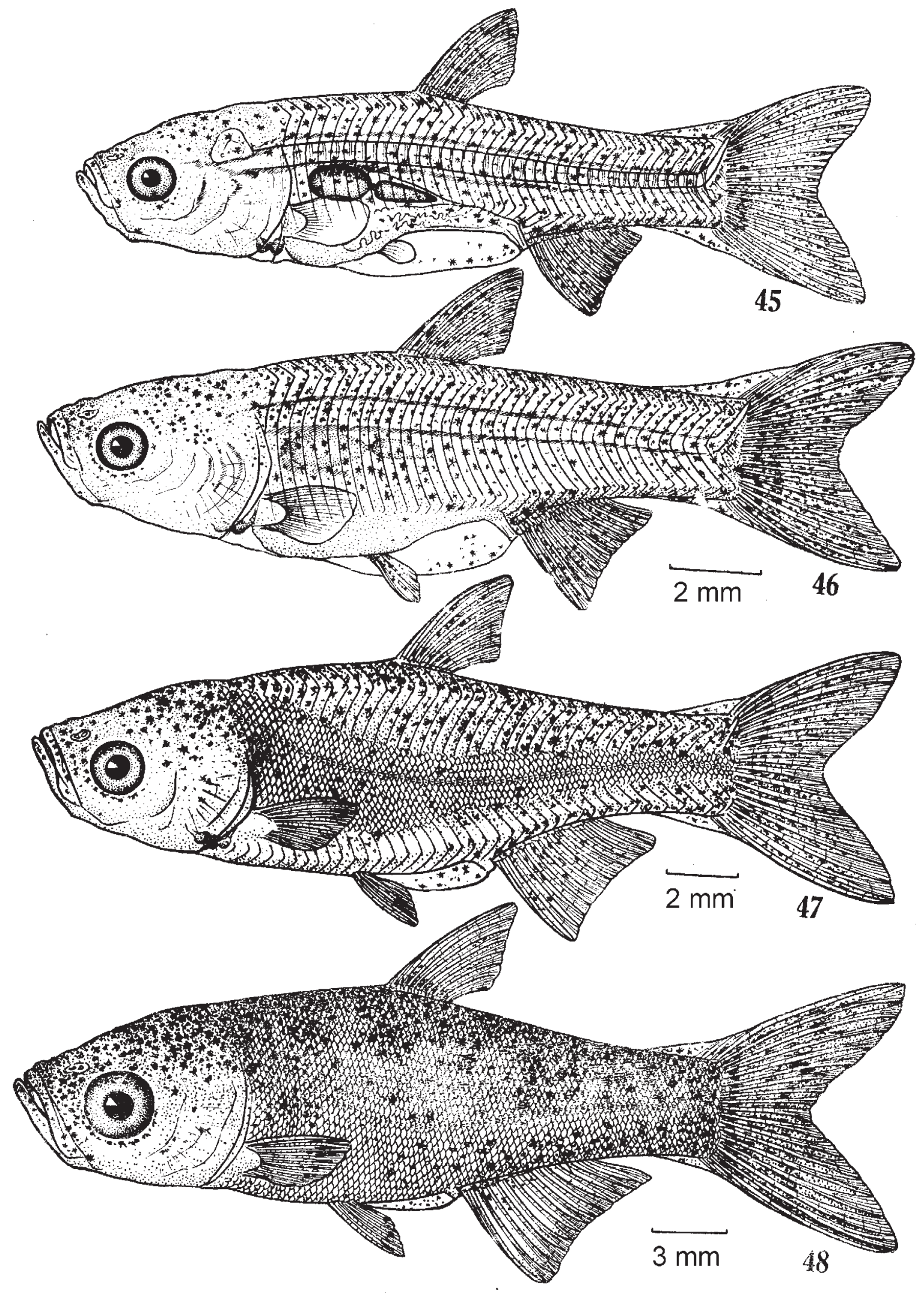

Figure 8 (45-48). The stages of post-hatch development of bighead carp: (45) anal fin formation, (46) pelvic fin formation, (47) squamation, and (48) juvenile stage. 


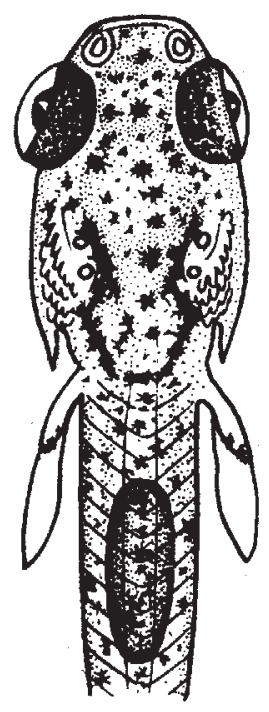

a

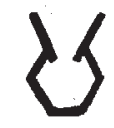

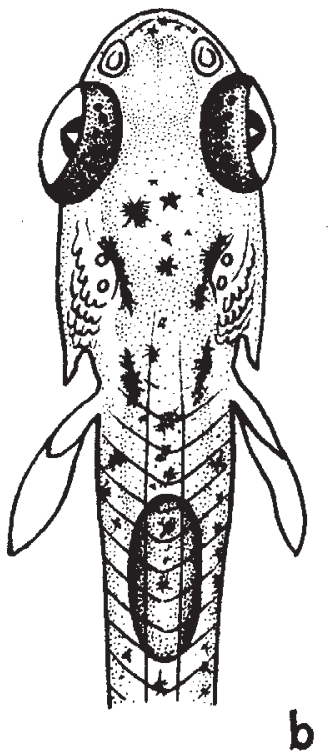

$1 /$

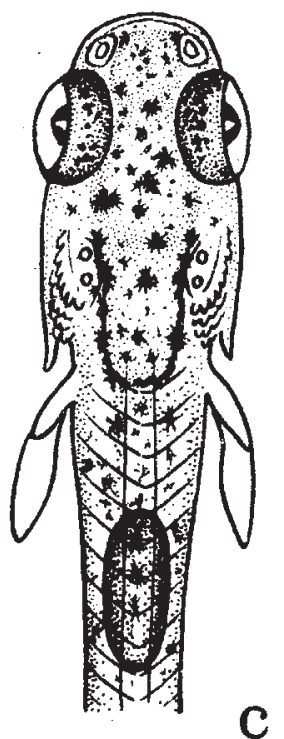

U

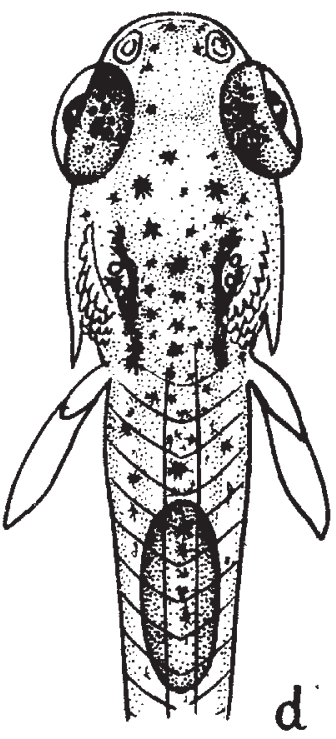

11
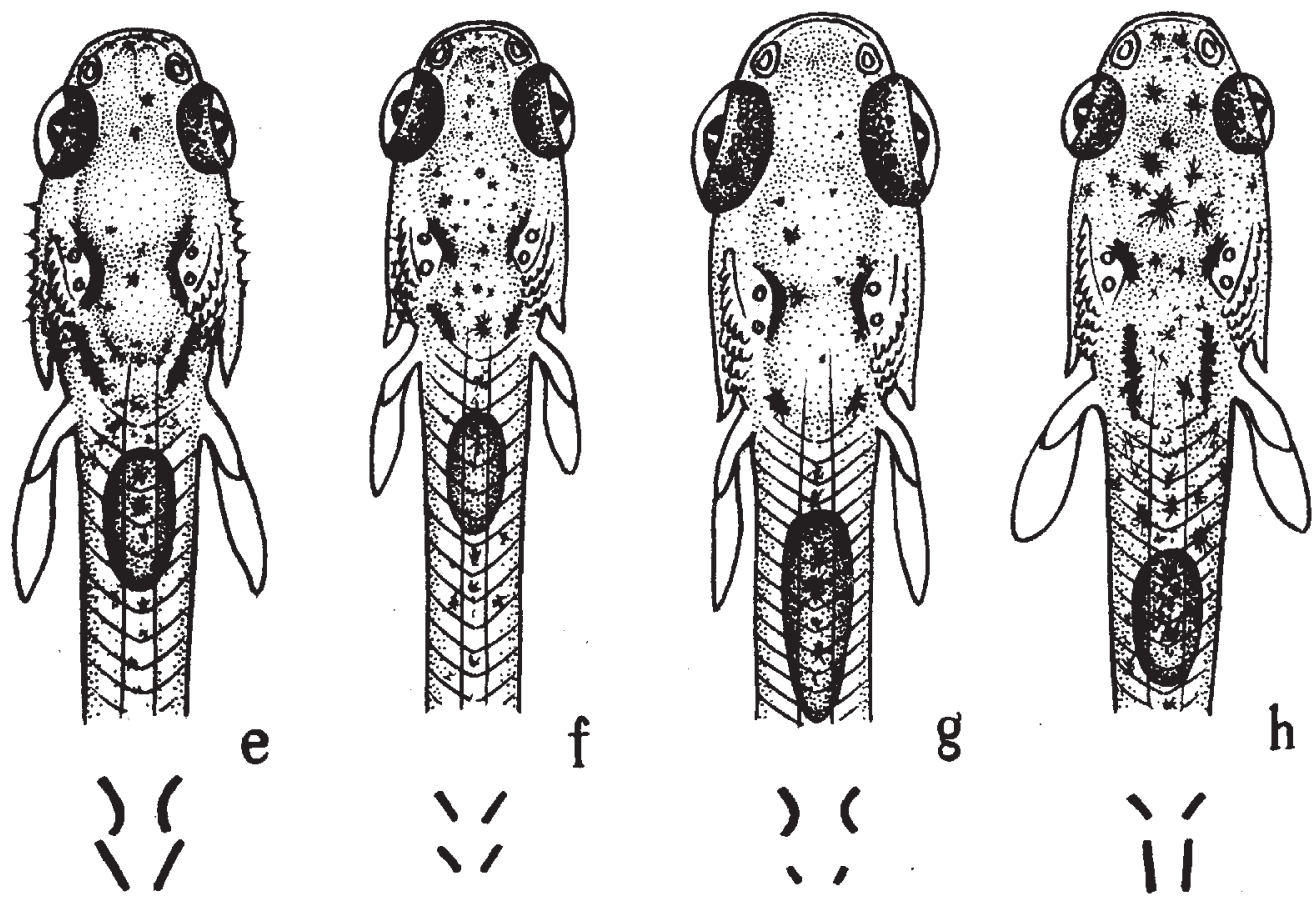

$1 \mathrm{~mm}$

Figure 9. Different patterns of melanophores of the heads of grass carp (a), black carp (b), silver carp (c), bighead carp (d), Rhinogobio typus (e), Parabramis pekinensis (f), Ochetobius elongatus $(\mathrm{g})$, and Elopichthys bambusa (h) at the one-chamber-gas-bladder stage. 


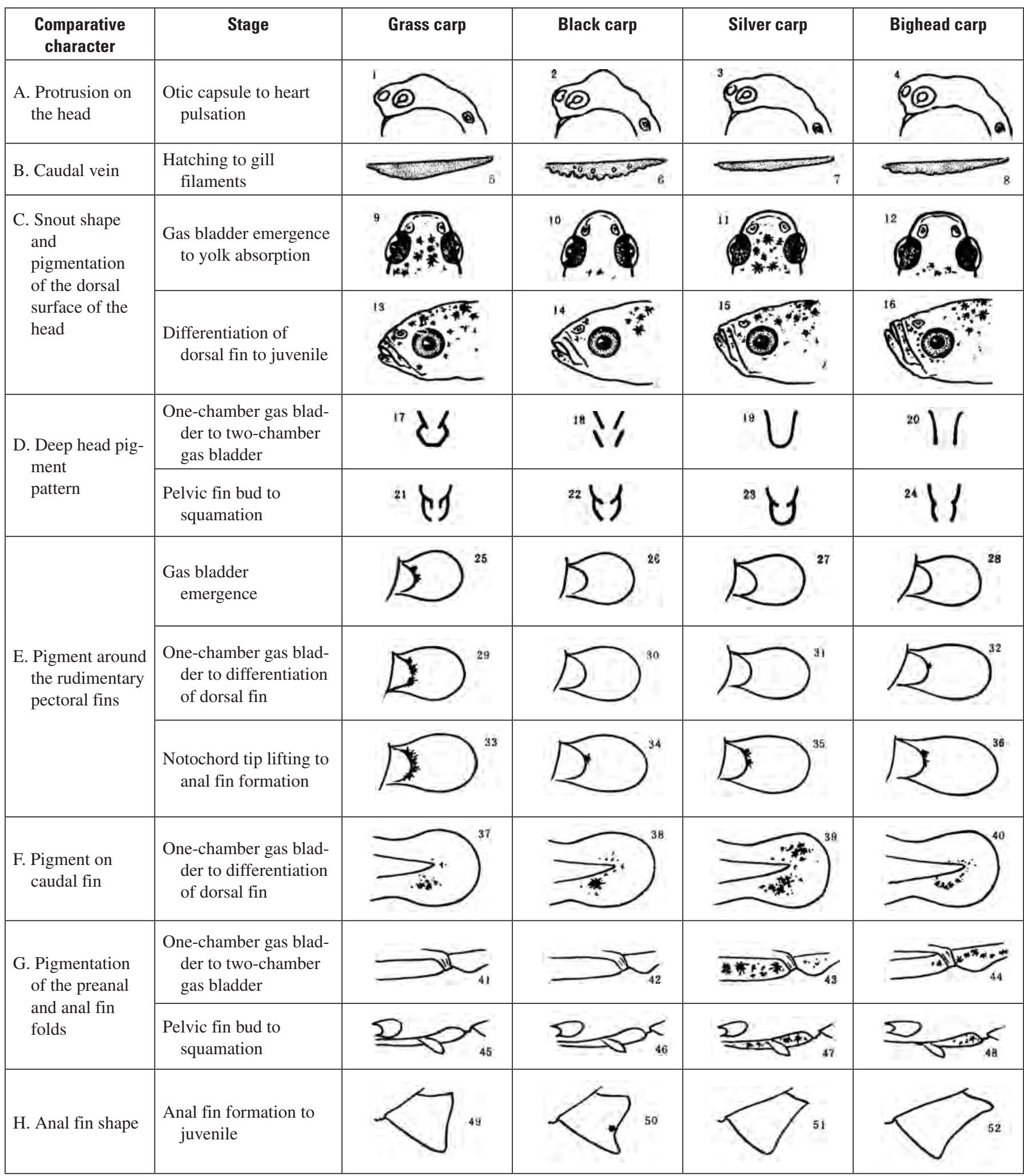

Figure 10. Primary diagnostic characteristics in the early development of grass, black, silver, and bighead carps collected from the Yangtze River. 
